San Jose State University

SJSU ScholarWorks

Master's Theses

Master's Theses and Graduate Research

Fall 2016

\title{
Synthesis and Characterization of Silica Hydride-Based Pentynoic Acid Stationary Phase
}

Nasrin Syed

San Jose State University

Follow this and additional works at: https://scholarworks.sjsu.edu/etd_theses

\section{Recommended Citation}

Syed, Nasrin, "Synthesis and Characterization of Silica Hydride-Based Pentynoic Acid Stationary Phase" (2016). Master's Theses. 4780.

DOI: https://doi.org/10.31979/etd.7dy3-kfy9

https://scholarworks.sjsu.edu/etd_theses/4780

This Thesis is brought to you for free and open access by the Master's Theses and Graduate Research at SJSU ScholarWorks. It has been accepted for inclusion in Master's Theses by an authorized administrator of SJSU ScholarWorks. For more information, please contact scholarworks@sjsu.edu. 


\title{
SYNTHESIS AND CHARACTERIZATION OF SILICA HYDRIDE-BASED PENTYNOIC ACID STATIONARY PHASE
}

\author{
A Thesis \\ Presented to \\ The Faculty of the Department of Chemistry \\ San José State University \\ In Partial Fulfillment \\ of the Requirements for the Degree \\ Master of Science \\ by \\ Nasrin Syed \\ December 2016
}


(C) 2016

Nasrin Syed

ALL RIGHTS RESERVED 
The Designated Thesis Committee Approves the Thesis Title

SYNTHESIS AND CHARACTERIZATION OF SILICA HYDRIDE-BASED PENTYNOIC ACID STATIONARY PHASE

by

Nasrin Syed

APPROVED FOR THE DEPARTMENT OF CHEMISTRY

SAN JOSE STATE UNIVERSITY

December 2016

Dr. Joseph J. Pesek, Ph. D.

Department of Chemistry

Dr. Roger H. Terrill, Ph. D.

Department of Chemistry

Dr. Annalise Van Wyngarden, Ph. D. Department of Chemistry 


\title{
ABSTRACT \\ SYNTHESIS AND CHARACTERIZATION OF SILICA HYDRIDE-BASED PENTYNOIC ACID STATIONARY PHASE FOR HPLC
}

\author{
by Nasrin Syed
}

High performance liquid chromatography is an important analytical technique used for the separation and identification of components in a mixture. The aim of this research project was to synthesize and characterize a silica hydride-based pentynoic acid stationary phase. Analytical techniques like elemental analysis and diffuse reflectance infrared fourier transform spectroscopy (DRIFT) were used to confirm the success of bonding between silica hydride and pentynoic acid moiety. The pentynoic acid Si-H column allows for retention of both polar and non-polar compounds by carefully selecting the concentration ratio of organic solvent to water in the mobile phase. The characterization of the column was done using a series of polar and nonpolar compounds by studying their aqueous normal-phase and reversed-phase chromatographic behavior. The interactions between the stationary phase and the analyte include both hydrophobic and ionic/electrostatic interactions. The effect of varying the $\mathrm{pH}$ of the mobile phase on retention time was examined. The column's ability to run under reverse and aqueous normal phase conditions provides unmatched versatility compared to type-B silica columns. 


\section{ACKNOWLEDGMENTS}

I would like to thank my advisor, Dr. Joseph Pesek for giving me an opportunity to work on this project and for his valuable guidance throughout my research work. I am thankful for his encouragement, patience, time, and support over these past years as I have strived to complete my degree. I am especially grateful for the patience he has while I raised a family and completed my thesis. I would also like to express my deepest thanks to Dr. Maria Matyska-Pesek for training me in instrumental techniques and providing me all the support. I would like to thank Dr. Roger H. Terrill and Dr. Annalise Van Wyngarden for being my committee members. I appreciate the time they spent on evaluating my thesis.

I am also extremely grateful to Kafeel Ahamad, my husband, who has been absolutely patient, encouraging, and my pillar of support throughout this journey. I would like to thank my parents, Syed China Bikari and Syed Mutharunnissa for all their encouragement and support over the years. I want to thank my extended family for all their support. I would also like to thank my nephew Parveez, for helping me in formatting my thesis. Irfan and Ayesha have been very supportive by watching my son for the past one year, as I have worked towards completing my degree. I greatly appreciate the support of my friends and family, and especially would like to thank my brothers and sister-in-law for their advice, support, and constant encouragement. Finally, I am deeply thankful to my son Zohaib, for his sweet smile and understanding. 


\section{TABLE OF CONTENTS}

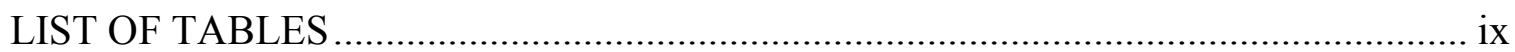

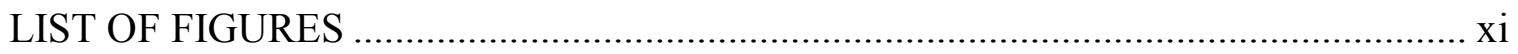

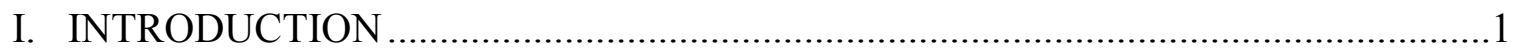

A. Historical Background of Chromatography ………...............................................

B. High Performance Liquid Chromatography.......................................................2

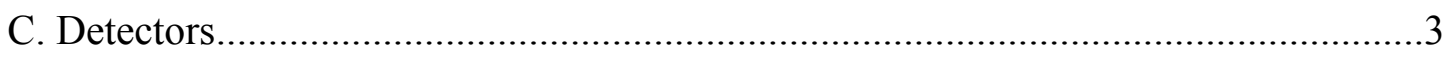

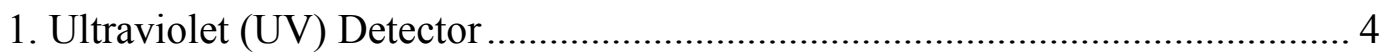

2. Photo Diode Array Detector ......................................................................... 4

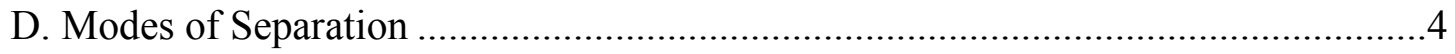

1. Normal Phase Chromatography .................................................................. 5

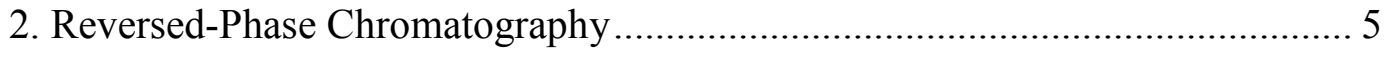

3. Aqueous Normal Phase Chromatography...................................................... 6

4. Hydrophilic Interaction Liquid Chromatography(HILIC) .................................. 7

5. Ion Exchange Chromatography ..................................................................... 7

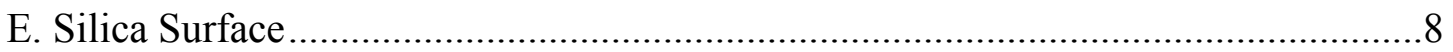

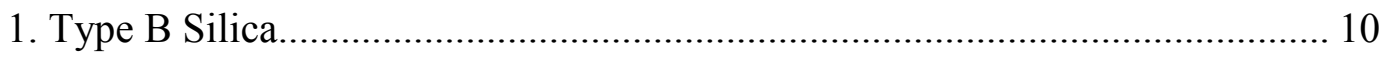

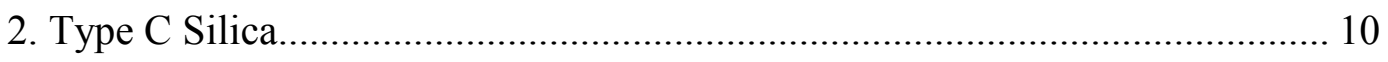

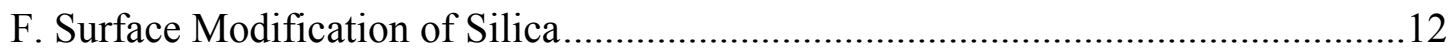

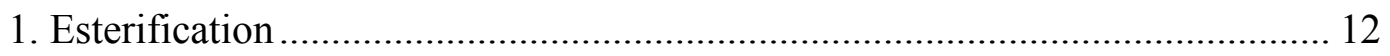

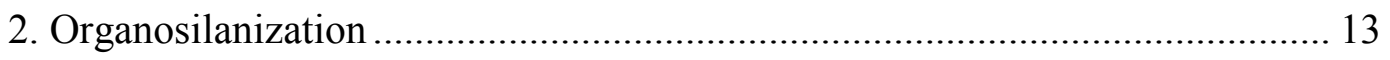

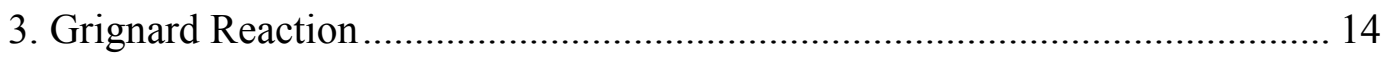

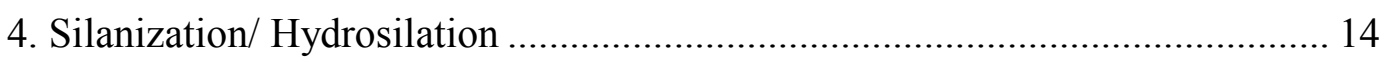

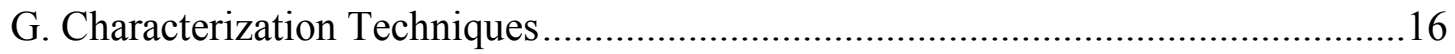


1.Diffuse Reflectance Infrared Fourier Transform Spectroscopy.......................... 16

2. Elemental Carbon Analysis: ......................................................................... 16

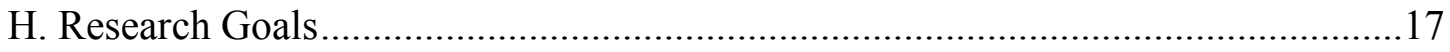

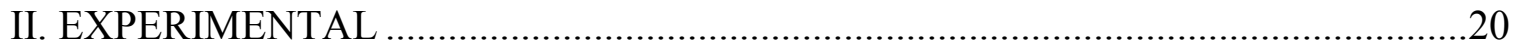

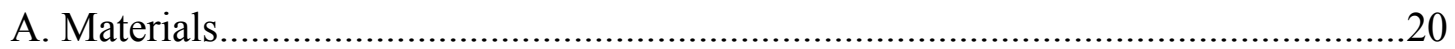

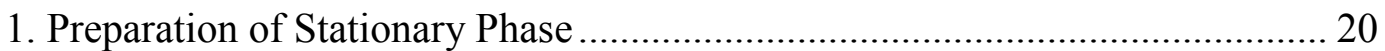

2. Chemicals Used in the Preparation of the Mobile Phases ................................. 21

3. Samples analyzed for the ANP/RP HPLC retention studies............................. 22

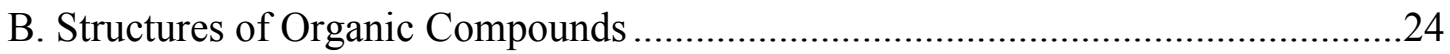

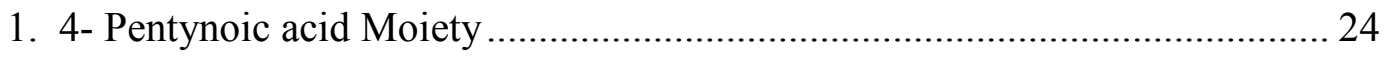

2. Analytes used for the Column Evaluation-Polar Compounds ........................... 24

3. Miscellaneous Compounds ……………………....................................... 25

4. Polycyclic Aromatic Hydrocarbons ............................................................ 26

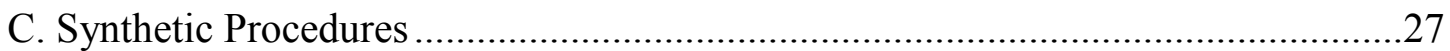

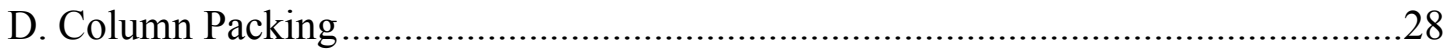

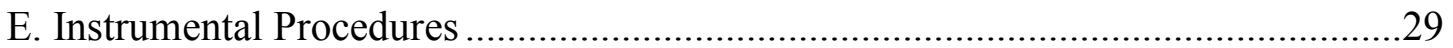

1. Diffuse Reflectance Infrared Fourier Transform Spectroscopy........................ 29

2. Carbon Elemental Analysis....................................................................... 30

3. High Performance Liquid Chromatography ……………………………........ 30

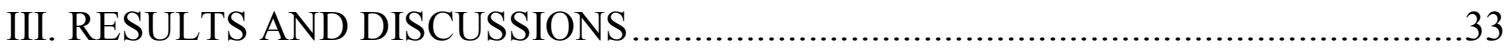

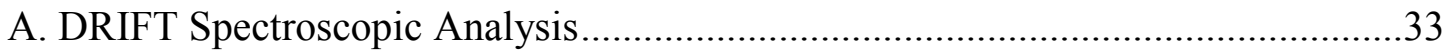

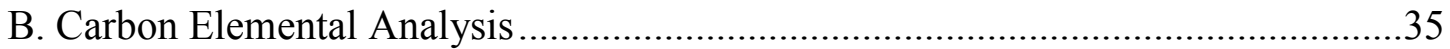

C. Chromatographic Characterization of the Stationary phase........................................36

1. ANP Behavior of Si-H Column Using an UV Detector ................................... 37 
1.1 Nucleobase related Compounds........................................................... 37

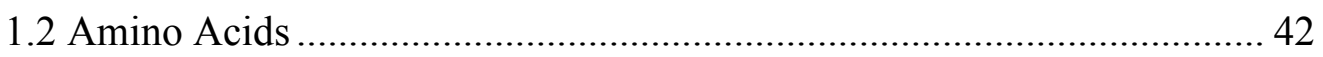

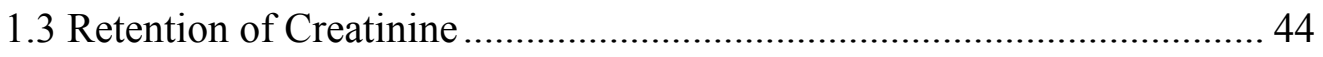

2. Reversed-Phase Retention of Nonpolar Compounds.......................................... 47

3. U-shaped Retention Curve ......................................................................... 50

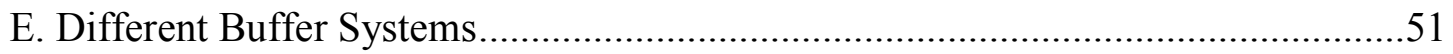

1. Formic Acid Buffer System ....................................................................... 52

2. Ammonium Acetate Buffer System............................................................. 59

2.1. Compatibility of Ammonium Acetate Buffer with Pentynoic acid Column

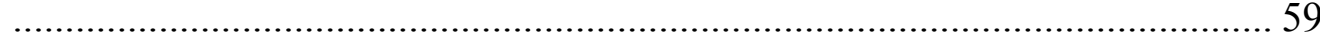

2.2 Varying Concentration of Ammonium Acetate Buffer ............................. 62

F. Comparison of Buffer Trends on Pentynoic acid and Undecynoic acid Columns ..64

G. Column Efficiency …………………………………...................................

H. Peak Symmetry Factor …………………………….....................................

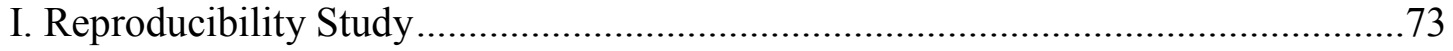

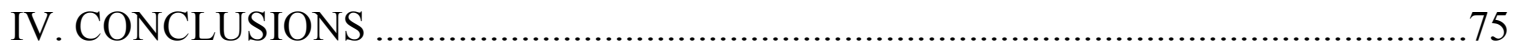

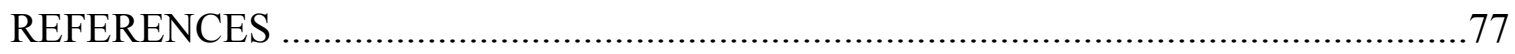




\section{LIST OF TABLES}

Table 1. Chemicals used in the synthesis of stationary phase............. 20

Table 2. Chemicals used in the preparation of mobile phase............... 21

Table 3. Samples analyzed for the ANP retention....................................... 22

Table 4. Miscellaneous compounds ………………………………......... 23

Table 5. Samples analyzed for RP retention ............................................ 23

Table 6. Surface coverage of carboxylic acid phases ................................. 35

Table 7. Surface coverage of bonded organic moiety ............................... 36

Table 8. Retention times of adenosine and cytosine ................................ 38

Table 9. Retention times of uracil and thymine ........................................ 40

Table 10. Retention times of amino acids ..................................................... 43

Table 11. Retention times of creatinine ………………………………..... 45

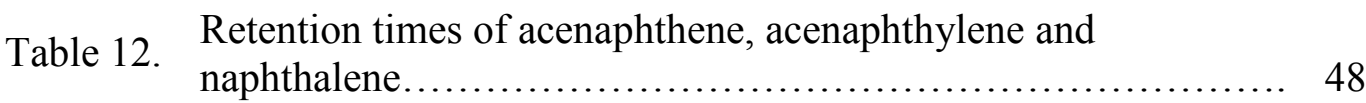

Table 13. Retention times of pyrene and phenanthrene ……....................... 49

Table 14. pH range for 20:80 mixtures of DI water and acetonitrile with formic acid ................................................................... 53

Table 15. Retention times at different concentrations of formic acid .......... 53

Table 16. Retention times of thiamine hydrochloride ................................. 55

Table 17. Retention times of benzoic acid ................................................. 57

Table 18. Retention times of polar solutes with ammonium acetate buffer . 61 
Table 19. $\mathrm{pH}$ range for 20:80 mixtures of DI water and acetonitrile with

Table 20. Retention times at different concentrations of ammonium acetate

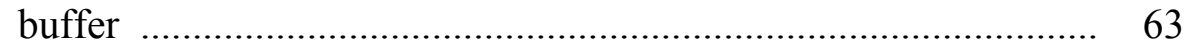

Table 21. Retention times for polar solutes with formic acid buffer (pentynoic acid column)

Table 22. Retention times for polar solutes with formic acid (undecynoic acid column) 66

Table 23. Retention times for polar solutes with ammonium acetate buffer (pentynoic acid column) 68

Table 24. Retention times for polar solutes with ammonium acetate buffer (undecynoic acid column)

Table 25. Method information .......................................................... 72

Table 26. Retention times, asymmetry and column plates data ................. 73

Table 27. Reproducibility of injections using UV ................................. 73 


\section{LIST OF FIGURES}

Figure 1. Schematic view of HPLC system ......................................... 3

Figure 2. Cation exchange chromatography ...................................... 7

Figure 3. Anion exchange chromatography .......................................... 8

Figure 4. Different forms of silanols on the silica surface ...................... 9

Figure 5. Type B (ordinary silica) and type C silica (silica hydride) ......... 11

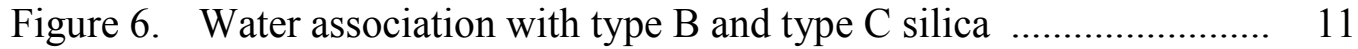

Figure 7. Esterification reaction ........................................................ 12

Figure 8. Organosilanization reaction ….......................................... 13

Figure 9. Chlorination of silanols by Grignard reagent and organolithium compounds ..................................................................... 14

Figure 10. Schematic representation of silanization /hydrosilation procedure 15

Figure 11. Generic retention map on Si-H stationary phase ....................... 19

Figure 12. Experimental set up for hydrosilation reaction ...................... 28

Figure 13. Newly synthesized pentynoic acid column ............................ 29

Figure 14. HP/Agilent 1050 series HPLC-UV instrument ....................... 31

Figure 15. HP/Agilent 1090 series HPLC-UV instrument ....................... 32

Figure 16. DRIFT spectrum of silica hydride based pentynoic acid ........... 34

Figure 17. Retention maps of adenosine and cytosine ............................ 39 
Figure 18. Retention maps of uracil and thymine

Figure 19. Retention map of amino acids

Figure 20. Retention map of creatinine 46

Figure 21. Retention profile of polar compounds

Figure 22. RP retention map of polycyclic aromatic hydrocarbons

Figure 23. U-shaped retention profile for pentynoic acid silica hydride stationary phase

Figure 24. Retention Time as a function of concentration of formic acid

Figure 25. Error bars indicate standard deviation in retention time (thiamine hydrochloride)

Figure 26. Error bars indicate standard deviation in retention time (benzoic acid)

Figure 27. Composition of environment near the surface of a particle with a silica hydride surface

Figure 28. Retention of polar solutes with ammonium acetate buffer 62

Figure 29. Retention time as a function of concentration of ammonium acetate.

Figure 30. Retention time as a function of concentration of formic acid (pentynoic acid column)

Retention time as a function of concentration of formic acid

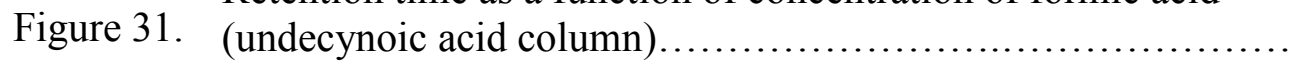

Figure 32. Retention time as a function of concentration of formic acid (pentynoic acid column) 
Figure 33. Retention time as a function of concentration of formic acid (undecynoic acid column)

Figure 34. Determination of peak asymmetry factor

Figure 35. Separation of acetophenone and biphenyl

Figure 36. Retention maps of uracil, pyridine and phenol 


\section{INTRODUCTION}

\section{A. Historical Background of Chromatography}

Chromatography is a powerful separation technique, which allows the separation of different molecular species from a mixture of compounds. Applications of chromatography are numerous in various fields such as biotechnology, pharmaceuticals, biochemical, environmental and related fields. Chromatography was invented by the Russian scientist Mikhail Twsett in 1903. He employed this technique to separate plant pigments such as chlorophylls and xanthophylls on a calcium carbonate column using ether. The separated molecular species appeared as colored bands on the column, which justifies the name he chose for this technique [1].

The stationary phase and the mobile phase play a major role in chromatography. For chromatographic separation, the stationary phase is typically in the form of a column with small porous particles on the surface of the packing material which is used to affect analyte attraction. The mobile phase which carries the sample is passed through the stationary phase. The separation of different compounds is achieved based on the affinity of the analyte towards the stationary phase or mobile phase. The difference in the retention time is the basis of separation of compounds in a mixture. A fundamental classification of chromatographic methods is mainly divided into three types based on the physical state of the mobile phase: gas chromatography (GC), liquid chromatography (LC), and supercritical-fluid chromatography (SFC) [1]. In gas chromatography, mixtures are examined in the vapor phase, so the sample has to be volatile in nature or thermally stable. Only $20-30 \%$ of chemical compounds are suitable for gas chromatography without 
some form of sample modification. During the 1970s, the most commonly used chromatographic techniques were paper chromatography, open column chromatography and thin layer chromatography. However, these techniques were not sufficient for good resolution between similar compounds. This led the way for the development of high pressure liquid chromatography. High performance liquid chromatography is the most widely used technique of all the separation methods.

\section{B. High Performance Liquid Chromatography}

High performance liquid chromatography (HPLC) is a highly efficient and advanced version of liquid chromatography. In industries like biotechnology and pharmaceuticals, HPLC has been recognized as a powerful tool for the purpose of identification, purification, and separation of biomolecules [2]. The basic HPLC instrumentation consists of five major components: pumping system, injector, column, detector and data processor. The pumping system can generate constant pressure up to 6000 psi to adjust the mobile phase flow rates ranging from 0.1 to $10 \mathrm{~mL} / \mathrm{min}$ [3]. The degasser is employed before the solvent injection system. Degassing can be carried out by sparging with helium or by nitrogen gas. Helium sparging removes dissolved air by displacing the unwanted dissolved gases. The samples can be separated in two elution modes: isocratic and gradient. A constant composition of one or more solvents can be used to analyze the samples which is called as isocratic elution. Gradient elution is another method of elution in which the concentration of the mobile phase solvents is

varied at certain intervals. The injector takes a small amount of sample from the vial and introduces it into the constant flow of the mobile phase. 
Separation of the analytes takes place in the column; hence it is called the heart of the chromatographic system. The column consists of a tube made up of stainless steel with a silica-based stationary phase. The length of the analytical column varies from 5 to $25 \mathrm{~cm}$ and the inner diameter of chromatographic columns is often 2.1 to $4.6 \mathrm{~mm}$ [4]. The mobile phase along with the analytes enter the detector, which produces an electrical signal proportional to the concentration of the analytes. This output is recorded as a chromatogram. The detection of molecular species eluted from the column can be done using a variety of techniques like UV-vis absorption, fluorescence and mass spectrometer (MS). Figure 1 represents the basic schematic view of HPLC instrument.

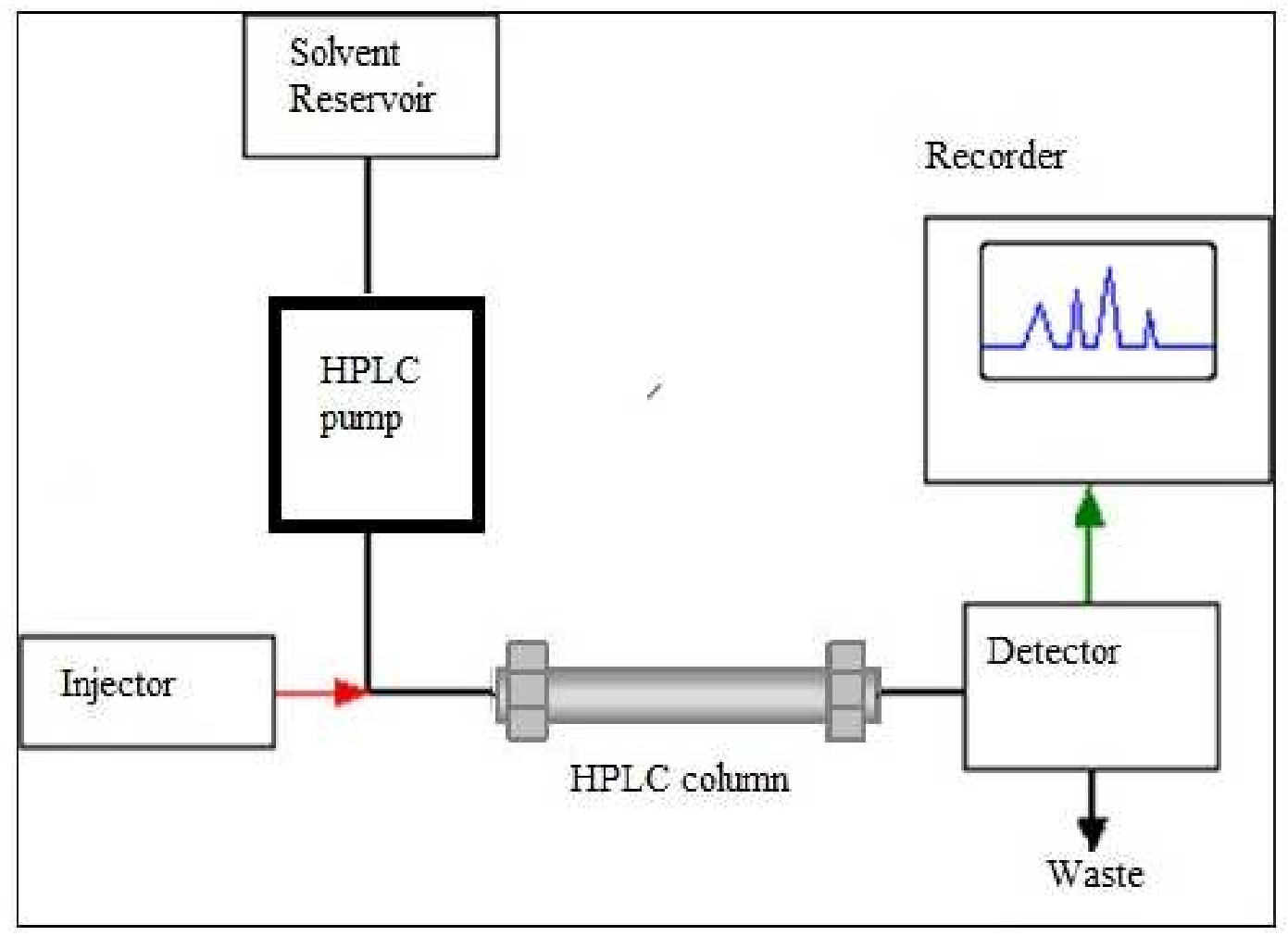

Figure 1. Schematic view of HPLC system 


\section{Detectors}

\section{Ultraviolet (UV) Detector}

UV-vis spectrophotometric detectors are the most commonly used. They are selective in principle, yet possess sufficient versatility to be useful for many applications. This detector is based upon the light absorption characteristics of the analyte. Many compounds in nature can absorb light in the ultraviolet-visible region (200 to $800 \mathrm{~nm}$ ) of the spectrum [1]. Some of the important chromophores are carbonyls, acids, esters, ethylenic, nitrile group, etc. They work on the principle of Beer's law which states that the absorbance of an analyte at a particular UV wavelength is directly proportional to its concentration [5]. The intense $254 \mathrm{~nm}$ radiation from mercury lamps is suitable for a wide range of applications.

\section{Photo Diode Array Detector}

This is similar to a UV detector which operates from 190-700 nm wavelength, which allows the recording of the entire spectrum of each solute as it passes through the diode array detector. The diode array detector (DAD) uses a polychromatic light source, which scans a range of wavelengths every few milliseconds and continually generates spectral information [6].

\section{Modes of Separation}

Based on the nature of the stationary phase and separation process, liquid chromatography can be classified into five different modes: ion-exchange chromatography, partition chromatography, size-exclusion chromatography, affinity chromatography and adsorption chromatography [1]. 
The most widely used type of HPLC is partition chromatography, in which the solute is retained on the basis of its distribution among two or more phases. Partition chromatography can be classified into either liquid-liquid or bonded-phase chromatography depending on how the stationary phase is held on the support surface. Depending upon the polarity of the stationary phase and the mobile phase, there are two main types of separation of HPLC: normal-phase HPLC and reversed-phase HPLC.

\section{Normal Phase Chromatography}

In normal phase chromatography, the mobile phase is non-polar (e.g., hexane, tetra-hydro furan or ethyl acetate) and the stationary phase is strongly polar (e.g., bare silica, cyano or amino bonded phases). In normal-phase chromatography the most nonpolar compounds elute first followed by polar compounds. Polar analytes tend to interact and stay with the stationary phase longer than the non-polar analytes, hence higher retention time for the polar compounds is expected, consequently non-polar analytes tend to elute faster resulting in lower retention time.

\section{Reversed-Phase Chromatography}

In reversed-phase chromatography, the stationary phase is non-polar (bonded alkyl groups such as $\mathrm{C} 8, \mathrm{C} 18$, etc.) and the mobile phase is polar (e.g. acetonitrile-water or methanol-water). Polar compounds elute first followed by non-polar compounds. In reversed-phase chromatography, the separation is based on the partitioning of the analyte between the stationary phase and the mobile phase. The non-polar stationary phases can be obtained by chemically bonding organic moieties on a solid surface such as silica. 
The major advantage of reversed phase is that water can be used as the mobile phase which is non-toxic and inexpensive. The interactions in reversed phase are considered to be hydrophobic forces [5]. In this mode, care must be taken to avoid $\mathrm{pH}$ values greater than 7.5 , as it leads to the dissolution of the stationary phase. However, some biomolecules and pharmaceutical drugs contain multiple polar sites, and are very difficult to separate solely based on NP or RP chromatography.

\section{Aqueous Normal Phase Chromatography}

A new chromatographic technique has been developed by Pesek et al called aqueous normal phase chromatography (ANP) [7]. Aqueous normal phase is a technique performed on a special stationary phase, silica hydride. ANP is a mode of chromatography that can retain both polar as well as nonpolar analytes on the same column [6]. This unique dual retention capability of ANP is observed due to silicahydride. It is one of the most versatile separation modes allowing for a wide range of multi-polarity molecules to be analyzed and separated at the same time [ 8]. The ANP mode shows the same retention behavior as normal phase but has some water as part of the binary solvent system. When the percentage of acetonitrile (nonpolar solvent) increases, there is an increase in the retention of the polar molecules in the aqueous normal phase mode. As the percentage of water (polar component) increases, non-polar molecules are retained in the reversed-phase mode. Moreover, additives such as formic acid, ammonium formate, or ammonium acetate in small amounts in the mobile phase are used to get better peak shape and to enhance the retention of both acidic and basic polar solutes $[9,10]$. 


\section{Hydrophilic Interaction Liquid Chromatography(HILIC)}

Hydrophilic interaction liquid chromatography is a type of HPLC, which is used to separate polar-ionic compounds. The chromatographic surface used for the stationary phase can be polar (diol, amino) or ionic. The mobile phase in HILIC is typically less polar such as $\mathrm{CH}_{3} \mathrm{OH}$ or $\mathrm{CH}_{3} \mathrm{CN}$ [5]. It is used for separation of the biomolecules and the small polar compounds [11]. The main draw back with HILIC separation is that, it can only separate polar compounds.

\section{Ion Exchange Chromatography}

Ion exchange chromatography is a separation process in which species (ions, polar molecules) are separated on the basis of differences in electric charge. Cation exchange is a type of HPLC used for the separation of positively charged species. The chemically bound ions are called fixed ions and the ions of opposite charge are called counter ions. In this type of HPLC the retention is based on the attraction between ions in a solution and the opposite charged sites which are chemically bound to the stationary phase. In a cation-exchanger, the fixed ion carries a negative charge and exchanges cations from the solution [12] as shown in the Figure 2.

\section{$\mathrm{R}-\mathrm{X}^{-} \mathrm{C}^{+}+\mathrm{M}^{+} \mathrm{B}^{-} \rightleftarrows \mathrm{R}-\mathrm{X}^{-} \mathrm{M}^{+}+\mathrm{C}^{+}+\mathrm{B}^{-}$ (stationary phase) (solution) $\quad$ (stationary phase) $\quad$ (solution)}

Figure 2. Cation exchange chromatography. 
Anion exchange chromatography is a type of HPLC used for the separation of negatively charged species. The ion exchanger is classified as anion-exchanger when the fixed ion carries a positive charge and exchanges anions from the solution. The mobile phase in ion-exchange chromatography usually consists of a buffer solution. Ion exchangers may be further classified as either strong or weak. Strong ion exchangers retain the charge on the fixed ion over a wide range of $\mathrm{pH}$, whereas weak cation exchangers are ionized within a narrower $\mathrm{pH}$ range. Figure 3 depicts the anion exchange chromatography reaction.

\section{$\underset{\text { (stationary phase) }}{\mathrm{R}_{-} \mathrm{X}^{+} \mathrm{A}^{-}+\mathrm{N}^{+} \mathrm{B}^{-} \rightleftarrows} \underset{\text { (solution) }}{\mathrm{R}-\mathrm{X}^{+} \mathrm{B}^{-}}+\underset{\text { (Stationary phase) }}{\mathrm{M}^{+}+}$}

Figure 3. Anion exchange chromatography.

\section{E. Silica Surface}

Silica-based materials have been commonly used as solid supports in liquid chromatography. The chemical composition of the stationary phase can strongly affect the efficiency of separation. Silica is a porous material. It is mechanically stable and can be processed into particles of different pore sizes and shapes. The pore size of the silica particles has a direct interrelation shape with the size of the molecules retained on the stationary phase [13]. Silica used for chromatography is a condensation product of silicic acid. Its' polymeric surface terminates in either a siloxane group ( $\mathrm{Si}-\mathrm{O}-\mathrm{Si})$ with the oxygen on the surface or one of the several forms of silanol groups ( $\mathrm{Si}-\mathrm{OH})$. Silanol 
groups on the surface of a silica particle can exist in germinal, vicinal or isolated form. These are hydrophilic in nature.

The silica surface can be best described as shown in Fig 4. Out of the two groups, silanols are more interesting to chromatographers since accessible silanol group localized on the silica surface will react with certain organic reagents to produce chemically bonded phases. The silanol group plays a very key role in the chromatographic separation properties of silica. Most of the properties are determined by their percentage of specific surface area and by the type of functional group attached. The concentration of silanol groups on the silica surface area is estimated to be $8 \mu \mathrm{mol} / \mathrm{m}^{2}$. Even short length columns can have sufficient surface area for analyte and stationary phase interactions [14].

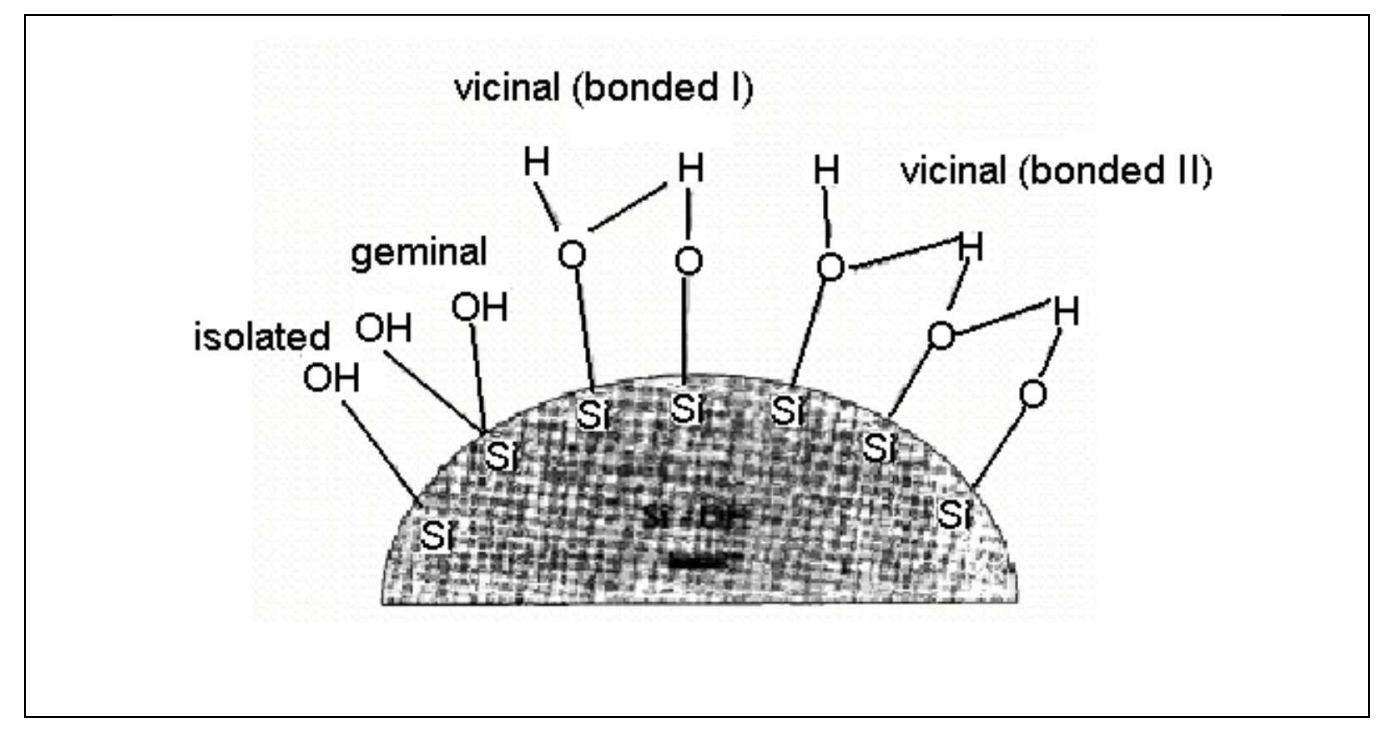

Figure 4. Different forms of silanols on the silica surface. Taken with permission from reference [12]. 


\section{Type B Silica}

Type B silica or ordinary silica is the most commonly used stationary phase material. The surface of Type B contains silanol groups (Si-OH). Type B silica has a less acidic surface and low metal content when compared to Type A silica. It is converted by derivatization to a reproducible bonding of the attached organic moieties such as, diols, carboxylic acids, phenyls, or hydrocarbons on the surface. The commonly used bonded Type B stationary phases are C8, C18, and diols.

Type B silica has many disadvantages like instability at high $\mathrm{pH}$ and the fact that polar compounds are poorly retained in the reversed-phase mode. There could be oncolumn degradation of analytes due to the adsorbed layer of water on the surface. Sometimes, there are long run times and long equilibrium times while running gradients. Type B silica stationary phases adsorb water from the mobile phase, due to free silanols and as the amount of water increases the retention of the analytes often changes [15].

\section{Type C Silica}

In order to overcome the limitations caused by the silanol groups on the surface of silica-based stationary phases, Pesek et al. introduced a new type of stationary phase known as silica hydride or Type $\mathrm{C}$ silica. The basic difference between Type B and Type $\mathrm{C}$ silica is that, silanols groups are present on the surface of ordinary silica while Si-H moieties are on the surface of silica hydride. This chemical change dramatically alters the surface properties of the two materials [15]. Figure 5 illustrates the comparison of the chemical surface composition of Type B and Type C silicas. 


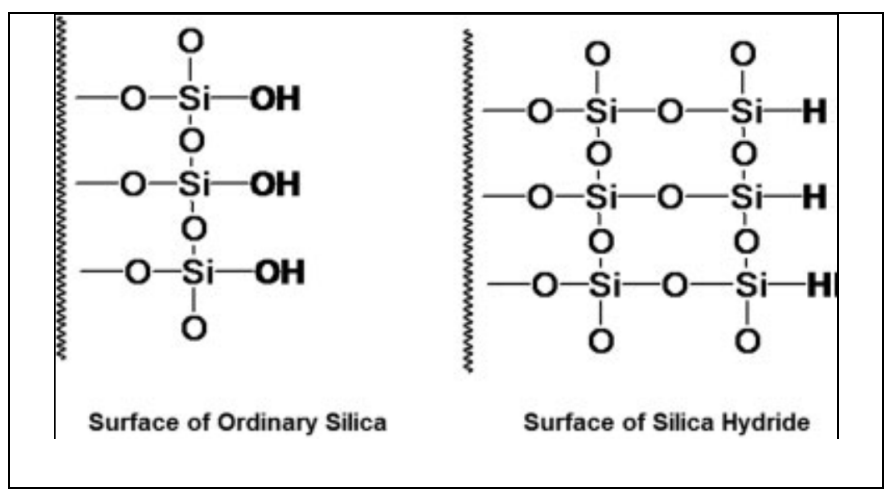

Figure 5. Type B (ordinary silica) and type C silica (silica hydride). Taken with permission from reference [16].

Type $\mathrm{C}$ silica is weakly hydrophobic in nature due to the presence of the hydride on the surface. In the case of silica hydride, there is weak adsorption of water as opposed to strong water adsorption on Type B silica [16]. Figure 6 shows the association of water molecules with Type B and Type $\mathrm{C}$ silica respectively.

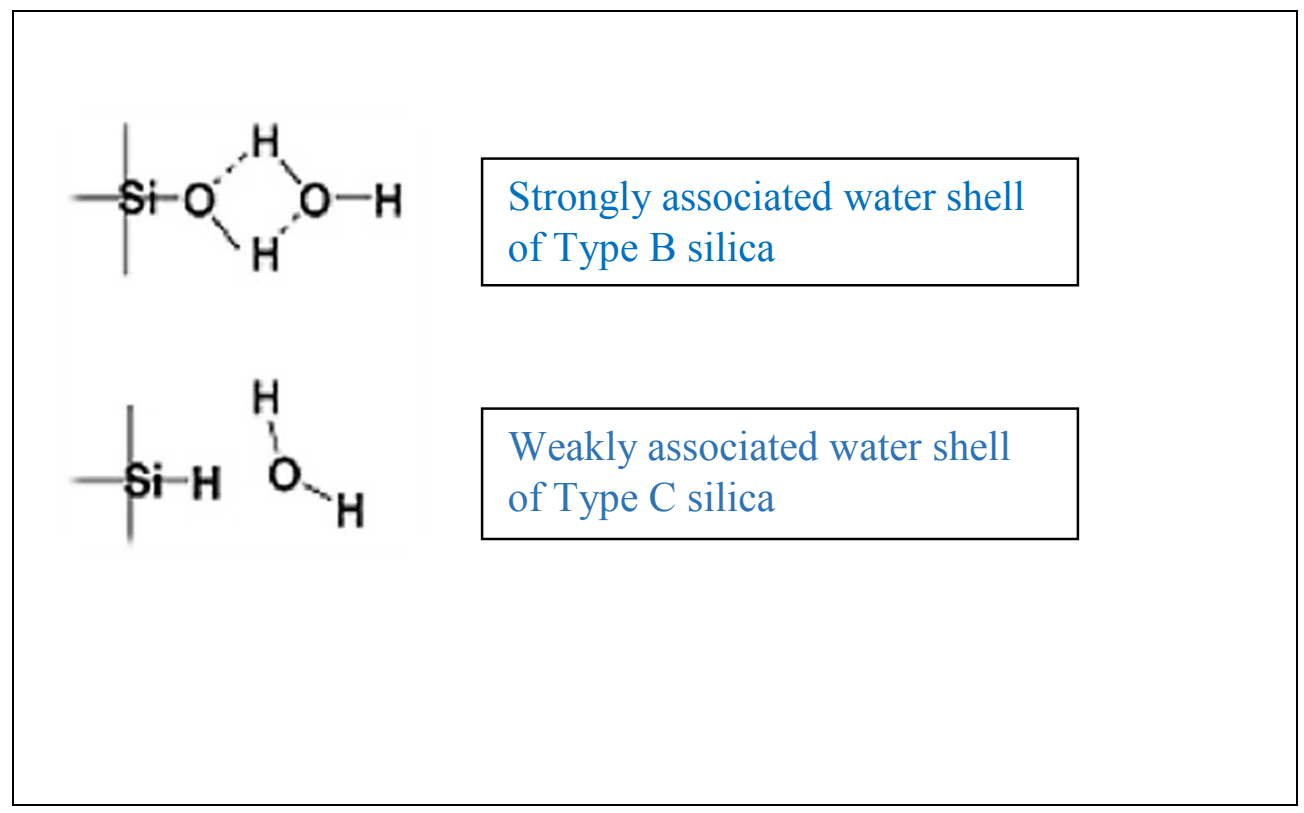

Figure 6. Water association with type B and type $\mathrm{C}$ silica. Taken with permission from reference [17]. 


\section{F. Surface Modification of Silica}

Different modification procedures can be used to modify the silica surface with a variety of ligands. The field of modification is a well-researched field of surface chemistry where a number of conversion methods to attach bonded organic moieties to silanol groups and their effects have been studied. Some of the reactions are esterification, organosilanization, chlorination, TES silanization and hydrosilation [18]. In all of these techniques, the organic moieties are covalently bonded to the silica surface.

\section{Esterification}

Esterification was the earliest method developed and it involves a reaction between an alcohol and the silanols on the surface to form a Si-O-C linkage as shown in Figure 7. This reaction is not suitable for most chromatographic applications because the Si-O-C linkages are hydrolytically unstable. $[18,19]$.

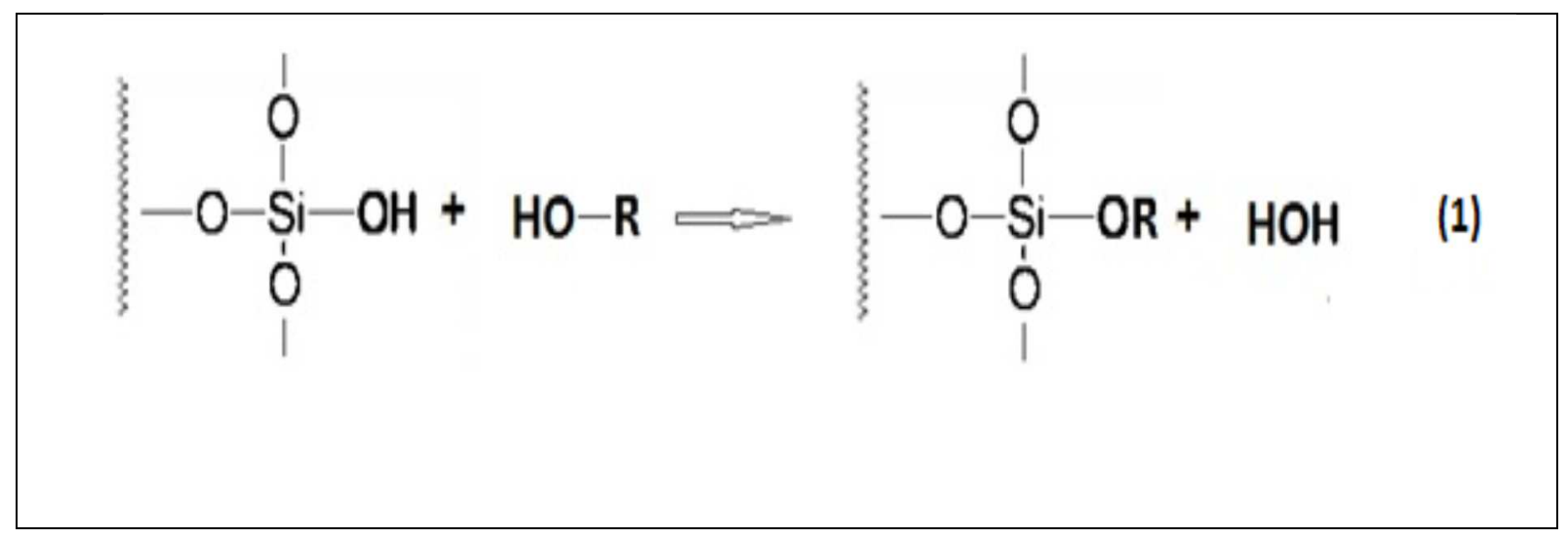

Figure 7. Esterification reaction. 


\section{Organosilanization}

Another method to remove the acidic - $\mathrm{OH}$ group of silanol is organosilanization. In this reaction, a dimethylalkyl silane (X-SiR'2R) replaces the $-\mathrm{OH}$ in silanol [18]. The reaction of surface silanols with alkylchlorosilanes produce Si-O-Si-C linkages. This monomeric phase goes through hydrolysis under moderately acidic and moderately basic conditions. In the second type of organisilanization as shown in Figure 8, a polymeric phase is formed when a trifunctional organosilane reacts with surface silanols [20]. The polymeric phase gives better hydrolytic stability but the reaction is not reproducible $[3,21]$.

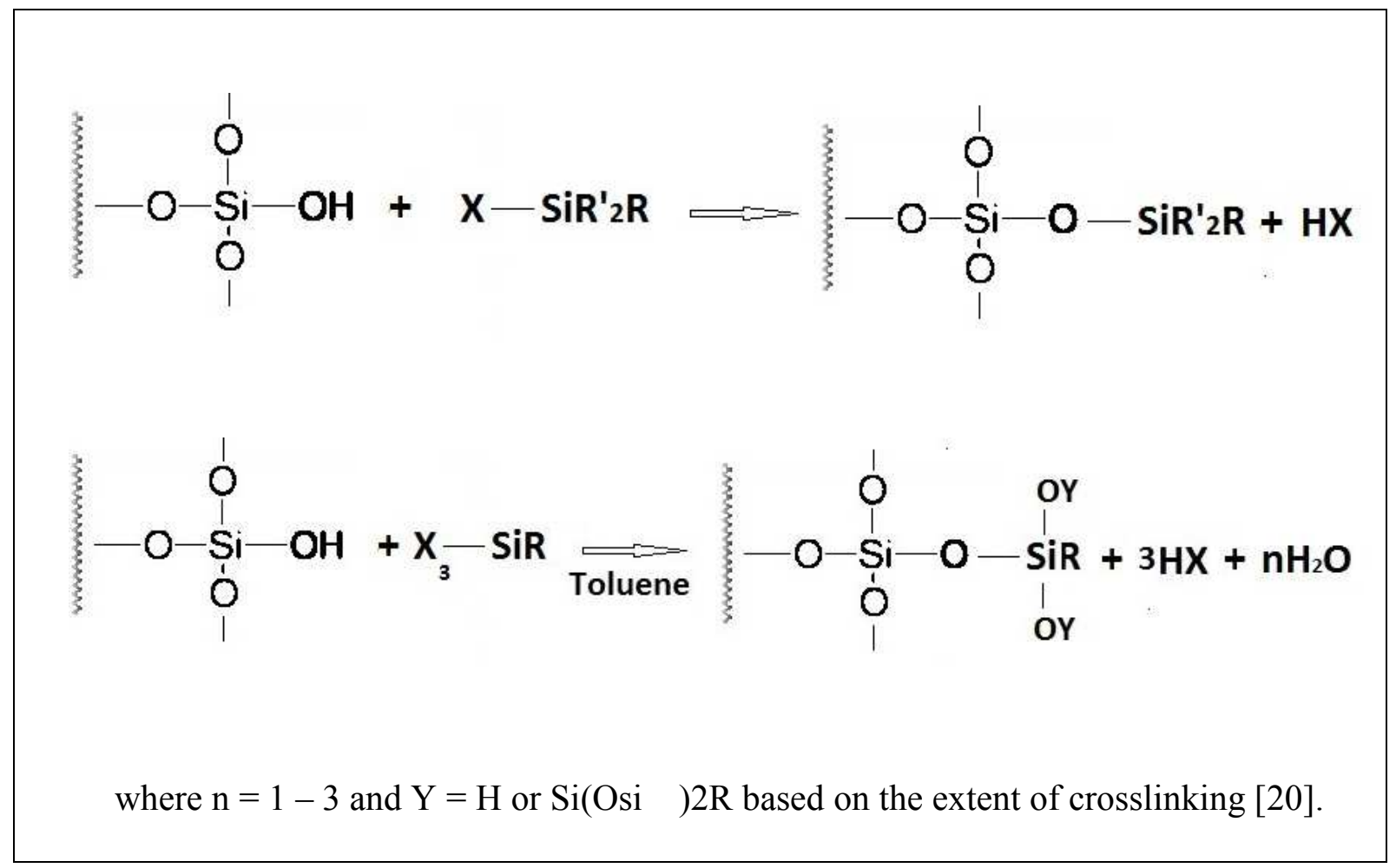

Figure 8. Organosilanization reaction. 


\section{Grignard Reaction}

Another approach that can be used is the chlorination of surface silanols followed by reaction of a Grignard reagent or oraganolithium compounds. As shown in Figure 9, this reaction produces a highly stable $\mathrm{Si}-\mathrm{C}$ bond at the surface which is more stable. The disadvantage of this method is the formation of undesirable products such as $\mathrm{MgClBr}$ or $\mathrm{LiCl}$ which are difficult to wash off and can act as a potential contaminant on the silica surface $[21,22]$.

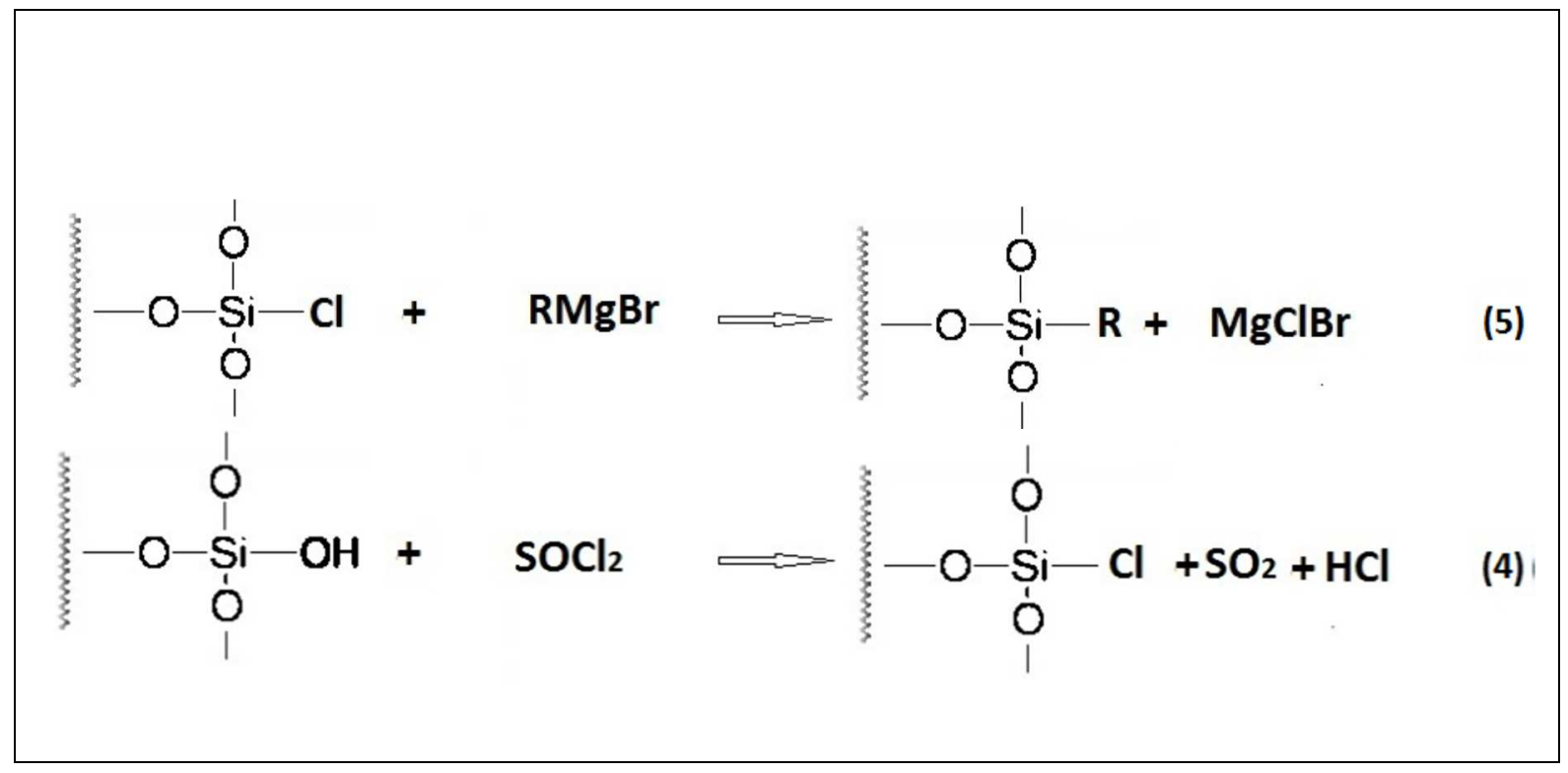

Figure 9. Chlorination of silanols by Grignard reagent and organolithium compounds.

\section{Silanization/ Hydrosilation}

A more recent approach involves silanization followed by a hydrosilation reaction to attach an organic moiety to the silica surface as introduced by Pesek et al; [23] The first step is the silanization reaction, which involves the formation of a stable $\mathrm{Si}-\mathrm{H}$ by the reaction of silica with TES in the presence of an acid catalyst. About $95 \%$ of surface 
silanols are converted into weakly hydrophobic $\mathrm{Si}-\mathrm{H}$. This reaction product, $\mathrm{Si}-\mathrm{H}$, serves as a stable intermediate for the hydrosilation reaction [21]. Figure 10 shows the schematic of the two-step synthesis procedure.

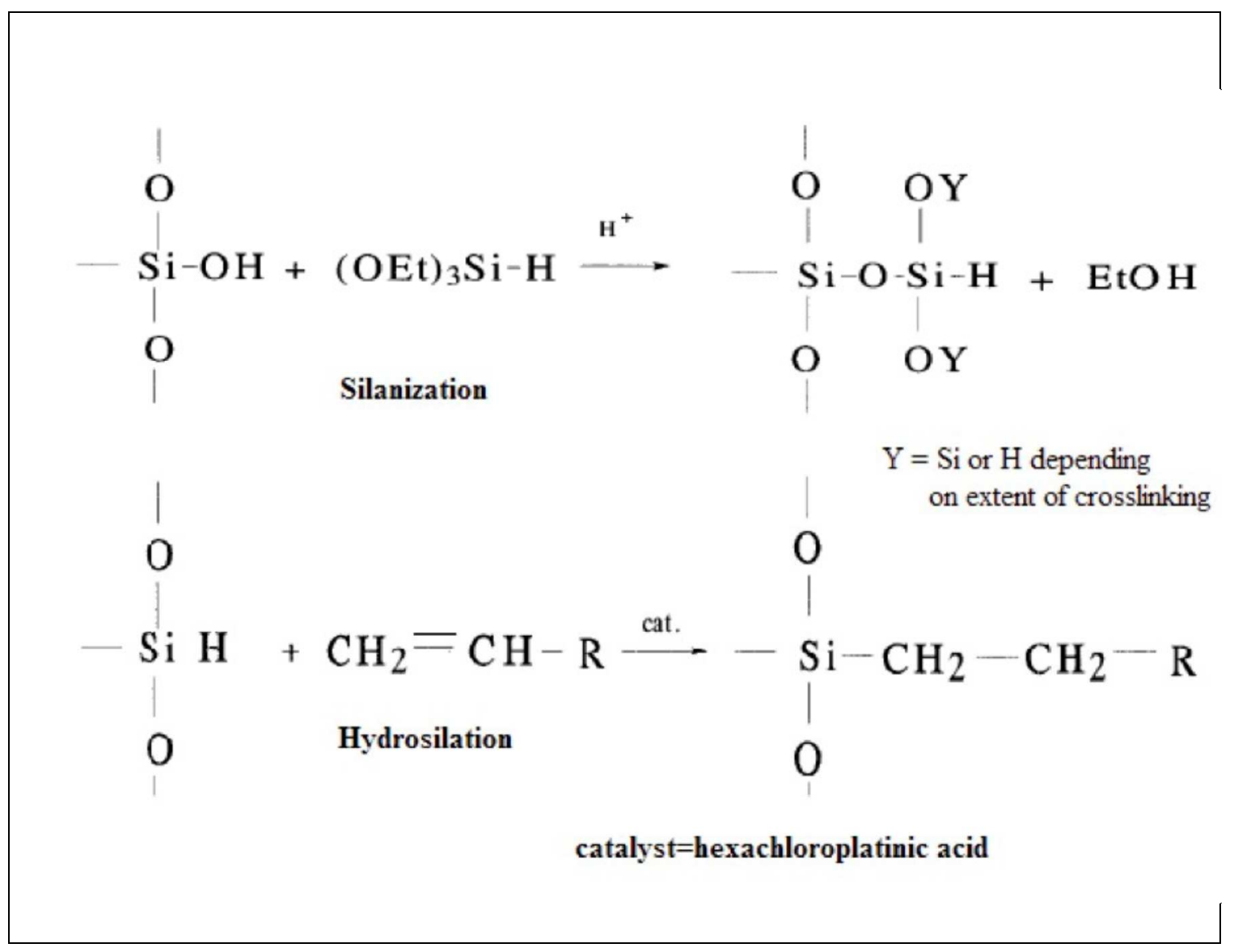

Figure 10. Schematic representation of silanization/hydrosilation procedure In the second step of hydrosilation, the desired organic moiety is attached on the surface of silica hydride using an acid catalyst, hexacholoroplatinic acid, also known as Speier's catalyst. The technique has opened the door to the production of a variety of stationary phases which are hydrophobic, hydrophilic or ionic depending upon the type of 
organic moiety attached. The separation of analytes on Type C columns, is due to the combined effect of the bonded organic moiety as well as the hydrophobic $\mathrm{Si}-\mathrm{H}$.

\section{G. Characterization Techniques}

Two main characterization methods, DRIFT and carbon elemental analysis, have been used to determine the success of bonding of pentynoic acid to a silica hydride surface, the material that is the focus of this study. The following sections describe the characterization methods used in this research.

\section{Diffuse Reflectance Infrared Fourier Transform Spectroscopy}

Diffuse reflectance infrared Fourier transform spectroscopy (DRIFT) provides information about the functional groups present in the molecule bonded to the surface. DRIFT spectroscopy gives sufficient information about the surface chemistry of high surface area powders. The completion of the silanization and hydrosilation reactions, as well as the presence of bonded raw materials can be explained qualitatively using DRIFT. DRIFT analysis of powders is conducted by focusing infrared light directly onto the powdered sample, and the diffusely reflected beam is collected in the spectrometer. In this research project, DRIFT analysis is performed by irradiating the powdered sample, placed in a small cup. The signal contains the fingerprint spectral characteristics about the bonded moiety.

\section{Elemental Carbon Analysis:}

Elemental analysis was carried out by micro-combustion. The combustion method is used to determine the elemental composition of organic compounds. Carbon percent values are useful to estimate the surface coverage of the bonded organic moiety. The 
Berendsen and de Galan equation provides the relationship between the carbon percentage and surface coverage $(\alpha)$ of the bonded phase as shown below.

$$
\alpha(\mu \mathrm{mol} / \mathrm{m} 2)=106 p \mathrm{c} /\left(10^{2} \mathrm{MC} \mathrm{nC}-p c \mathrm{MR}\right) \mathrm{SBET}
$$

In the above equation,

$p c-$ carbon $\%$ of the bonded material.

$\mathrm{nC}$ - number of carbon atoms in bonded organic groups.

$\mathrm{MC}$ - the atomic weight of carbon.

MR - molecular weight of organic compound.

SBET - specific surface area of silica material.

\section{H. Research Goals}

The primary goal in this research project was to synthesize a silica hydride based pentynoic acid stationary phase. The pentynoic acid moiety was selected because it contains an alkyl carbon chain as well as a carboxylic group. Modification of silica is a two-step process. The first step is the silanization process, which was used to convert the silanols of silica to silica hydride. Previously prepared silica hydride was used as a starting material. The second step is hydrosilation, in which the pentynoic acid moiety is attached to the surface of silica hydride. The synthesized stationary phase was characterized using two analytical techniques: DRIFT and elemental analyses. DRIFT analysis data confirmed the presence of spectral frequencies of the bonded moiety, pentynoic acid. Carbon elemental analysis estimated the amount of pentynoic acid attached to the silica hydride material 
The next objective was to analyze the separation ability of the silica hydride based pentynoic acid bonded material. A number of compounds including amino acids, nucleobases, nucleotide, nucleosides, ergogenic acids and polycyclic aromatic hydrocarbons were tested to investigate their retention on the silica hydride column. This study was done by selecting analytes from both hydrophobic and hydrophilic categories to observe the retention behavior of each under RP and ANP modes. A majority of the work was done using a UV detector. Retention maps of individual compounds were plotted under isocratic conditions. Dual retention capability and U-shaped retention profiles for polar and nonpolar compounds on the silica hydride based stationary phase were demonstrated.

The final goal of this project was to study the effect of varying $\mathrm{pH}$ on the retention time of compounds. Two different buffer systems, formic acid and ammonium acetate, were used in this study A reproducibility study was also performed to evaluate the column performance. Figure 11 shows an ideal retention map for silica hydride-based stationary phases, when using a mixture of polar and nonpolar solvents as the mobile phase. 


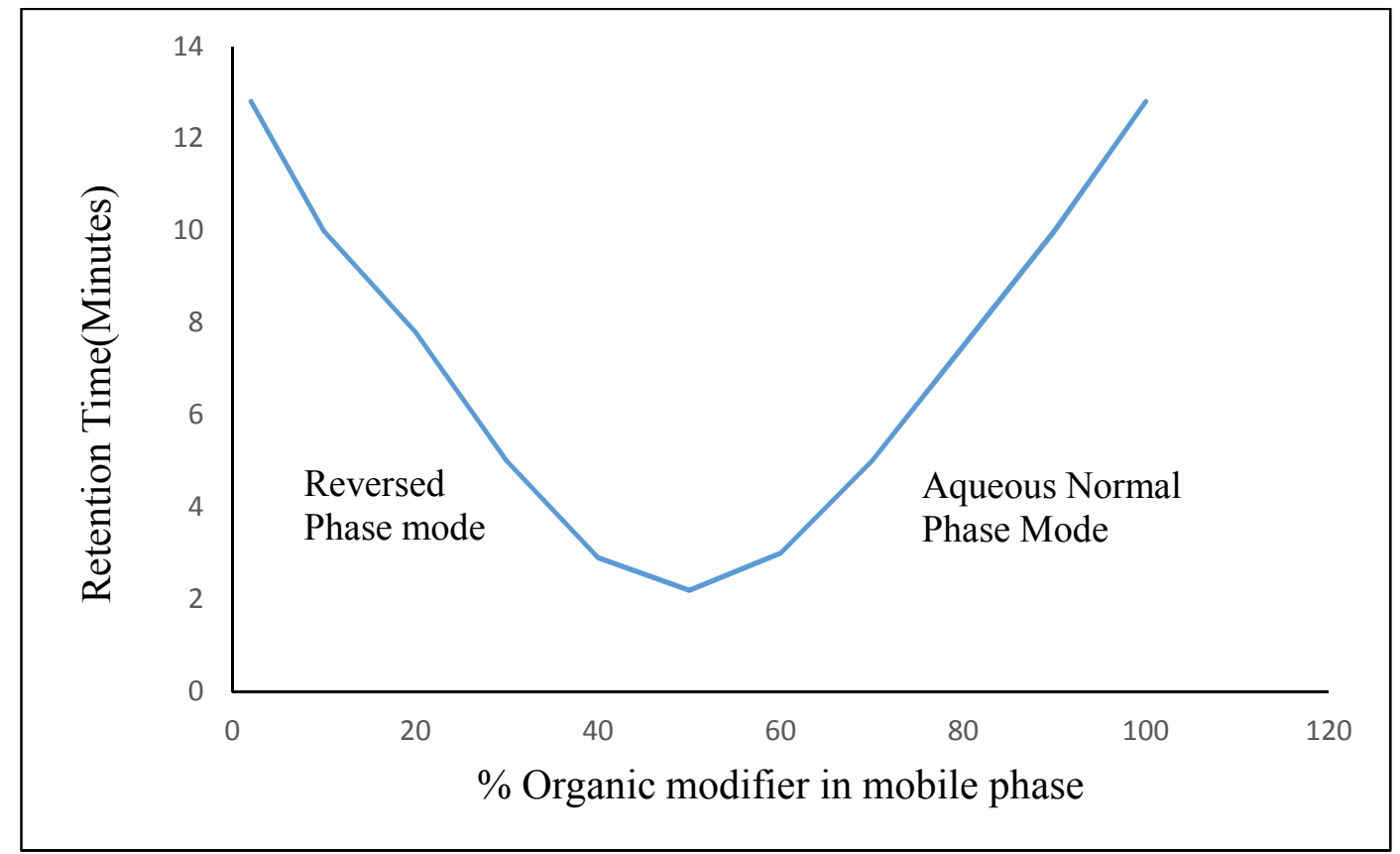

Figure 11. Generic retention map on $\mathrm{Si}-\mathrm{H}$ stationary phase. 


\section{EXPERIMENTAL}

\section{A. Materials}

\section{Preparation of Stationary Phase}

The chemicals used in the preparation of the pentynoic acid stationary phase via the hydrosilation process are shown in Table1.

Table 1. Chemicals used in the synthesis of stationary phase.

\begin{tabular}{|c|c|}
\hline Chemical Name & Manufacturing Company \\
\hline 4-Pentynoic acid & GFS Chemicals, Inc. \\
\hline Hexachloroplatinic Acid & Sigma-Aldrich \\
\hline Toulene & Fisher Chemicals \\
\hline Diethyl ether & Sigma-Aldrich \\
\hline Dichloromethane & Fisher Chemicals \\
\hline
\end{tabular}




\section{Chemicals Used in the Preparation of the Mobile Phases}

The chromatographic evaluation of the stationary phase is carried out by using different concentrations of an organic solvent, acetonitrile, and a polar solvent, DI water. In addition to the above solvents, formic acid is used as an additive in small amounts. The mobile phases used in this research project can be found in Table 2 .

Table 2. Chemicals used in the preparation of mobile phase.

\begin{tabular}{|c|c|}
\hline Chemical Name & Manufacturing Company \\
\hline Acetonitrile & Honeywell \\
\hline Formic acid & Spectrum Mfg. Corp. \\
\hline Ammonium Acetate & Matheson Coleman \& Bell \\
\hline MilliQ DI Water & Millipore \\
\hline
\end{tabular}




\section{Samples analyzed for the ANP/RP HPLC retention studies}

The small polar molecules and non-polar molecules used in the evaluation of the column are listed in the Tables 3 through 5.

Table 3. Samples analyzed for ANP retention

\begin{tabular}{|c|c|}
\hline Chemical Name & Manufacturing Company \\
\hline Adenosine & Calbiochem Co. \\
\hline Cytosine & Nutritional Biochemical Corp. \\
\hline Uracil & Sigma Chemical Co. \\
\hline Thymine & Nutrional Biochemical Corp. \\
\hline Phenylalanine & Sigma-Aldrich \\
\hline Tyrosine & Pierce chemical Co. \\
\hline & \\
\hline & \\
\hline
\end{tabular}


Table 4. Miscellaneous compounds.

\begin{tabular}{|c|c|}
\hline Chemical Name & Manufacturing Company \\
\hline Benzoic Acid & Mallinckrodt \\
\hline Thiamine Hydrochloride & MCB Mfg. Chemists \\
\hline
\end{tabular}

Table 5. Samples analyzed for RP retention

\begin{tabular}{|c|c|}
\hline Chemical Name & Manufacturing Company \\
\hline Acenaphthene & Aldrich \\
\hline Anthracene & Aldrich \\
\hline Naphthalene & J.T. \& Baker Chemical Co. \\
\hline Phenanthrene & Sigma-Aldrich \\
\hline Pyrene & Aldrich \\
\hline
\end{tabular}




\section{B. Structures of Organic Compounds}

1. 4- Pentynoic acid Moiety

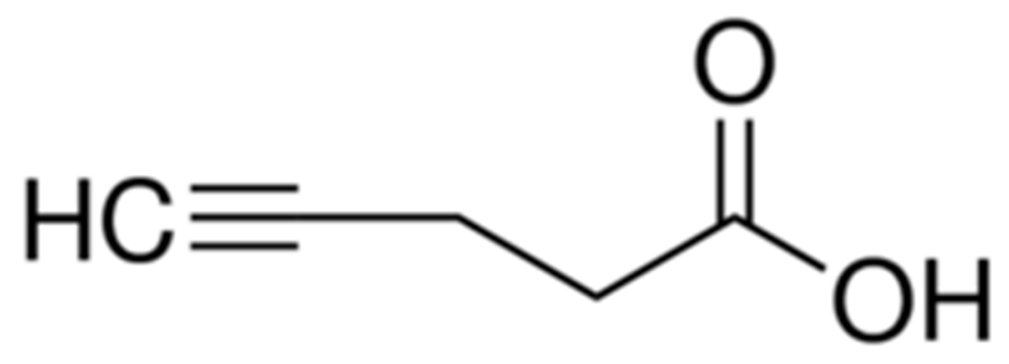

2. Analytes used for the Column Evaluation-Polar Compounds

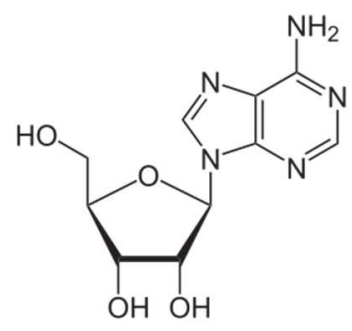

Adenosine<smiles>O=c1cc[nH]c(=O)[nH]1</smiles>

Uracil<smiles>Cc1c[nH]c(=O)[nH]c1=O</smiles>

Thymine 


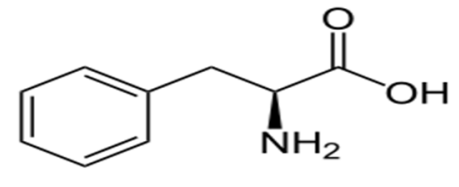

Phenylalanine

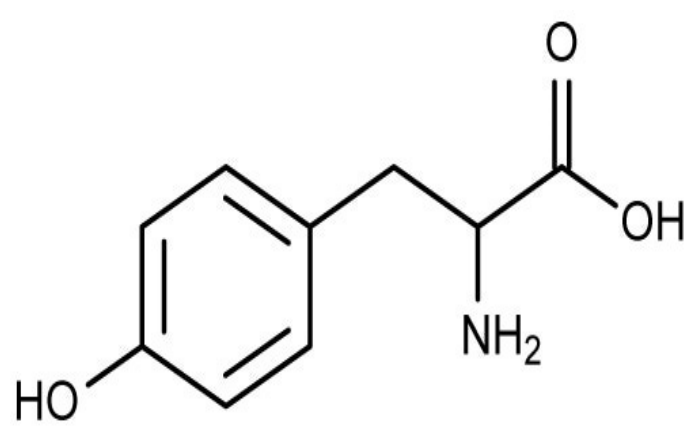

Tyrosine

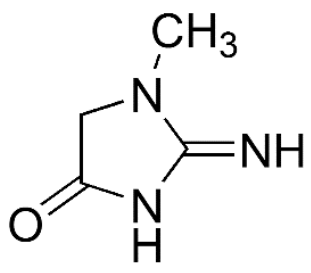

Creatinine

\section{Miscellaneous Compounds}<smiles>Cc1ncc(C[n+]2csc(CCO)c2C)c(N)n1</smiles>

Thiamine Hydrochloride

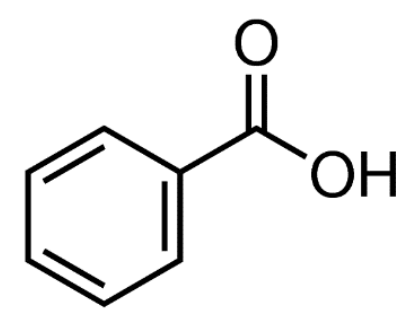

Benzoic Acid 


\section{Polycyclic Aromatic Hydrocarbons}

The polycyclic aromatic hydrocarbons, acenaphthene, acenaphthylene, naphthalene, phenanthrene, and pyrene were used as another group of non-polar analytes. The structure of each compound is shown below.<smiles>c1cc2ccc3cccc4ccc(c1)c2c34</smiles>

Pyrene

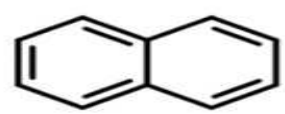

Naphthalene

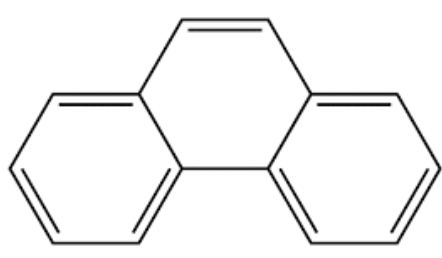

Phenanthrene
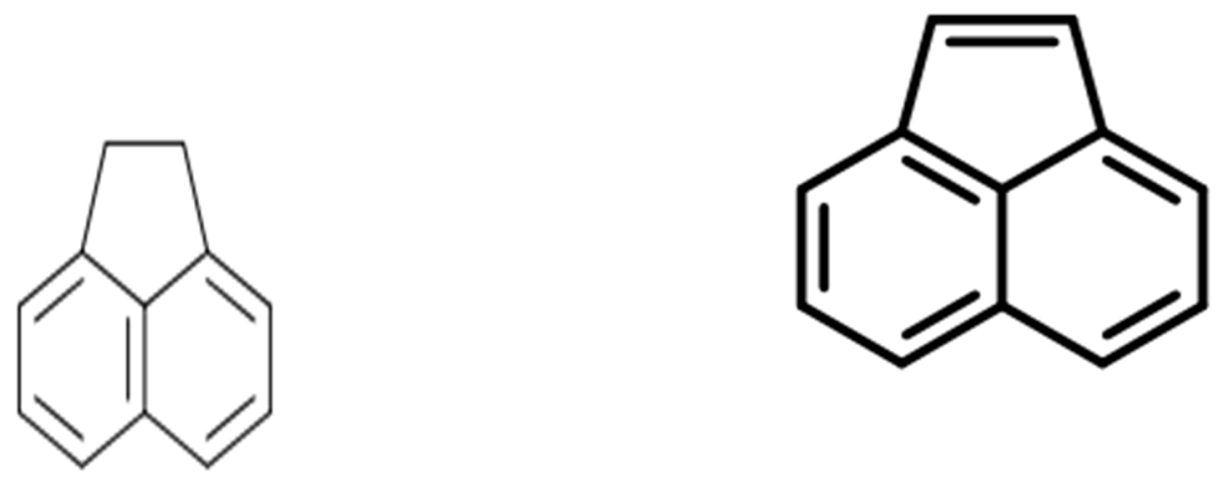

Acenaphthylene 


\section{Synthetic Procedures}

The synthesis of pentynoic acid silica hydride involves two steps. Silanization is the first step, in which silanol groups are converted into silica hydride. Previously synthesized silica hydride was used in this project. The second step is hydrosilation. The hydrosilation reaction was carried out in order to bond pentynoic acid moieties onto the silica hydride surface. All the glassware required for the synthesis was dried overnight in an oven at $110^{\circ} \mathrm{C}$. Five grams of silica hydride, which is synthesized by the silanization procedure, were also dried overnight in a vacuum oven at $120^{\circ} \mathrm{C}$ prior to synthesis. The organic moiety, 4-pentynoic acid $\left(\mathrm{HC} \equiv \mathrm{C}\left(\mathrm{CH}_{2}\right)_{2} \mathrm{COOH}\right)$, was used for this particular reaction. A $500 \mathrm{~mL}$ three necked round bottom flask was attached to a condenser with a drying tube, a thermometer, and a stopper. The round bottom (RB) flask was kept in a heating mantle, which was placed on the electric heater. A magnetic stir bar was placed inside the RB flask. About $200 \mathrm{ml}$ of toluene, $0.5 \mathrm{~mL}$ of $10 \mathrm{mM}$ Speier's catalyst and 2.5 g of $98 \%$ pure 4-pentynoic acid were transferred to the flask. The reaction mixture was heated at a constant temperature of $70^{\circ} \mathrm{C}$ for an hour with constant stirring to ensure complete activation of the new complex formed. After one hour, $2.5 \mathrm{~g}$ of silica hydride was added gradually to the flask and in small portions with constant stirring. This reaction mixture was refluxed at $110^{\circ} \mathrm{C}$ for 96 hours. Afterwards, this reaction mixture was allowed to cool down and filtered through a crucible using vacuum suction. The filtered solid was washed successively with $50 \mathrm{~mL}$ of toluene, $50 \mathrm{~mL}$ of dichloromethane and $50 \mathrm{~mL}$ of diethyl ether. The final silica hydride (pentynoic acid bonded to silica hydride) product was dried overnight at room temperature by placing the beaker in the 
hood to evaporate the ether used during the washing cycles. The final product was then dried overnight in the vacuum oven at $110^{\circ} \mathrm{C}$ for 24 hours. Figure 12 shows the experimental set-up for the hydrosilation reaction.

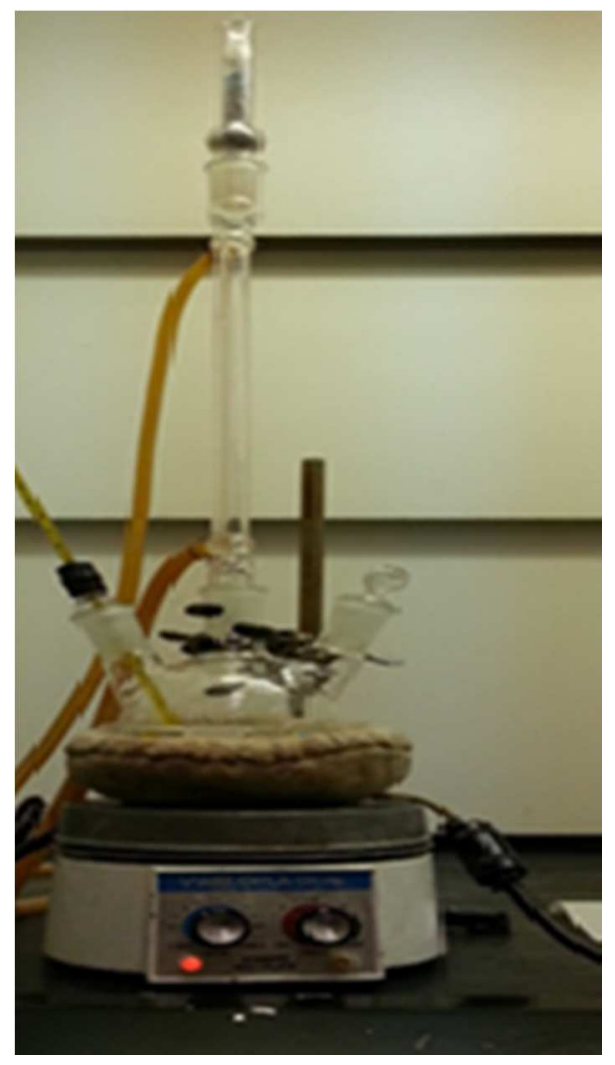

Figure 12. Experimental setup for hydrosilation reaction.

\section{Column Packing}

Column packing involves loading the synthesized stationary phase under high pressure into a stainless steel column. The packing of 4-pentynoic acid was done by the Micro-Solv Technology Corporation (Eatontown, NJ). The dimensions of the stainless steel tubes used for packing the bonded phase material were $75 \times 4.6 \mathrm{~mm}$, pore size 100 
$\AA$ and particle size $4-\mu \mathrm{m}$. Figure 13 shows the newly synthesized pentynoic acid column.

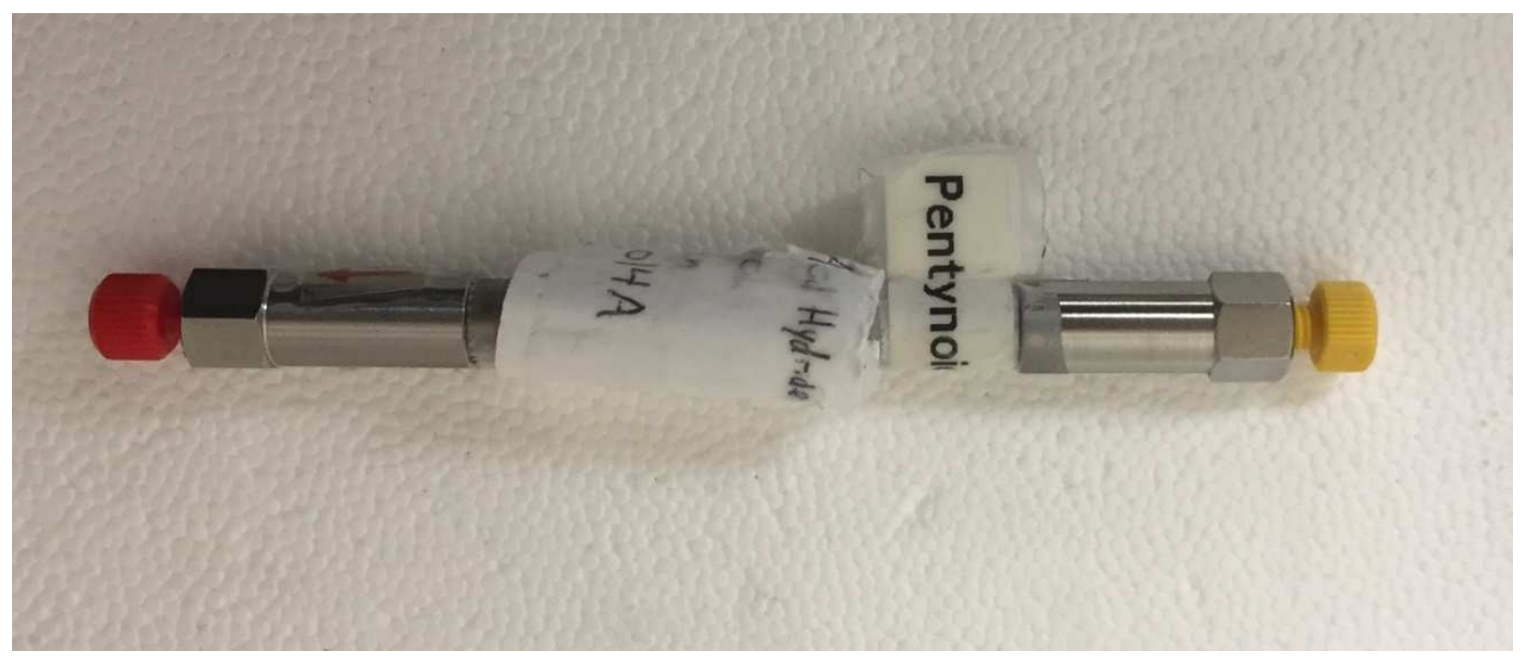

Figure 13. Newly synthesized pentynoic acid column.

\section{E. Instrumental Procedures}

Two main characterization methods, DRIFT and carbon analysis have been used to determine the success of bonding 4-pentynoic acid to the silica hydride surface.

\section{Diffuse Reflectance Infrared Fourier Transform Spectroscopy}

An ATI Mattson Infinity Series FT-IR ${ }^{\mathrm{TM}}$ spectrophotometer that is equipped with a deuterated triglycine sulfate (DTGS) detector and Hewlett Packard computer was used to collect the spectrum of pentynoic acid bonded to silica hydride. The sample was put into a diffuse reflectance cup, a round hollow container $3 \mathrm{~mm}$ in diameter and $2 \mathrm{~mm}$ deep, and the surface was smoothed using a spatula. First, a background signal was collected and then the sample cup was placed carefully in the instrument. The infrared region at which the spectra were recorded was $4000-450 \mathrm{~cm}^{-1}$. 


\section{Carbon Elemental Analysis}

The surface coverage provides quantitative information about the organic groups on the surface of the silica hydride. Elemental analysis was done by the combustion method. Carbon analysis provides valuable information about the percentage of carbon in the bonded phase. $10 \mathrm{mg}$ of pentynoic acid bonded phases, obtained from the hydrosilation step, were sent to ALS Environmental laboratories (Tucson, AZ) for carbon elemental analysis. The structure of the attached organic moiety plays an important role in the surface of the packing material. The value of $\% \mathrm{C}$ was used to calculate the surface coverage of the bonded phase on the silica material.

\section{High Performance Liquid Chromatography}

The HPLC instrument used in this research consisted of a Hewlett Packard series 1050 instrument equipped with a variable wavelength UV detector, a quaternary pump, auto sampler and an Alltech in-line degasser. The common main processor (CMP) controls all functions of the modules. The software used for data analysis was Chem station. An HP Deskjet printer was used to print the chromatograms. The pump flow rate was set at $0.5 \mathrm{~mL} / \mathrm{min}$ for a majority of the samples. The volume of the samples for each injection was 4-5 $\mu \mathrm{L}$ and the column temperature was maintained at ambient. Figure 14 shows the HPLC instrument used for analysis. 


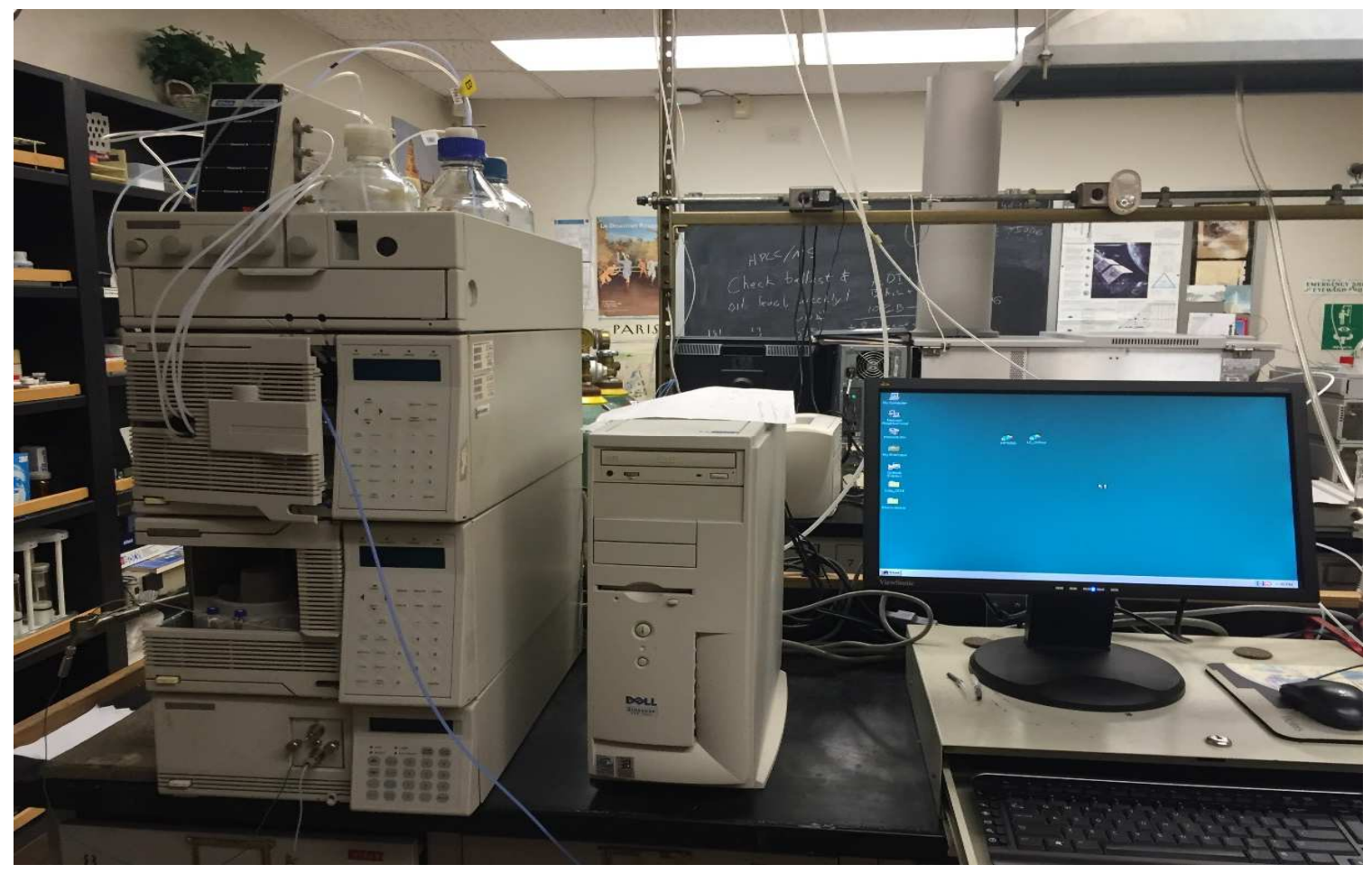

Figure 14. HP/Agilent 1050 series HPLC-UV instrument.

The second HPLC instrument used was an HP 1090 Series II. The instrument was equipped with a three-solvent system, oven compartment, and an HP-IB interface board. The detector was a UV/Vis diode array detector. This instrument had a solvent degassing nitrogen inlet to remove the other gases dissolved in the solvents. Chem Station software was used for the purpose of instrument control and data collection. The results of the analyses were printed using an HP Laser jet printer. The HP 1090 used to study varying concentration of buffers is shown in Figure 15. 


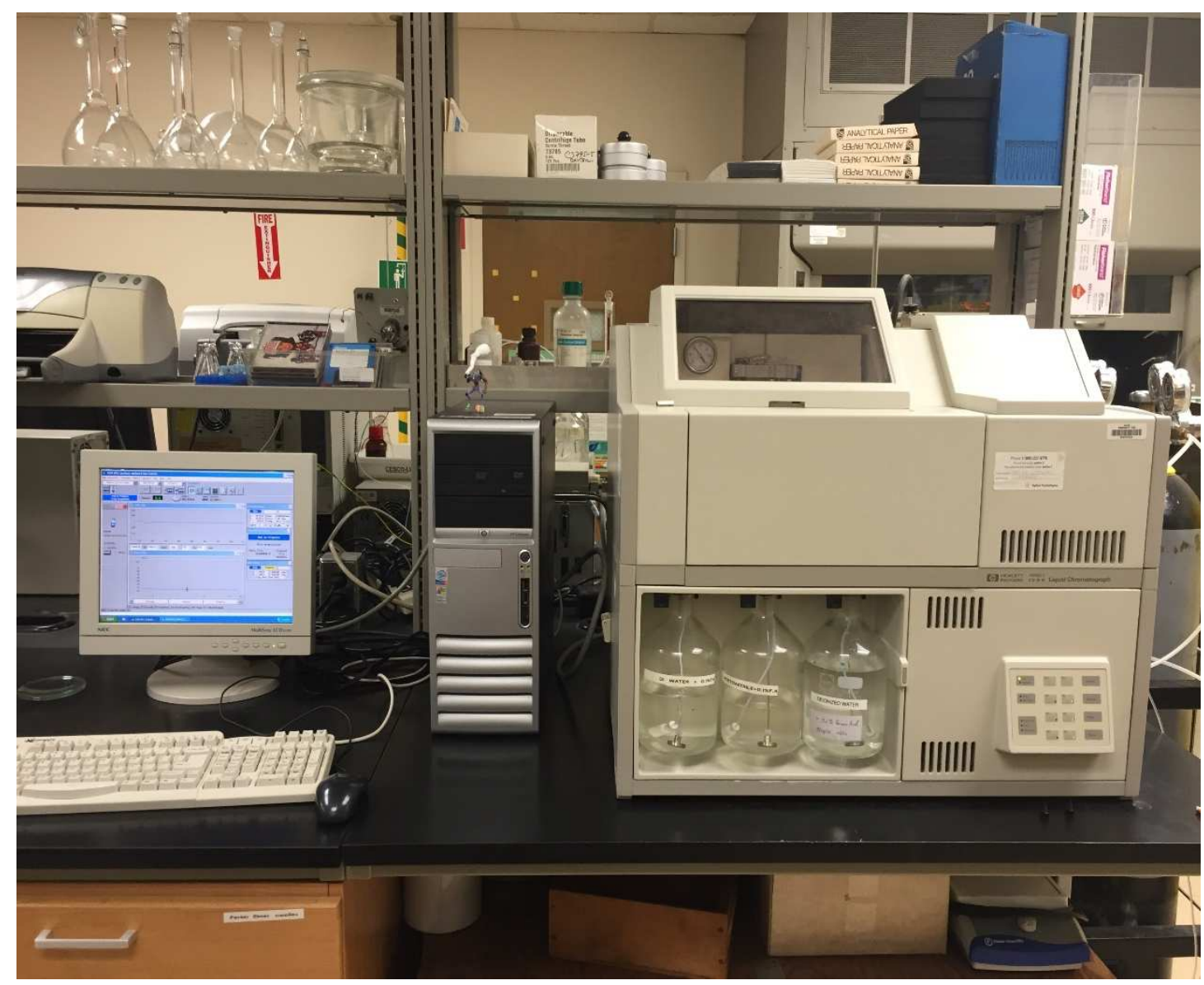

Figure 15. HP/Agilent 1090 series HPLC-UV instrument.

The DI water used for mobile phases was prepared on a Milli-QTM purification system. The mobile phase was vacuum filtered with a Nylon filter to enhance the purity of the solvent. The columns were flushed with $100 \%$ methanol for 1.0 hour as a means of preparation before the actual study. The instrument was set for two wavelengths at $214 \mathrm{~nm}$ and $254 \mathrm{~nm}$ for optimum detection of all analytes using the HP 1090 system. 


\section{RESULTS AND DISCUSSION}

\section{A. DRIFT Spectroscopic Analysis}

The success of the hydrosilation synthetic procedure can be confirmed using DRIFT spectroscopy. The DRIFT spectrum of the 4-pentynoic acid hydride bonded phase is shown in Figure 16, which confirms the bonding of the organic moiety on the surface of the silica hydride.

The presence of the sharp peak at the $2250 \mathrm{~cm}^{-1}$ frequency is due to the stretching vibrations of the Si-H functional group. This intense $\mathrm{Si}-\mathrm{H}$ band confirms the presence of $\mathrm{Si}-\mathrm{H}$ bonds on the surface. The characteristic features of the spectrum are the presence of peaks at the approximately $2950-3000 \mathrm{~cm}^{-1}$ region, representing $\mathrm{C}-\mathrm{H}$ stretching bands which is indicative of an organic moiety (4-pentynoic acid) and the sharp peak near 1700 $\mathrm{cm}^{-1}$ was indicative of the presence of a $\mathrm{C}=\mathrm{O}$ bond which is consistent with the organic compound structure. It also confirms that bonding between silica hydride and pentynoic acid is successful. 


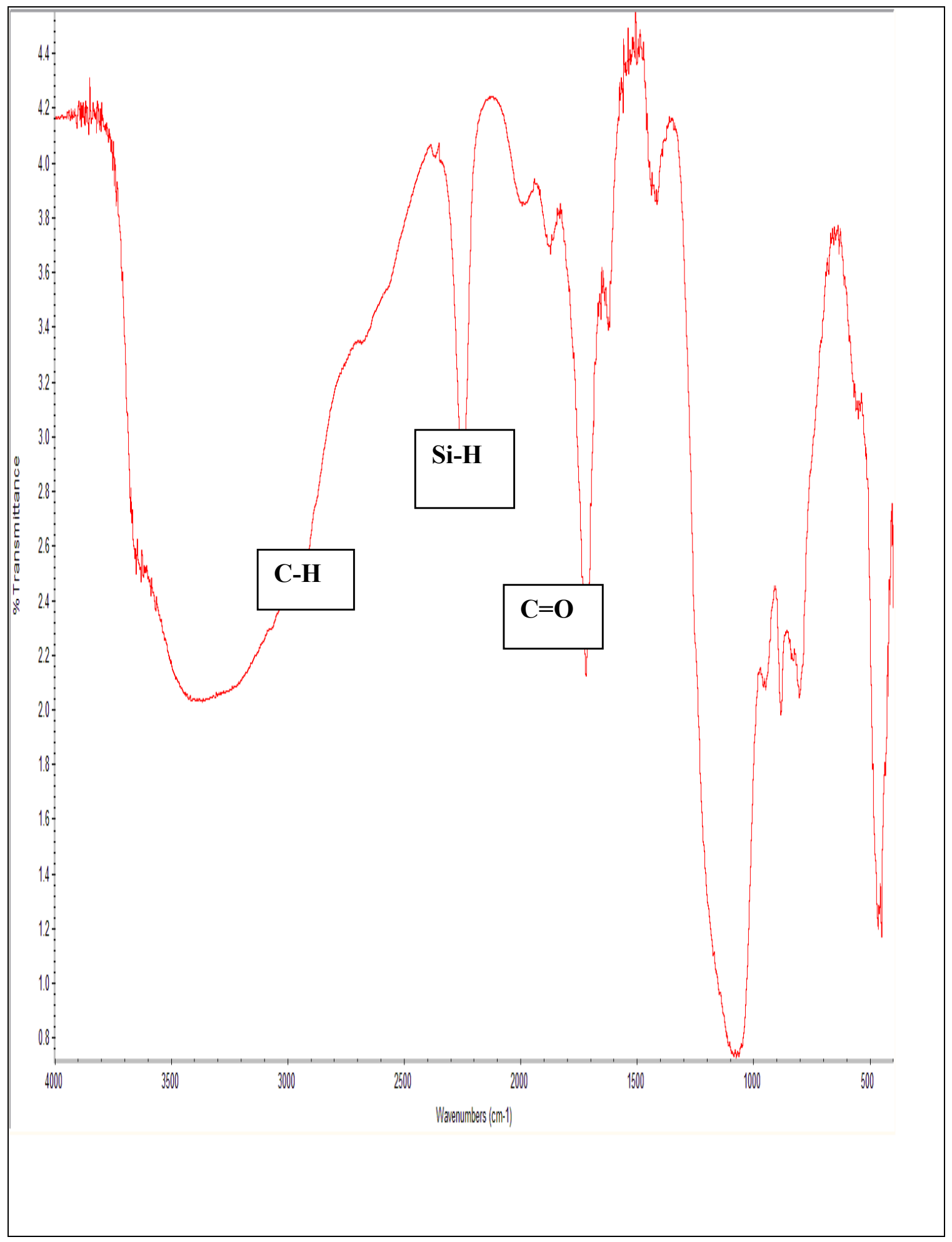

Figure 16. DRIFT spectrum of silica hydride based pentynoic acid 


\section{B. Carbon Elemental Analysis}

Elemental analysis is a quantitative method for determining the bonding of an organic moiety to the surface of silica hydride. It provides information about surface coverage of the pentynoic acid moiety. Surface coverage plays an important role in the retention time, selectivity, and stability of the bonded phase. The surface coverage of carbon was calculated using the Berendsen and de Galan equation. A high percent of carbon means more carbon loading on the surface, and a high surface coverage value indicates that more organic moiety has been successfully bonded to the silica surface. Table 6 shows the surface coverage values for the three carboxylic acid phases C-5, C-8 and $\mathrm{C}-18$.

Table 6. Surface coverage of carboxylic acid phases

\begin{tabular}{|c|c|}
\hline Column & Surface Coverage \\
\hline C-5 & $4.64 \mu \mathrm{mol} / \mathrm{m}^{2}$ \\
\hline C-8 & $4.72 \mu \mathrm{mol} / \mathrm{m}^{2}$ \\
\hline C-18 & $3.5 \mu \mathrm{mol} / \mathrm{m}^{2}$ \\
\hline
\end{tabular}

The molecular weight of 4-pentynoic acid is $98.10 \mathrm{~g} / \mathrm{mol}$. The surface coverage value for 4-pentynoic acid bonded phase is $4.64 \mu \mathrm{mol} / \mathrm{m}^{2}$. High surface coverage was achieved, which means greater column capacities and better resolution. Table 7 shows the specific surface area value for silica, the molecular formula of the alkyne that has been attached to 
silica hydride, the percentage of carbon loading, and the surface coverage values in $\mu \mathrm{mol} / \mathrm{m}^{2}$ for the 4-pentynoic acid bonded phase.

Table 7. Surface coverage of bonded organic moiety.

\begin{tabular}{|c|c|c|c|c|}
\hline Silica & $\begin{array}{c}\mathrm{S}_{\mathrm{BET}} \\
\left(\mathrm{m}^{2} / \mathrm{g}\right)\end{array}$ & Bonding moiety & $\begin{array}{c}\text { \% C } \\
\text { Elemental } \\
\text { analysis }\end{array}$ & $\begin{array}{c}\text { Surface } \\
\text { coverage } \\
(\alpha) \mu \mathrm{mol} / \mathrm{m}^{2}\end{array}$ \\
\hline Atrosil & 350 & $\begin{array}{c}\text { 4-pentynoic acid } \\
\text { Molecular Formula- } \\
\mathrm{CH} \equiv \mathrm{CCH}_{2} \mathrm{CH}_{2} \mathrm{COOH}\end{array}$ & 8.42 & 4.64 \\
\hline
\end{tabular}

\section{Chromatographic Characterization of the Stationary Phase}

The main objective of this research was to characterize and establish the ANP retention behavior of the silica hydride based 4-pentynoic acid column. The dimensions of the silica hydride based pentynoic acid column were $7.5 \mathrm{~cm} \times 4.6 \mathrm{~mm}$. Different types of analytes ranging from those that exhibit ANP behavior (hydrophilic compounds) such as amino acids, nucleobases and analytes with RP characteristics (hydrophobic compounds) such as polycyclic aromatic hydrocarbons were chosen for retention behavior studies. Each HPLC run was repeated three times to check if the HPLC results were repeatable. The retention profile of different samples was studied using UV-vis and PDA detectors. The retention performance of this column is discussed in the following sections. 


\section{ANP Behavior of Si-H Column Using an UV Detector}

The column was first conditioned for an hour using 50:50 methanol and water to remove impurities. Polar solutes like amino acids, nucleobases, nucleosides and ergogenic acids were tested for chromatographic characterization of the silica hydride

column. The mobile phase was composed of a mixture of polar and nonpolar solvents. The polar solvent used was DI water and the nonpolar solvent was acetonitrile. The polar solvent is referred to as solvent A and the nonpolar solvent is referred to as solvent B. The parameters used for HPLC runs were a flow rate of $0.5 \mathrm{~mL} / \mathrm{min}$, the column temperature was ambient and the injection volume was $5 \mu \mathrm{L}$ for most of the analytes.

\subsection{Nucleobase related Compounds}

The nucleobases cytosine, adenosine, thymine and uracil were analyzed under ANP solvent conditions on the pentynoic acid column. Stock solutions of the samples were prepared at $1000 \mathrm{ppm}(1 \mathrm{mg} / \mathrm{mL})$ in 50:50 acetonitrile and water (both premixed with $0.1 \%$ formic acid). Some samples like thymine and uracil were further diluted to overcome the overloading issue which could result in peak shape distortions. The optimized injection volume was $5 \mu \mathrm{L}$. The flow rate was $0.5 \mathrm{~mL} / \mathrm{minute}$. A $254 \mathrm{~nm} \mathrm{UV}$ wavelength was selected and stabilized with the starting conditions of the isocratic system. Table 8 shows the retention times of adenosine and cytosine at various compositions of acetonitrile: water with $0.1 \%$ formic acid 
Table 8. Retention times of adenosine and cytosine.

\begin{tabular}{|c|c|c|c|}
\hline \multicolumn{2}{|c|}{ Concentration (\%) } & \multicolumn{2}{|c|}{ Retention Time (Minutes) } \\
\hline $\begin{array}{c}\text { DI Water + } \\
\quad 0.1 \% \\
\text { Formic Acid }\end{array}$ & $\begin{array}{c}\text { Acetonitrile }+ \\
0.1 \% \\
\text { Formic Acid }\end{array}$ & Adenosine & Cytosine \\
\hline 90 & 10 & 4.291 & 4.070 \\
\hline 80 & 20 & 3.715 & 3.868 \\
\hline 70 & 30 & 3.249 & 3.535 \\
\hline 60 & 40 & 4.275 & 5.208 \\
\hline 50 & 50 & 4.675 & 6.471 \\
\hline 40 & 60 & 4.989 & 6.687 \\
\hline 30 & 70 & 5.891 & 10.607 \\
\hline 20 & 80 & 8.712 & 19.604 \\
\hline 10 & 90 & 18.441 & * \\
\hline
\end{tabular}

*peak was not observed

The graphical representation of the analytes retention is plotted as $\% \mathrm{ACN}$ versus retention time of nucleobase which is referred to as a retention map. Figure 17 shows the retention maps of adenosine and cytosine. Both the compounds have very good retention on the pentynoic acid column. According to the retention maps, as the polarity of the mobile phase decreases i.e. from $40 \%$ to $90 \% \mathrm{ACN}$, the retention time for polar compounds increases which shows the typical ANP behavior. The retention time of 
compounds decrease when the mobile phase becomes more hydrophilic (above $40 \%$ water) showing the RP behavior of the column. Around $40 \% \mathrm{ACN}$, the column is switching from the RP mode to the ANP mode. In the ANP mode, the retention of the compound increases as the percentage of acetonitrile increases. The mechanism of ANP retention is most likely due to various interactions between the analyte and polar $(\mathrm{COOH})$ moiety of the column.

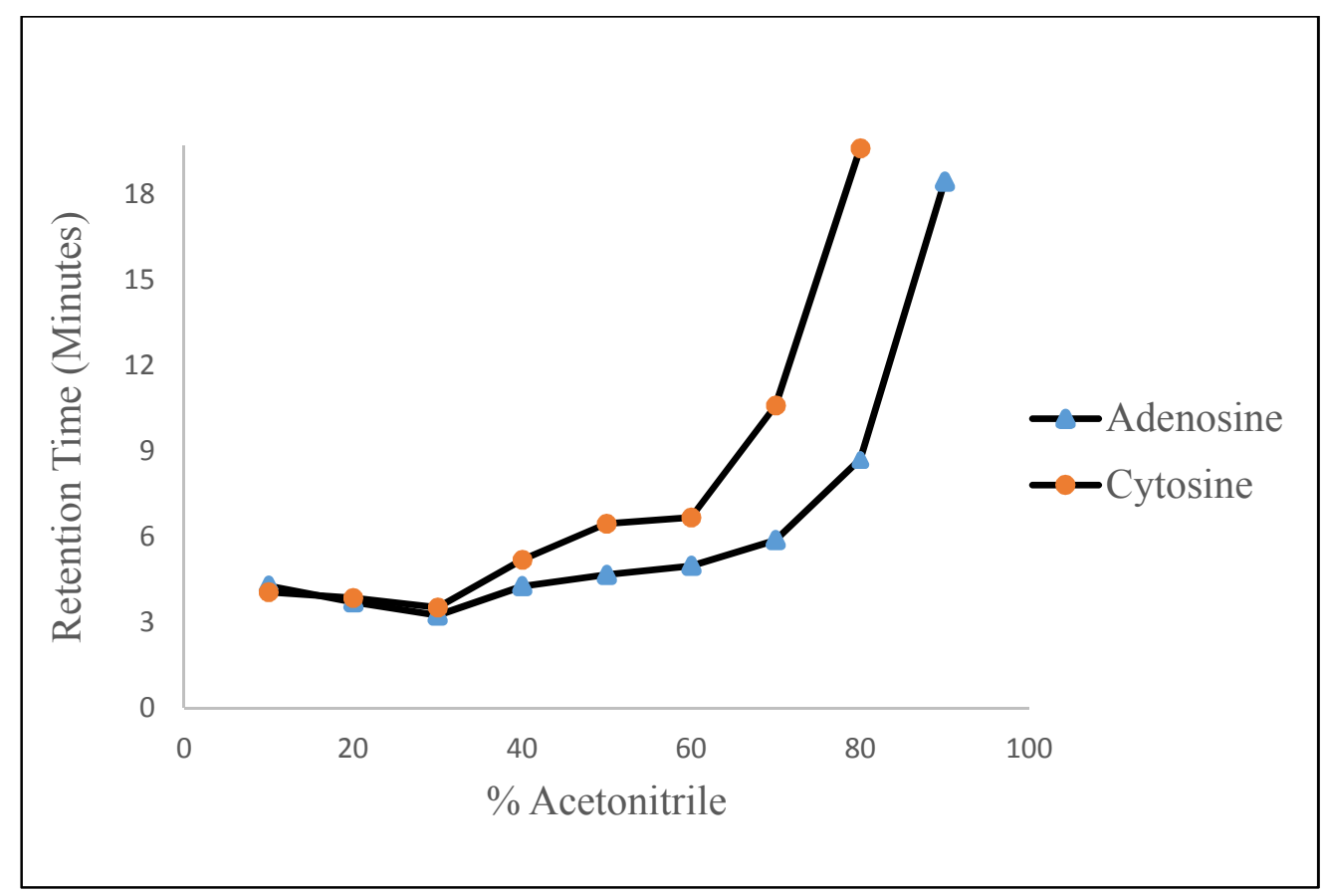

Figure 17. Retention maps of adenosine and cytosine.

Table 9 shows the retention times for uracil and thymine. All the nucleobase compounds showed good ANP retention. Nucleobases like uracil and thymine showed less retention time when compared to adenosine and cytosine. Uracil is generally used to determine the void volume in RP chromatography, due to its high polarity. Both the compounds were retained on the pentynoic acid column with distinguishable retention 
time differences as the percentage of acetonitrile increases in the mobile phase.

According to the retention maps of uracil and thymine which are shown in Figure 18, the pentynoic acid bonded stationary phase shows RP and ANP retention for these polar compounds.

Table 9. Retention times of uracil and thymine.

\begin{tabular}{|c|c|c|c|}
\hline \multicolumn{2}{|c|}{ Concentration $(\%)$} & \multicolumn{2}{|c|}{ Retention Time (Minutes) } \\
\hline $\begin{array}{c}\text { DI Water + } \\
0.1 \% \\
\text { Formic Acid }\end{array}$ & $\begin{array}{c}\text { Acetonitrile }+ \\
0.1 \% \\
\text { Formic Acid }\end{array}$ & Uracil & Thymine \\
\hline 90 & 10 & 2.3082 & 2.569 \\
\hline 80 & 20 & 2.195 & 2.328 \\
\hline 70 & 30 & 2.134 & 2.218 \\
\hline 60 & 40 & 2.565 & 2.639 \\
\hline 50 & 50 & 2.56 & 2.509 \\
\hline 40 & 60 & 2.568 & 2.529 \\
\hline 30 & 70 & 2.606 & 2.724 \\
\hline 20 & 80 & 2.890 & 2.873 \\
\hline 10 & 90 & 2.926 & 3.109 \\
\hline
\end{tabular}




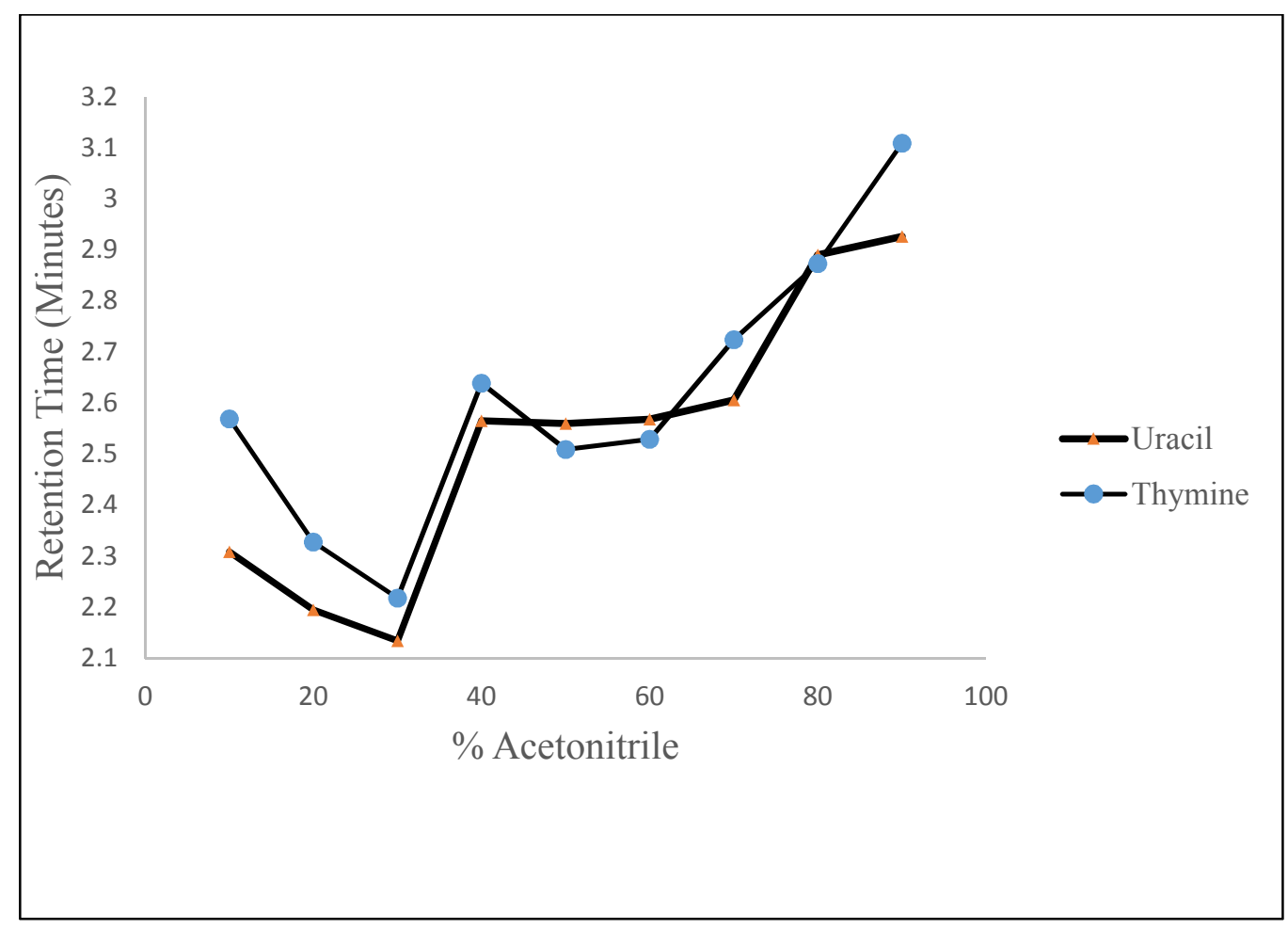

Figure 18. Retention maps of uracil and thymine. 


\subsection{Amino Acids}

The next group of polar compounds to be analyzed under ANP / RP conditions was the two amino acids, phenylalanine and tyrosine. The sample solutions were prepared at $1 \mathrm{mg} / \mathrm{ml}$ concentration using 50:50 acetonitrile: DI water mixed with $0.1 \%$ formic acid. Phenylalanine was dissolved easily, whereas tyrosine was hard to dissolve. The tyrosine sample was sonicated further. In this study, solvent A was DI water and solvent B was acetonitrile with $0.1 \%$ formic acid as buffer. The optimized injection volume was set to $5 \mu \mathrm{L}$. The UV detector was used for this study with $254 \mathrm{~nm}$ as the wavelength of detection. Retention times are plotted on the y-axis versus $\% \mathrm{ACN}$ on the $\mathrm{x}$-axis. Figure 19 shows the retention pattern for phenylalanine and tyrosine.

Due to the presence of the -OH polar functional group, tyrosine showed higher ANP retention compared to phenylalanine. As the concentration of acetonitrile increases i.e. from $40 \%$ to $80 \% \mathrm{ACN}$, the retention time for polar compounds increases which is typical ANP behavior. ANP behavior of the amino acids can be due to the effect of various interactions between the analyte and polar pentynoic acid stationary phase.

A mobile phase which consists of a binary solvent system and runs on a stationary phase with dual RP/ANP properties, the column behaves in the ANP mode at lower concentrations of polar solvent and in the RP mode at lower concentrations of ACN which is a nonpolar solvent. Table 10 summarizes the retention time in minutes at different compositions of mobile phase. 
Table 10. Retention times of amino acids.

\begin{tabular}{|c|c|c|c|}
\hline \multicolumn{2}{|c|}{} & \multicolumn{2}{c|}{ Retention Time (Minutes) } \\
\hline $\begin{array}{c}\text { DI Water + } \\
0.1 \% \\
\text { Formic Acid }\end{array}$ & $\begin{array}{c}\text { Acetonitrile }+ \\
0.1 \% \\
\text { Formic Acid }\end{array}$ & Phenylalanine & Tyrosine \\
\hline 90 & 10 & 3.460 & 2.876 \\
\hline 80 & 20 & 3.149 & 2.759 \\
\hline 70 & 30 & 2.982 & 2.698 \\
\hline 60 & 40 & 3.896 & 3.592 \\
\hline 50 & 50 & 4.110 & 4.044 \\
\hline 40 & 60 & 5.168 & 4.455 \\
\hline 30 & 70 & 5.562 & 4.434 \\
\hline 20 & 80 & 10.059 & 19.604 \\
\hline
\end{tabular}




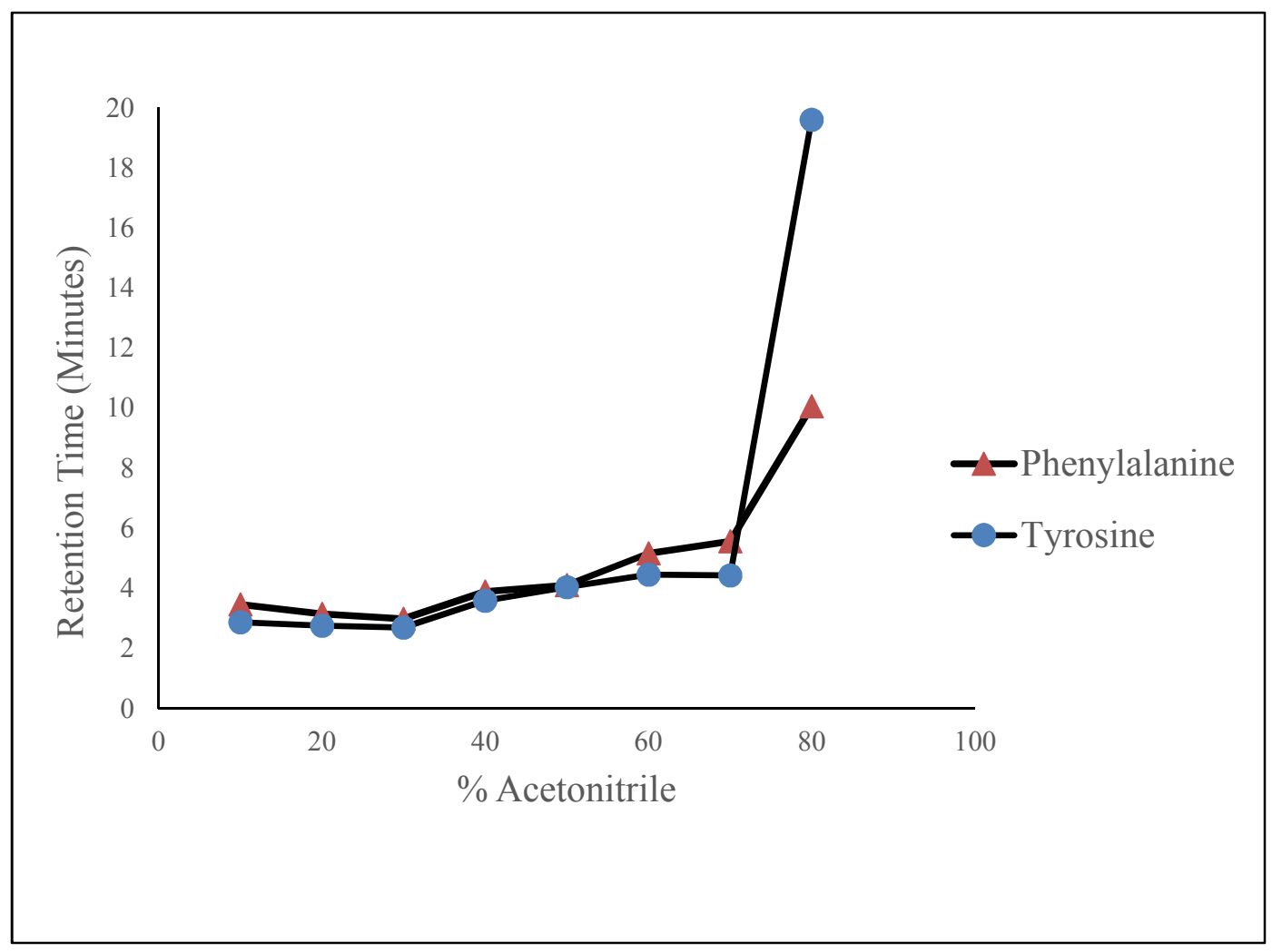

Figure 19. Retention map of amino acids.

\subsection{Retention of Creatinine}

Creatinine is a breakdown product of creatinine phosphate in muscle. Creatinine is an ergogenic acid which is polar in nature. The mobile phase for each run was composed of a mixture of water and acetonitrile solvents. The flow rate was set at $0.5 \mathrm{~mL} / \mathrm{min}$ with a $5 \mu \mathrm{L}$ injection volume. The UV detector wavelength was set at $210 \mathrm{~nm}$. The concentration of the creatinine sample was $1 \mathrm{mg} / \mathrm{ml}$. Table 11 shows the retention times of creatinine at different compositions of the mobile phase. 
The chromatographic runs began in the RP mode which means a decrease in the retention time as the percentage of water decreases followed by an increase in the retention time as the percentage of $\mathrm{ACN}$ increases. Figure 20 shows the retention map of creatinine which is very well retained on the silica hydride pentynoic acid stationary phase.

Table 11. Retention times for creatinine.

\begin{tabular}{|c|c|c|}
\hline \multicolumn{2}{|c|}{ Concentration (\%) } & Retention Time (Minutes) \\
\hline $\begin{array}{c}\text { DI Water }+ \\
0.1 \% \\
\text { Formic Acid }\end{array}$ & $\begin{array}{c}\text { Acetonitrile }+ \\
0.1 \% \\
\text { Formic Acid }\end{array}$ & Creatinine \\
\hline 90 & 10 & 4.190 \\
\hline 80 & 20 & 3.977 \\
\hline 70 & 30 & 3.625 \\
\hline 60 & 40 & 5.354 \\
\hline 50 & 50 & 8.638 \\
\hline 40 & 60 & 9.709 \\
\hline 30 & 70 & \\
\hline 20 & & \\
\hline
\end{tabular}




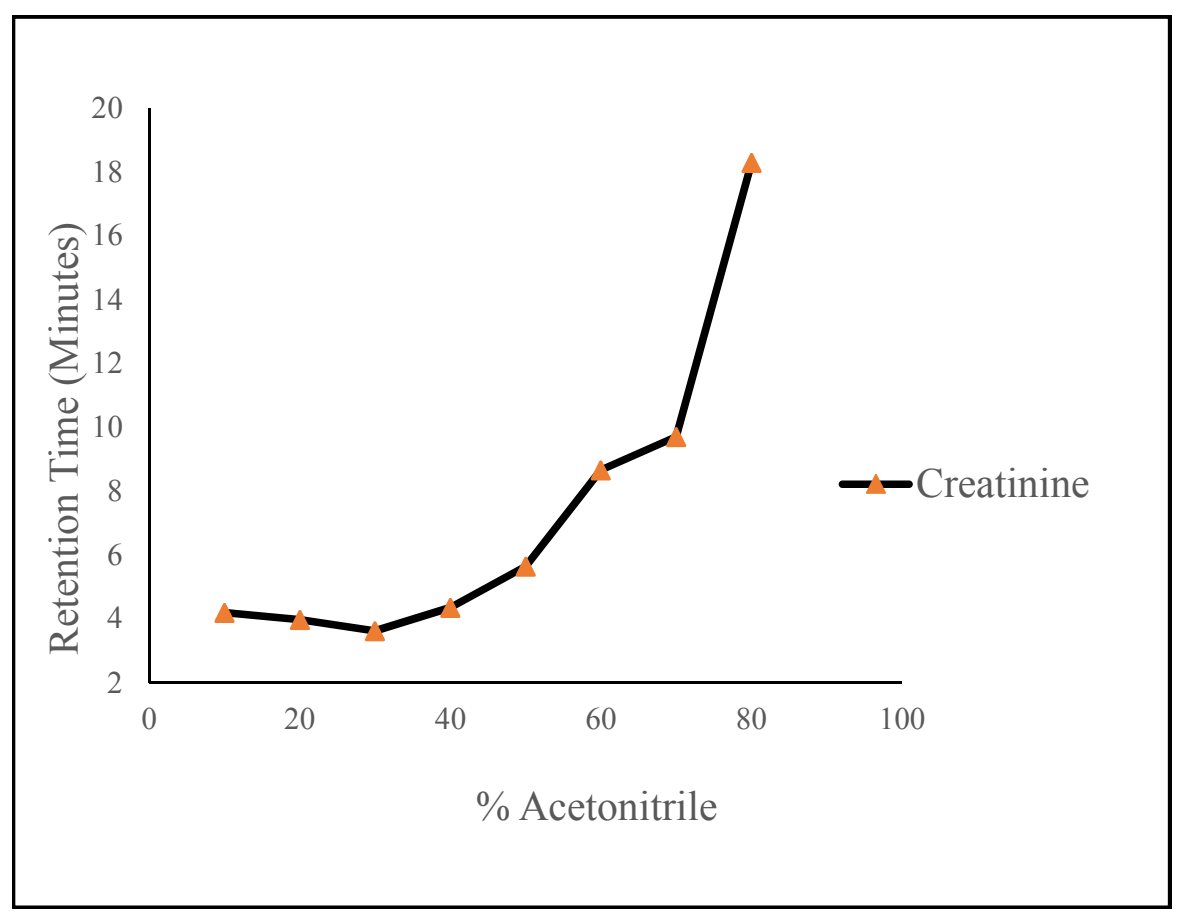

Figure 20. Retention map of creatinine.

A mobile phase which consists of a binary solvent system and runs on a stationary phase with dual RP/ANP properties, the column behaves in the ANP mode at lower concentrations of polar solvent and in the RP mode at lower concentrations of ACN which is a nonpolar solvent. It can be concluded that the pentynoic acid bonded stationary phase exhibits both ANP and RP retention behavior as shown in the Figure 21 . It is important to note that the RP retention of the pentynoic acid column is minimal. 


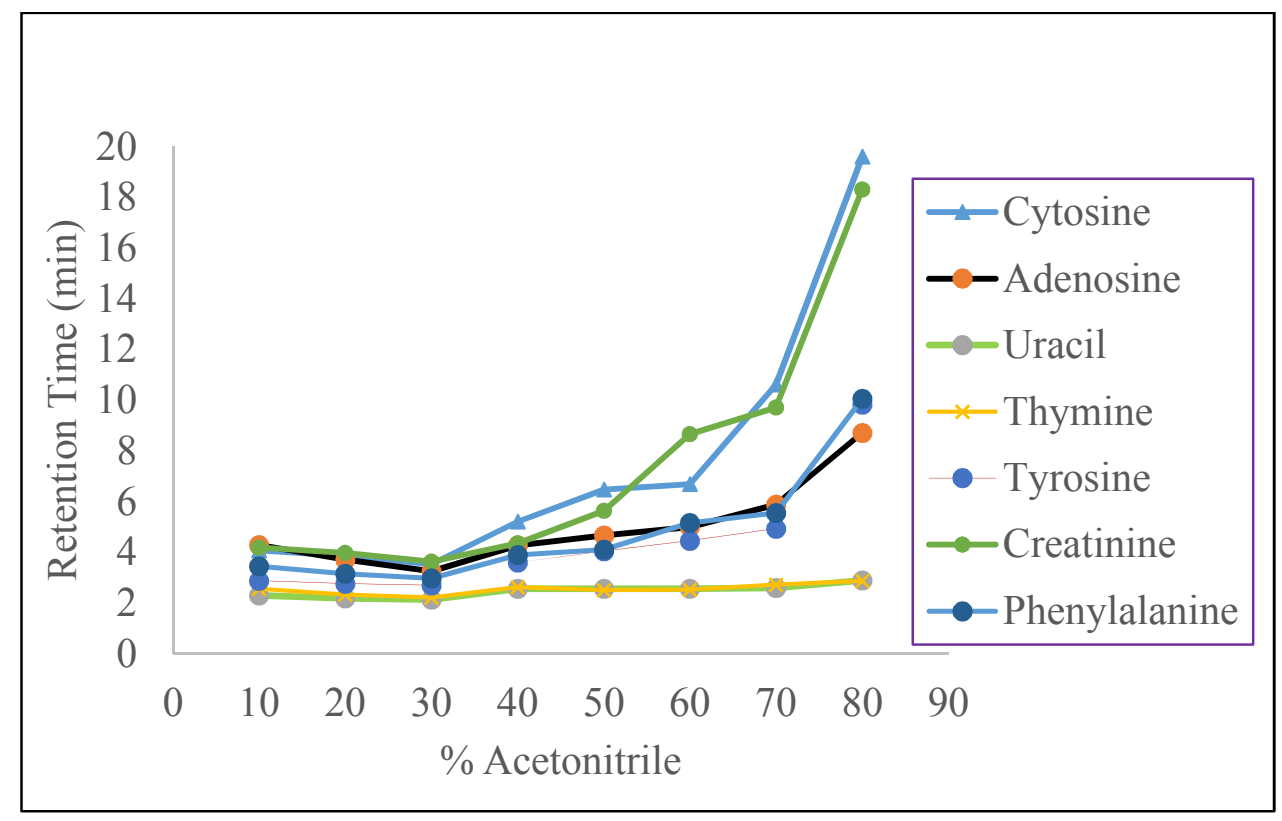

Figure 21. Retention profile of polar compounds.

\section{Reversed-Phase Retention of Nonpolar Compounds}

The next step of the project was to test the retention of hydrophobic compounds in the reverse phase mode. The RP behavior of the 4-pentynoic acid bonded stationary phase was tested using polycyclic aromatic hydrocarbons. Acenaphthene, pyrene, naphthalene, acenaphthylene and phenanthrene were used as test analytes. In this study, solvent A was DI water and solvent B was acetonitrile with $0.1 \%$ formic acid as buffer. All the samples were prepared by dissolving in $100 \%$ acetonitrile (premixed with $0.1 \%$ formic acid) to make a $1 \mathrm{mg} / \mathrm{mL}$ sample solution.

The flow rate was set to $0.5 \mathrm{~mL} / \mathrm{min}$, and a UV absorption wavelength of $254 \mathrm{~nm}$ was used. The injection volume was $5 \mu \mathrm{L}$. The retention times at different compositions of mobile phase are provided in Tables 12 and 13. Figure 22 shows the reverse phase retention maps for all five hydrocarbons. As the concentration of acetonitrile increases 
from $10 \%$ to $90 \%$, the retention time decreases for all the hydrocarbons. Above $80 \%$ of acetonitrile there was no significant change in the retention time, as the fact that the compounds elute faster with a higher amount of acetonitrile demonstrates the RP behavior of the column. The non-polar compounds for this study when testing the pentynoic acid bonded stationary phase exhibit RP behavior entirely.

Table 12. Retention times of acenaphthene, acenaphthylene, and naphthalene.

\begin{tabular}{|c|c|c|c|c|}
\hline \multicolumn{2}{|c|}{} & \multicolumn{3}{c|}{ Retention Time (Minutes) } \\
\hline $\begin{array}{c}\text { DI Water + } \\
0.1 \% \\
\text { Formic Acid }\end{array}$ & $\begin{array}{c}\text { Acetonitrile + } \\
0.1 \% \\
\text { Formic Acid }\end{array}$ & Acenaphthene & Acenaphthylene & Naphthalene \\
\hline 80 & 20 & 13.400 & 12.482 & 8.956 \\
\hline 70 & 30 & 5.232 & 5.217 & 4.654 \\
\hline 60 & 40 & 4.393 & 4.232 & 3.977 \\
\hline 50 & 50 & 3.187 & 3.154 & 3.079 \\
\hline 40 & 60 & 2.653 & 2.631 & 2.598 \\
\hline 30 & 70 & 2.007 & 2.005 & 2.008 \\
\hline 20 & 80 & 1.857 & 2.075 & 2.075 \\
\hline 10 & 90 & 1.857 & 1.857 & 1.857 \\
\hline
\end{tabular}


Table 13. Retention times of pyrene and phenanthrene.

\begin{tabular}{|c|c|c|c|}
\hline \multicolumn{2}{|c|}{ Concentration $(\%)$} & \multicolumn{2}{|c|}{ Retention Time (Minutes) } \\
\hline $\begin{array}{c}\text { DI Water + } \\
0.1 \% \\
\text { Formic Acid }\end{array}$ & $\begin{array}{c}\text { Acetonitrile }+ \\
0.1 \% \\
\text { Formic Acid }\end{array}$ & Pyrene & Phenanthrene \\
\hline 70 & 30 & 8.957 & 7.054 \\
\hline 60 & 40 & 5.147 & 4.594 \\
\hline 50 & 50 & 3.398 & 3.237 \\
\hline 40 & 60 & 2.674 & 2.622 \\
\hline 30 & 70 & 1.958 & 1.939 \\
\hline 20 & 80 & 1.875 & 1.866 \\
\hline 10 & 90 & 1.855 & 1.846 \\
\hline
\end{tabular}




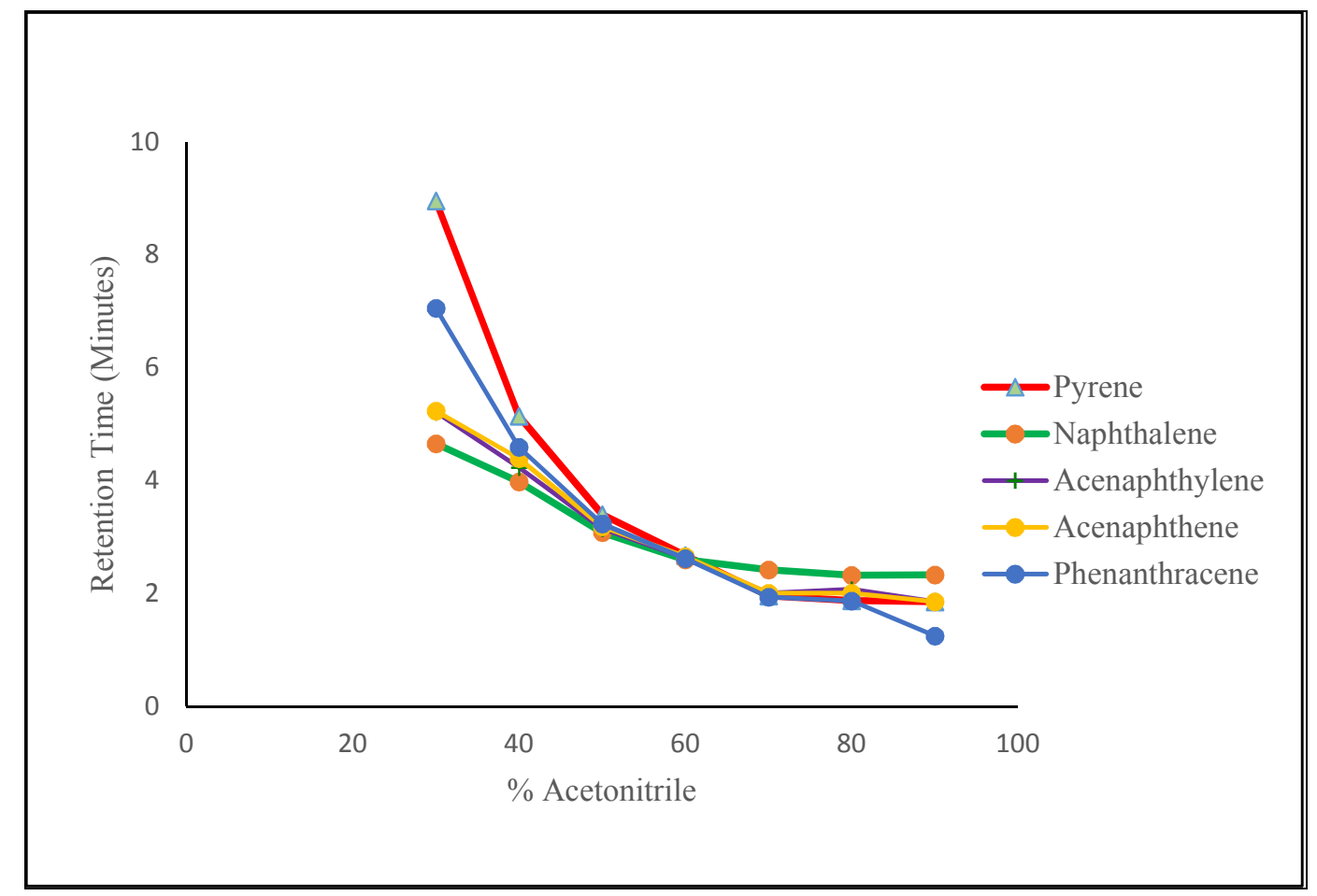

Figure 22. RP retention map of polycyclic aromatic hydrocarbons.

\section{U-shaped Retention Curve}

The dual retention ability of the pentynoic acid silica hydride-based stationary phase was confirmed by the U-shaped retention curve. The elution characteristics of the polar molecules and non-polar molecules for this study are compared in Figure 23. The right side of the curve shows ANP retention of polar analytes and the left side of the curve shows the RP behavior of nonpolar compounds. The columns ability to run under reverse phase and aqueous normal phase conditions is demonstrated by these experiments. 


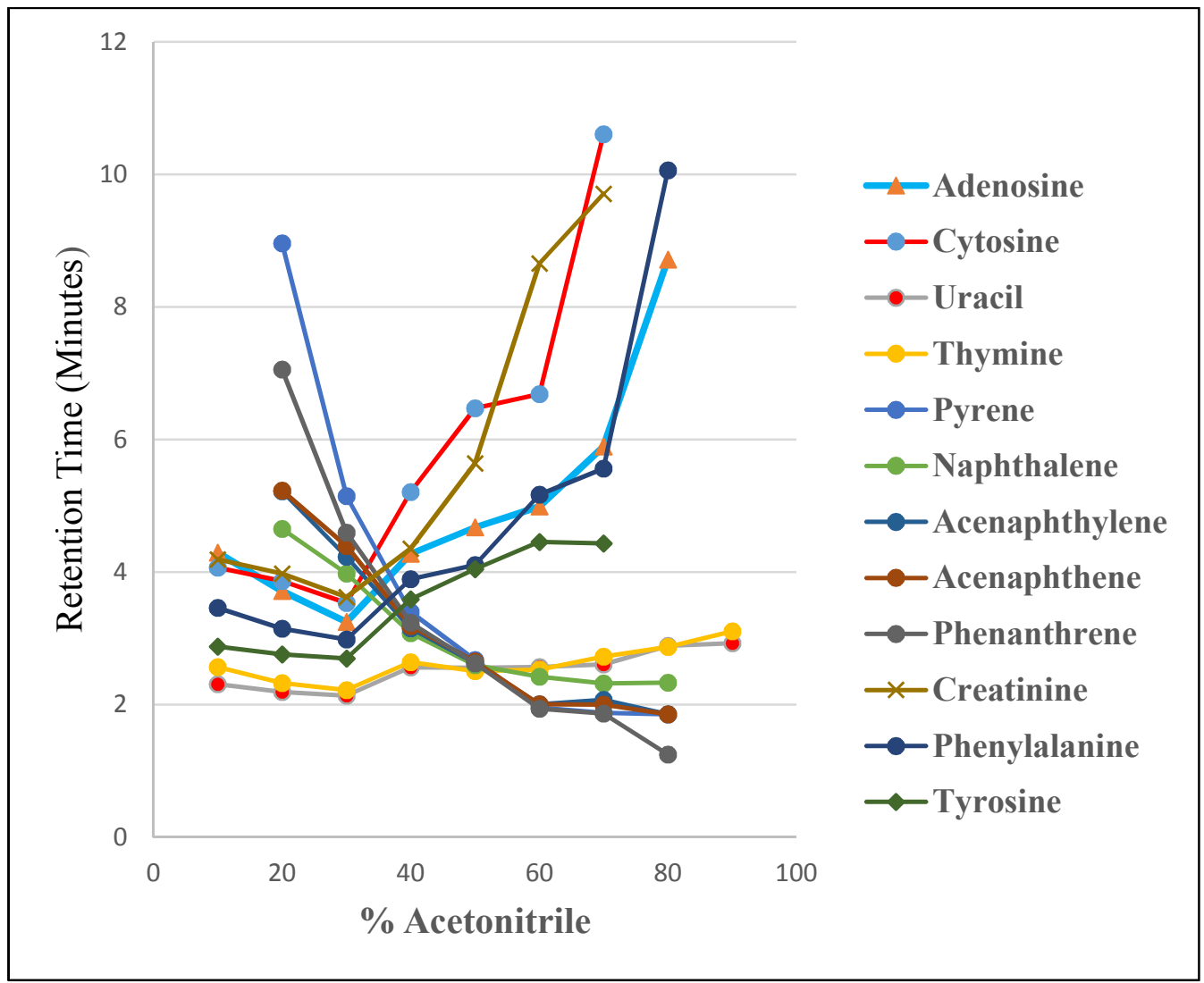

Figure 23. U-shaped Retention Profile for Pentynoic acid Silica Hydride Stationary Phase.

\section{E. Different Buffer Systems}

The next goal of this project was to identify the effect of varying concentrations of buffer on the retention of polar and nonpolar analytes. The mobile phase $\mathrm{pH}$ value can be controlled by using different buffers. The $\mathrm{pH}$ of the mobile phase can affect chromatography, in many ways like selectivity, peak shape, and retention. Silica hydride columns are stable between $\mathrm{pH} 2-\mathrm{pH} 8$. 


\section{Formic Acid Buffer System}

To further study the retention behavior of polar and nonpolar solutes with the pentynoic acid stationary phase, formic acid was used as a buffer. Formic acid is the most suitable buffer for Type-C columns (silica hydride). In this study, solvent A was DI water and solvent B was acetonitrile. Samples were prepared by dissolving $1 \mathrm{mg}$ of the compound in $1 \mathrm{~mL}$ of 50:50 A: B solvent composition. Polar test compounds used to study the effect of $\mathrm{pH}$ were cytosine, tyrosine, phenylalanine, and creatinine. Four test samples were prepared for every single compound with five different buffer concentrations. A mobile phase composition of 20:80A: B was used. Different concentrations of formic acid were added ranging from 0.05 to $0.3 \%$. The $\mathrm{pH}$ range of these buffers in 20:80 ratio of DI water: acetonitrile was determined using a Beckman pH meter. It is important to note that the $\mathrm{pH}$ meter was calibrated at $\mathrm{pH} 4.0$ and $\mathrm{pH} 7.0$ with standards. Table 14 shows the $\mathrm{pH}$ range of the mobile phases at five different concentrations of formic acid. Creatinine was analyzed using a wavelength of $210 \mathrm{~nm}$ for detection and $0.5 \mathrm{~mL} / \mathrm{min}$ mobile phase flow rate. All other compounds were analyzed using a UV wavelength of $254 \mathrm{~nm}$ to monitor the peaks. The mobile phase flow rate was set to $0.5 \mathrm{~mL} / \mathrm{min}$. Table 15 shows the retention of polar analytes at different concentrations of formic acid. 
Table 14. $\mathrm{pH}$ range for 20:80 mixtures of DI water and acetonitrile with formic acid

\begin{tabular}{|c|c|c|}
\hline \multicolumn{2}{|c|}{$20: 80$ ratio of DI water + Acetonitrile } \\
\hline Buffer & $\begin{array}{c}\text { Concentration } \\
\text { range }\end{array}$ & $\mathrm{P}^{\mathrm{H}}$ range \\
\hline Formic Acid & $0.05-0.3$ & $3.26-2.86$ \\
\hline
\end{tabular}

Table 15. Retention times at different concentrations of formic acid.

\begin{tabular}{|c|c|c|c|c|}
\hline $\begin{array}{c}\text { Concentration } \\
\%\end{array}$ & \multicolumn{4}{|c|}{ Retention Time (min) } \\
\hline $\begin{array}{c}\text { \% Formic } \\
\text { Acid }\end{array}$ & Cytosine & Tyrosine & Creatinine & Phenylalanine \\
\hline 0.05 & 8.606 & 9.006 & 16.216 & 8.923 \\
\hline 0.075 & 8.111 & 8.612 & 14.356 & 8.368 \\
\hline 0.2 & 7.23 & 7.69 & 12.31 & 7.767 \\
\hline 0.3 & 6.052 & 7.628 & 12.67 & 7.772 \\
\hline
\end{tabular}


Those data can be seen graphically in Figure 24. It shows the plot of retention time as a function of the percent of formic acid phenylalanine, tyrosine, creatinine and cytosine. As the concentration of formic acid increases from $0.05 \%$ to $3 \%$, there is a decrease in the retention time of polar compounds.

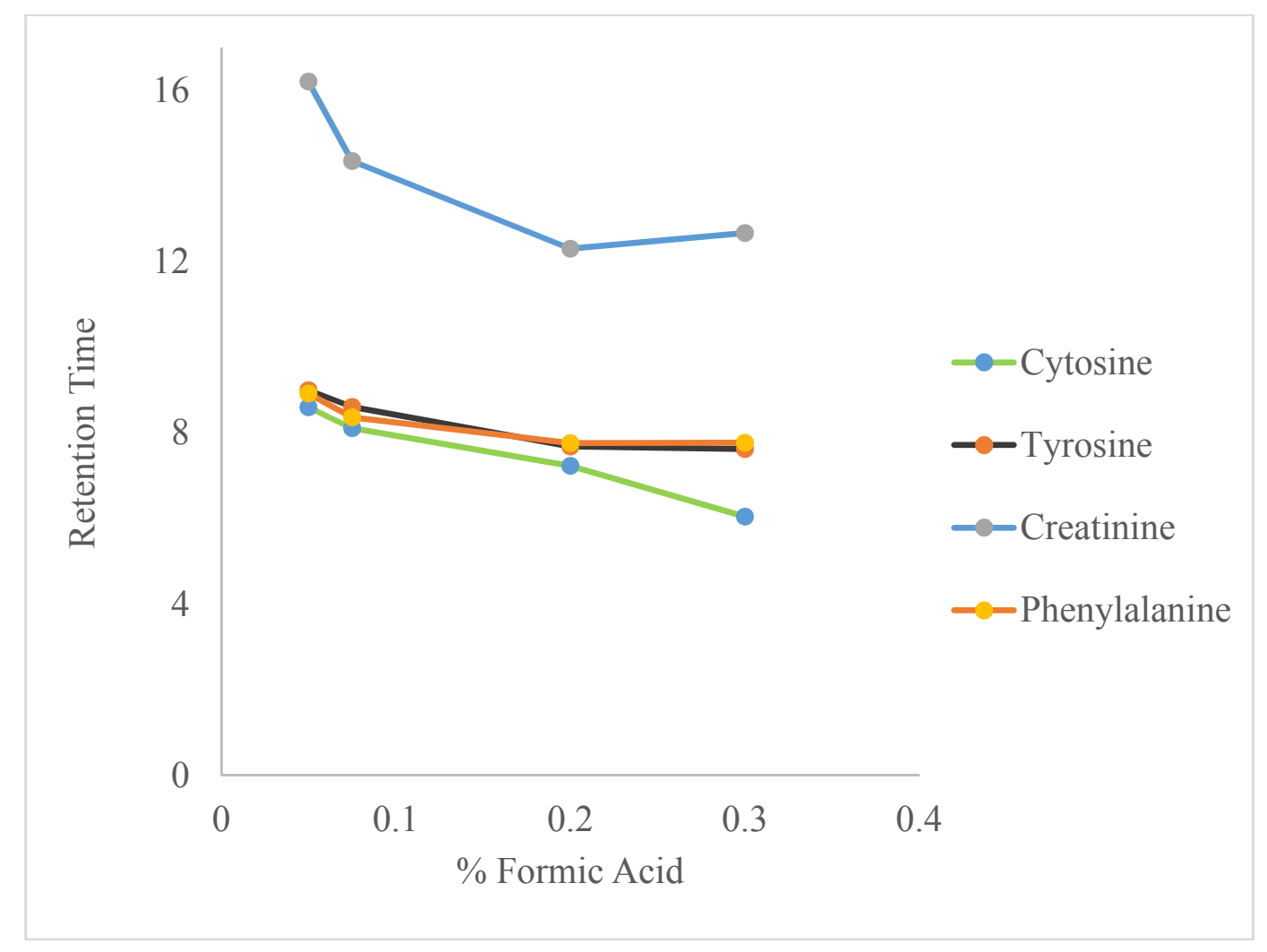

Figure 24. Retention time as a function of concentration of formic acid. 


\subsection{Varying concentration Formic Acid (Thiamine hydrochloride and Benzoic acid)}

Polar test compounds used to study the effect of $\mathrm{pH}$ were thiamine hydrochloride and benzoic acid. Thiamine is a highly positively charged compound, whereas benzoic acid is neutral compound. To study the effect of $\mathrm{pH}$, different concentrations of formic acids prepared were: $0.05 \%, 0.075 \%, 0.1 \%$, and $0.2 \%$. DI Water was used as solvent A and acetonitrile was used as solvent B. A mobile phase composition of 20:80 A: B was used with four different percentages of the formic acid. The optimized sample injection volume was $5 \mu \mathrm{L}$, and the flow rate was set to $0.5 \mathrm{~mL} /$ minute to monitor the peaks. Table 16 and table 17 shows the retention times in minutes for these polar test compounds. Figure 25 and Figure 26 shows the plot of retention time as a function of the percent of formic acid for thiamine hydrochloride and benzoic acid. Error bars indicate the standard deviation in retention time.

Table 16. Retention times of thiamine hydrochloride.

\begin{tabular}{|c|c|c|c|c|c|}
\hline $\begin{array}{c}\text { \% Formic } \\
\text { acid }\end{array}$ & $\begin{array}{c}\text { Retention } \\
\text { Time } \\
\text { Run1 }\end{array}$ & Run 2 & Run 3 & Average & $\begin{array}{c}\text { Standard } \\
\text { deviation }\end{array}$ \\
\hline 0.05 & 2.509 & 2.578 & 2.510 & 2.5323 & 0.04 \\
\hline 0.075 & 2.443 & 2.447 & 2.420 & 2.4367 & 0.01 \\
\hline 0.1 & 2.321 & 2.321 & 2.351 & 2.3310 & 0.02 \\
\hline 0.2 & 2.399 & 2.382 & 2.324 & 2.3683 & 0.04 \\
\hline 0.3 & 1.932 & 1.935 & 1.999 & 1.9553 & 0.04 \\
\hline
\end{tabular}




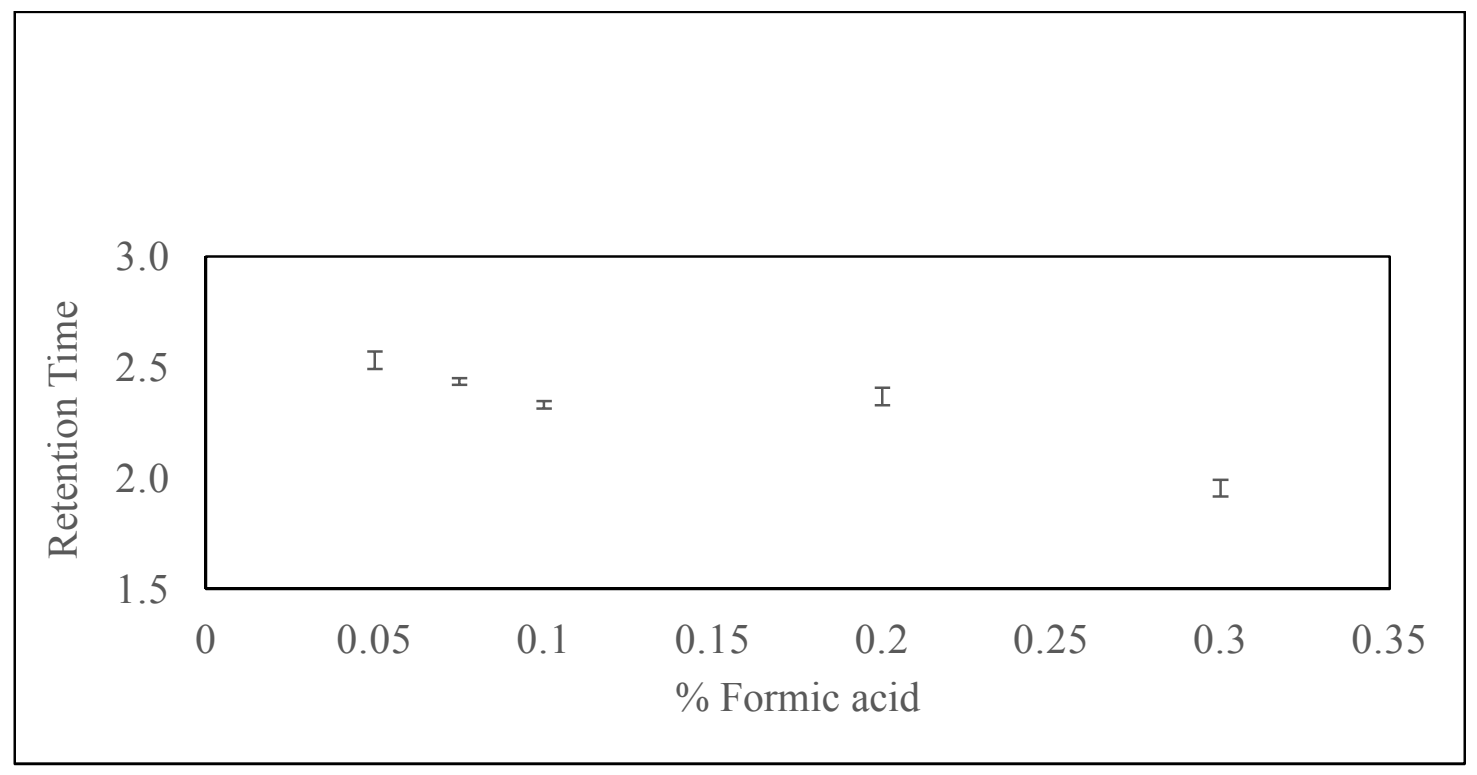

Figure 25. Error bars indicate standard deviation in retention time (thiamine hydrochloride).

The error bars in Figure 25 and Figure 26 represents the retention time deviation of thiamine hydrochloride and benzoic acid. With an increase in the concentration of buffer formic acid from $0.05 \%$ to $3 \%$, there is a decrease in the retention time of thiamine hydrochloride. However, in the case of a neutral compound benzoic acid, there is no apparent change in the retention time with varying concentration of formic acid. 
Table 17. Retention times of benzoic acid.

\begin{tabular}{|c|c|c|c|c|c|}
\hline $\begin{array}{c}\text { Formic } \\
\text { acid }\end{array}$ & $\begin{array}{c}\text { Retention } \\
\text { Time } \\
\text { Run1 }\end{array}$ & Run 2 & Run 3 & Average & $\begin{array}{c}\text { Standard } \\
\text { deviation }\end{array}$ \\
\hline 0.05 & 2.351 & 2.352 & 2.364 & 2.3557 & 0.01 \\
\hline 0.075 & 2.383 & 2.383 & 2.372 & 2.3793 & 0.01 \\
\hline 0.1 & 2.341 & 2.342 & 2.379 & 2.3540 & 0.02 \\
\hline 0.2 & 2.355 & 2.359 & 2.375 & 2.3628 & 0.01 \\
\hline 0.3 & 2.335 & 2.243 & 2.337 & 2.3050 & 0.05 \\
\hline
\end{tabular}

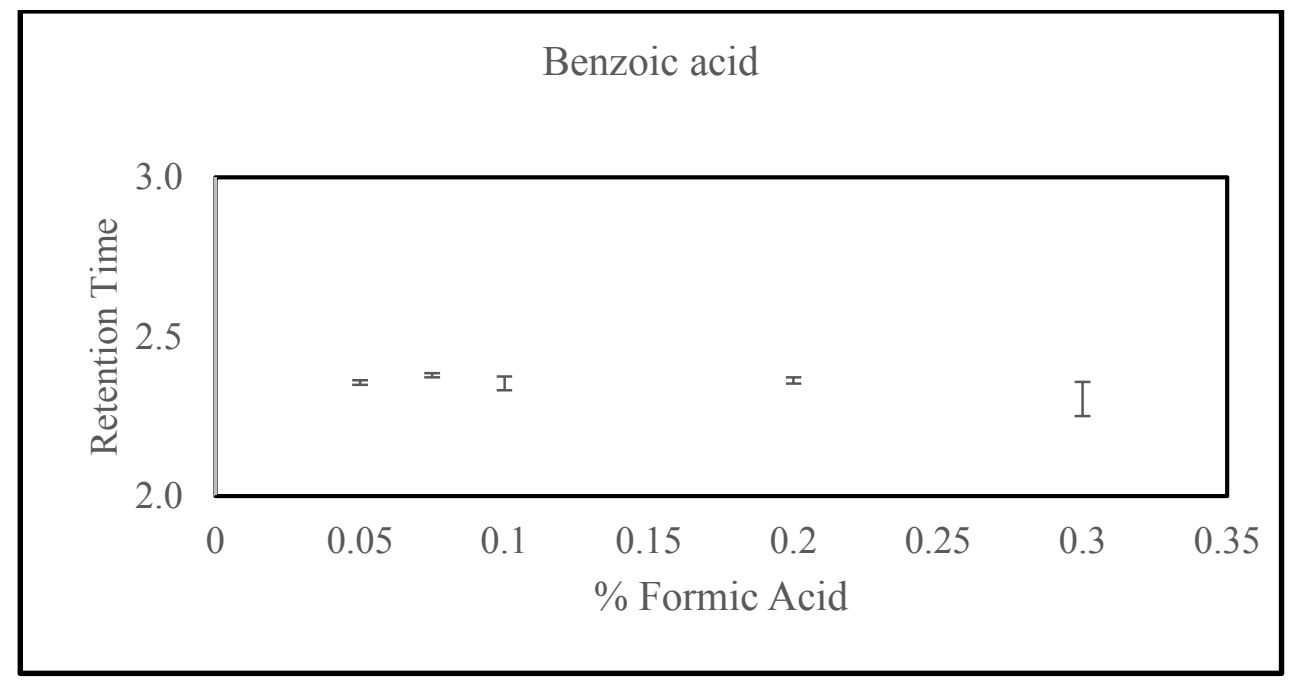

Figure 26. Error bars indicate standard deviation in retention time (benzoic acid). 


\subsection{Difference Between ANP and HILIC Retention Modes}

For polar compounds, with an increase in the concentration of formic acid buffer there is a decrease in the retention time observed on pentynoic acid column. It has been reported in literature, that buffer concentration studies performed on HILIC column showed the opposite trend. Hence, it can be predicted that the retention mechanism involved in silica hydride-based stationary phase is different from HILIC. However, retention times for a neutral compound, benzoic acid, were found to be independent of buffer concentration.

The mechanism of aqueous normal phase retention is an active area of investigation. A recent study has demonstrated that the water layer adsorbed onto the surface of the silica hydride surface is on average only 0.5 on a monolayer, very much less compared to the water adsorbed onto a surface containing silanol groups $[24,25]$. This low amount of water differentiates the polar analyte retention mechanism in the HILIC and ANP modes. A variety of experiments have been conducted to understand the surface of silica hydride in the presence of typical mobile phase solvents like acetonitrile and water. These studies have also shown that the silica hydride surface possess a very high negative charge (by measuring the zeta potential) this charge is due to the presence of excess hydroxide ions on the surface from the aqueous component of the mobile phase as shown in the Figure 27. The $\varepsilon$ value shown in the figure is the zeta potential indicating the high negative charge near the surface [26]. In the case of HILIC, the negative charge is attributed to the presence of silanols (from bare silica). It can be deduced from these 
experiments, that the ANP mechanism is most likely a combination of ion attraction for positively charged compounds or ion displacement for negatively charged species. For polar neutral compounds, it may be due to displacement /adsorption effects for retention.

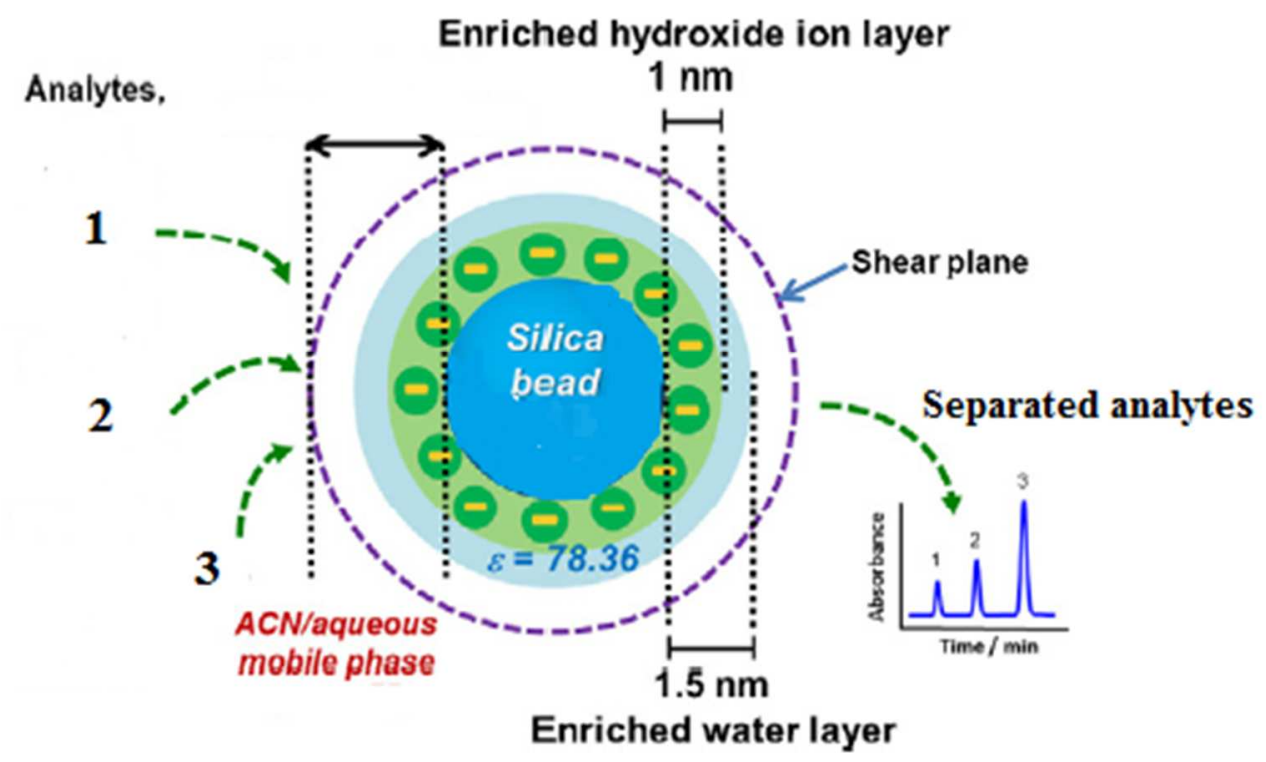

Figure 27. Composition of environment near the surface of a particle with a silica hydride surface. Adapted from reference [25].

\section{Ammonium Acetate Buffer System}

\subsection{Compatibility of Ammonium Acetate Buffer with Pentynoic acid Column}

The next experiment was designed to study the effect of ammonium acetate buffer on the retention of polar solutes. The $\mathrm{pH}$ of ammonium acetate is much higher than formic acid. Whenever the ammonium acetate was used, the sample solution and the mobile phase solution were filtered using nylon membrane filter. Two hundred and fifty $\mathrm{ml}$ of $300 \mathrm{mM}$ ammonium acetate stock solution was prepared by dissolving $5.7811 \mathrm{~g}$ of 
ammonium acetate in $250 \mathrm{~mL}$ of DI water. Water and acetonitrile were used as solvents A and B. The ammonium acetate should be in both the acetonitrile and water. However, the acetonitrile cannot be pure acetonitrile. It should be 90:10 acetonitrile water. If there is no water present, the ammonium acetate can easily precipitate out of solution. This water and acetonitrile binary mobile phase system with a $\mathrm{pH} \sim 6$ was used in the following sections for the retention studies of polar molecules. The buffer concentration was set to $2 \mathrm{mM}$.

The polar analytes analyzed using UV detection were phenylalanine, adenosine and cytosine. They were analyzed using a wavelength of $254 \mathrm{~nm}$ for detection and 0.5 $\mathrm{mL} / \mathrm{min}$ mobile phase flow rate. This sample solution was used to evaluate the pentynoic acid column using 50:50, 60:40, 70:30, 80:20, and $90: 10$ acetonitrile: water at a $\mathrm{pH} \sim 6$ mobile phase compositions. Table 18 lists the retention times for three test solutes in minutes at different compositions of the mobile phase. Figure 28 demonstrates that the three polar test solutes exhibit typical ANP retention profile in the presence of ammonium acetate buffer. Therefore, it was concluded that ammonium acetate is a suitable buffer system for the pentynoic acid silica hydride based stationary phase. 
Table 18. Retention times of polar solutes with ammonium acetate buffer.

\begin{tabular}{|c|c|c|c|c|}
\hline \multicolumn{2}{|c|}{ Concentration $(\%)$} & \multicolumn{3}{|c|}{ Retention Time (Minutes) } \\
\hline $\begin{array}{c}\text { DI Water }+ \\
2 \mathrm{mM} \\
\text { Ammonium } \\
\text { Acetate }\end{array}$ & $\begin{array}{c}\text { Acetonitrile } \\
+ \\
2 \mathrm{mM} \\
\text { Ammonium } \\
\text { Acetate }\end{array}$ & Phenylalanine & Cytosine & Adenosine \\
\hline 50 & 50 & 2.444 & 5.624 & 2.541 \\
\hline 40 & 60 & 2.679 & 5.437 & 2.560 \\
\hline 30 & 70 & 2.851 & 6.132 & 3.191 \\
\hline 25 & 75 & 3.715 & 6.563 & 3.087 \\
\hline 20 & 80 & 4.631 & 7.474 & 3.451 \\
\hline 15 & 85 & 6.427 & 9.258 & 4.016 \\
\hline
\end{tabular}




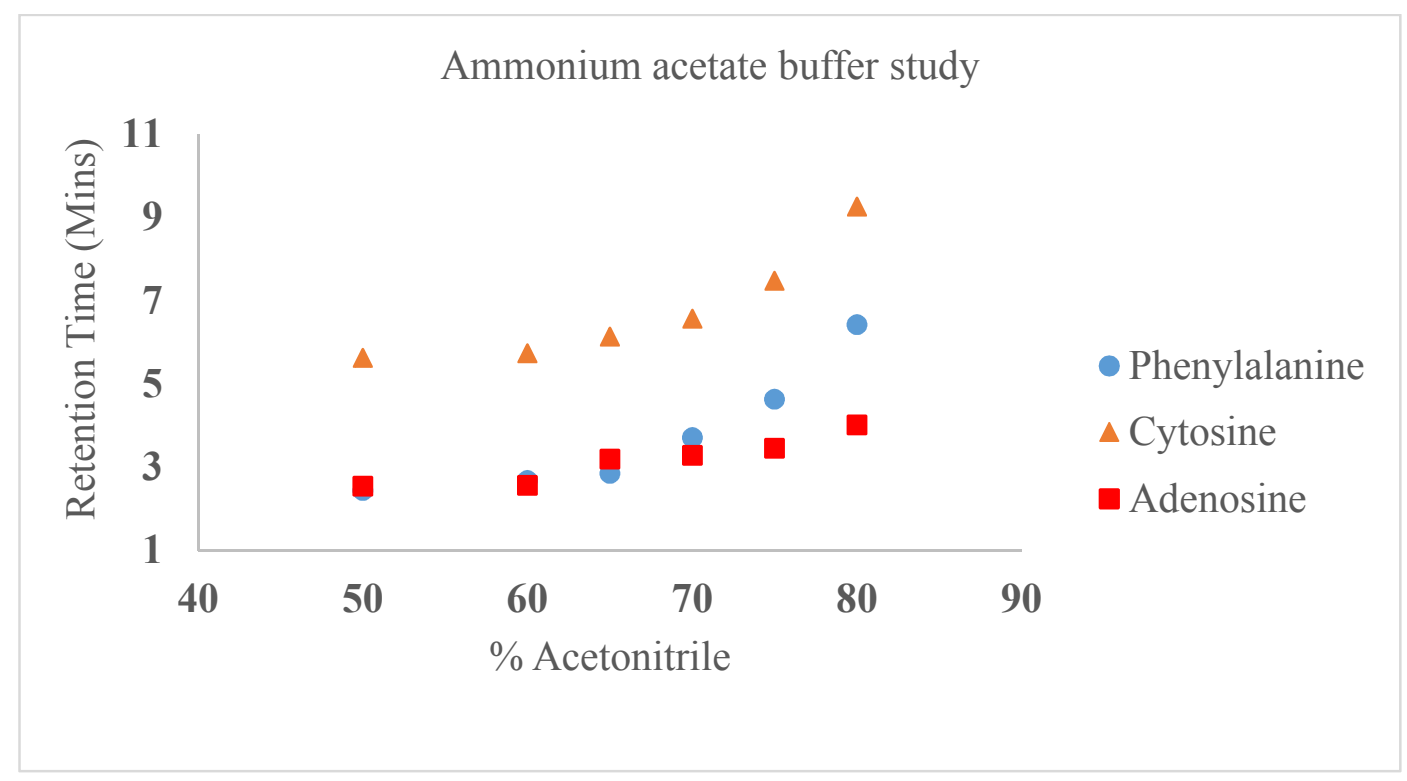

Figure 28. Retention of polar solutes with ammonium acetate buffer.

\subsection{Varying Concentration of Ammonium Acetate Buffer}

To study the effect of varying concentrations of ammonium acetate three polar solutes were selected. The different buffer concentrations prepared for this study were $2 \mathrm{mM}, 4 \mathrm{mM}, 6 \mathrm{mM}, 8 \mathrm{mM}$, and $10 \mathrm{Mm}$. The $\mathrm{pH}$ of the 20:80 compositions of A: B solution at five different buffer concentrations was measured using a Beckman $\mathrm{pH}$ meter. The flow rate was set to $0.5 \mathrm{~mL} / \mathrm{min}$ and the UV absorption wavelength was $254 \mathrm{~nm}$. The sample solution at a concentration of $1 \mathrm{mg} / \mathrm{mL}$ was made using 50:50 acetonitrile: water. The optimized injection volume was $5 \mu 1$.

Figure 29 includes three different plots for cytosine, adenosine and uracil. It shows the plot of retention time as a function of concentration of ammonium acetate $(\mathrm{mM})$ for three different solutes. Table 19 shows the $\mathrm{pH}$ range of the mobile phases at five different concentrations of ammonium acetate. Table 20 summarizes retention times in minutes for 
the three polar compounds. With an increase in the concentration of buffer ammonium acetate from $2 \mathrm{mM}$ to $10 \mathrm{mM}$, there is no specific trend observed in terms of retention time.

Table 19. $\mathrm{pH}$ range for 20:80 mixtures of DI water and $\mathrm{ACN}$ with ammonium acetate.

\begin{tabular}{|c|c|c|}
\hline \multicolumn{2}{|c|}{$20: 80$ ratio of DI water + Acetonitrile } \\
\hline Buffer & $\begin{array}{c}\text { Concentration } \\
\text { range }\end{array}$ & $\mathrm{P}^{\mathrm{H}}$ range \\
\hline Ammonium acetate & $2-10 \mathrm{mM}$ & $6.47-5.68$ \\
\hline
\end{tabular}

Table 20. Retention times at different concentrations of ammonium acetate.

\begin{tabular}{|c|c|c|c|}
\hline \multirow{2}{*}{$\begin{array}{l}\text { Concentration of } \\
\begin{array}{l}\text { Ammonium } \\
\text { Acetate }(\mathrm{mM})\end{array}\end{array}$} & \multicolumn{2}{|c|}{ Retention Time (Minutes) } \\
\cline { 2 - 4 } & Cytosine & Adenosine & Uracil \\
\hline 2 & 7.475 & 3.451 & 2.467 \\
\hline 4 & 9.259 & 3.595 & 2.801 \\
\hline 6 & 7.199 & 3.750 & 2.676 \\
\hline 8 & 6.086 & 3.289 & 2.765 \\
\hline 10 & 6.125 & 3.377 & 2.953 \\
\hline
\end{tabular}




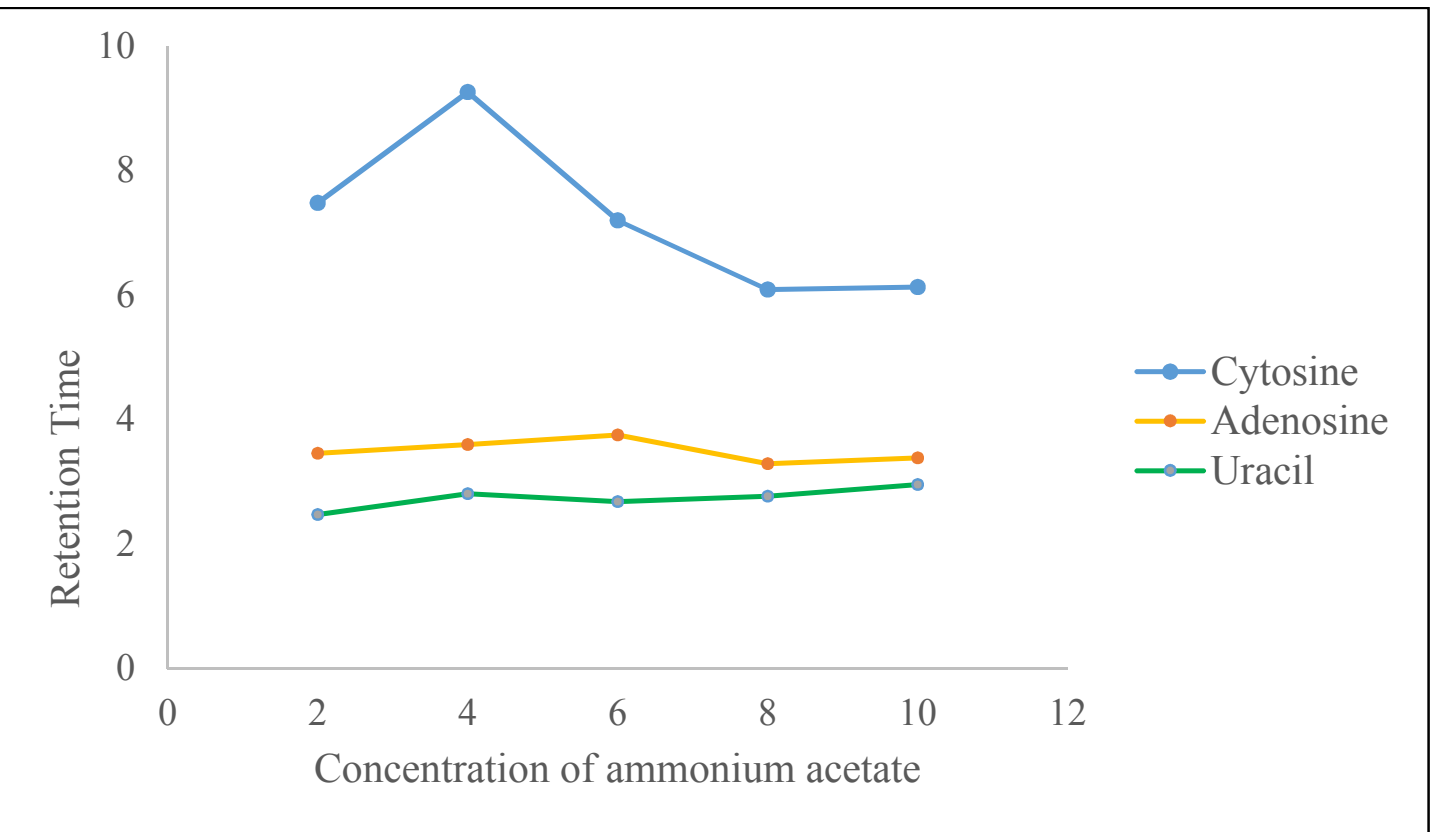

Figure 29. Retention time as a function of concentration of ammonium acetate.

\section{F. Comparison of Buffer Trends on Pentynoic acid and Undecynoic acid Columns}

The alkyl chain length of the bonded phase is an important factor during the method development process. There are several possible retention characteristics that these phases could possess. Undecynoic acid has a long hydrocarbon chain as well as a polar carboxylic group; whereas pentynoic acid contains a 5- carbon chain, will have less hydrophobic retention and a carboxylic group.

The buffer trends on two silica hydride based columns with different alkyl chain lengths, pentynoic acid and undecynoic acid were compared in this experiment. Sample solutions were prepared by weighing out $1 \mathrm{mg}$ solid standards and dissolving them in a premixed 50:50 mixture of DI water and acetonitrile. The polar analytes analyzed using UV detection were tyrosine, uracil, and cytosine. The solvent ratio for the polar compounds 
was 20:80 of A: B. They were analyzed using a wavelength of $254 \mathrm{~nm}$ for detection and $0.5 \mathrm{~mL} / \mathrm{min}$ mobile phase flow rate.

Table 21 shows the retention time of cytosine and tyrosine on the pentynoic acid column and Table 22 shows the retention time of cytosine and uracil on the undecynoic acid column [27]. Figure 30 and Figure 31 include two different plots for cytosine and uracil. It shows the plot of retention time as a function of concentration of formic acid $(\mathrm{mM})$ on two different columns, pentynoic acid and undecynoic acid. The polar compounds had a drastic decrease in retention as the concentration of formic acid was increased. This sharp decrease is clearly seen in case of the pentynoic acid column, whereas there is no trend observed in case of undecynoic acid [27] as demonstrated in Figure 31.

Table 21. Retention time for polar solutes with formic acid.

\begin{tabular}{|c|c|c|}
\hline \% Formic acid & Cytosine & Tyrosine \\
\hline 0.05 & 8.606 & 9.006 \\
\hline 0.075 & 8.111 & 8.612 \\
\hline 0.2 & 7.230 & 7.690 \\
\hline 0.3 & 6.052 & 7.628 \\
\hline
\end{tabular}




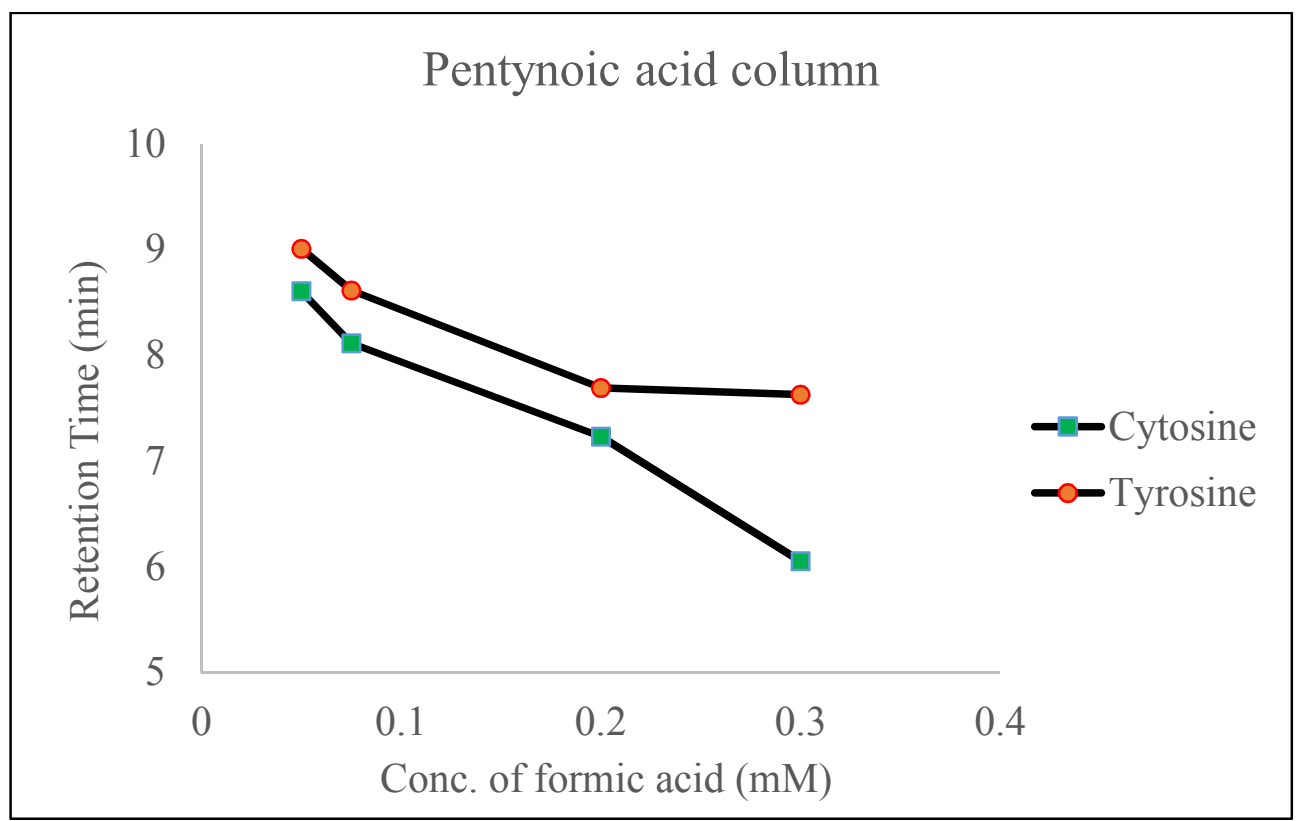

Figure 30. Retention time as a function of concentration of formic acid (pentynoic acid clolumn).

Table 22. Retention time for polar solutes with formic acid.

\begin{tabular}{|c|c|c|}
\hline \% Formic acid & Cytosine & Uracil \\
\hline 0.05 & 3.435 & 1.9397 \\
\hline 0.075 & 2.862 & 1.9463 \\
\hline 0.2 & 2.529 & 1.9473 \\
\hline 0.3 & 1.966 & 1.9463 \\
\hline
\end{tabular}




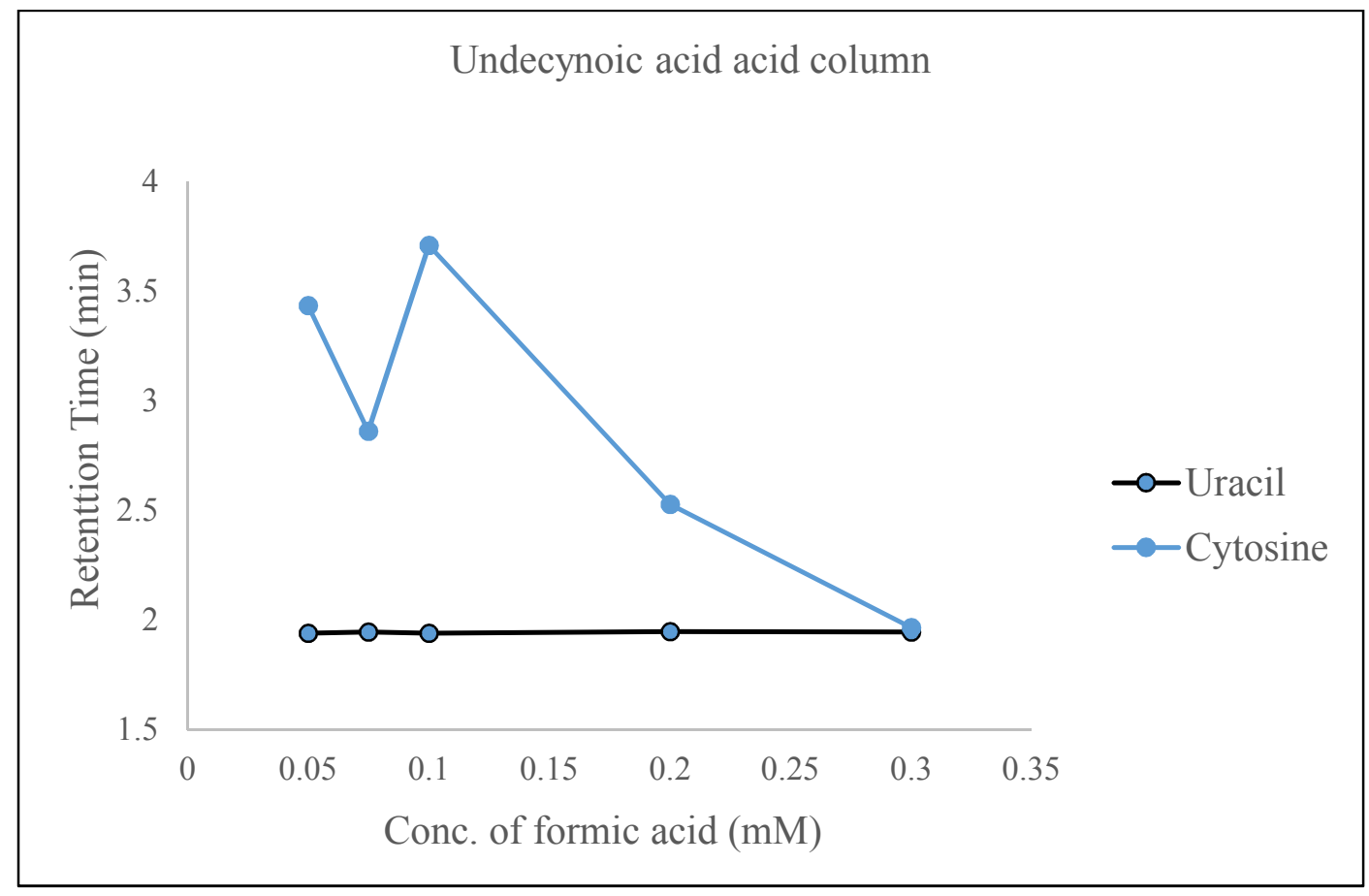

Figure 31. Retention time as a function of concentration of formic acid (undecynoic acid column)

The relationship between the concentration of ammonium acetate (buffer with a higher $\mathrm{pH}$ range) and retention times of polar analytes was studied on both the columns. The $\mathrm{pH}$ of the 20:80 compositions of $\mathrm{A}$ : B solution at five different buffer concentrations was measured. Table 23 shows the retention time of cytosine and uracil on pentynoic acid column and table 24 shows the retention time of cytosine and uracil on 1undecynoic acid column. Figure 27 and Figure 28 include two different plots for cytosine and uracil. It shows the plot of retention time as a function of concentration of ammonium acetate (mM) on two different columns, pentynoic acid and undecynoic acid [27]. With an increase in the concentration of buffer ammonium acetate from $2 \mathrm{mM}$ to $15 \mathrm{mM}$, there is no specific trend observed in terms of retention time on both the columns. These results are different than what was observed with the formic acid buffer system. 
Table 23. Retention times for polar Solutes with ammonium acetate buffer.

\begin{tabular}{|c|c|c|}
\hline $\begin{array}{c}\text { Ammonium Acetate } \\
(\mathrm{mM})\end{array}$ & Cytosine & Uracil \\
\hline 2 & 7.475 & 2.467 \\
\hline 4 & 9.259 & 2.801 \\
\hline 6 & 7.199 & 2.676 \\
\hline 8 & 6.086 & 2.765 \\
\hline 10 & 6.125 & 2.953 \\
\hline
\end{tabular}

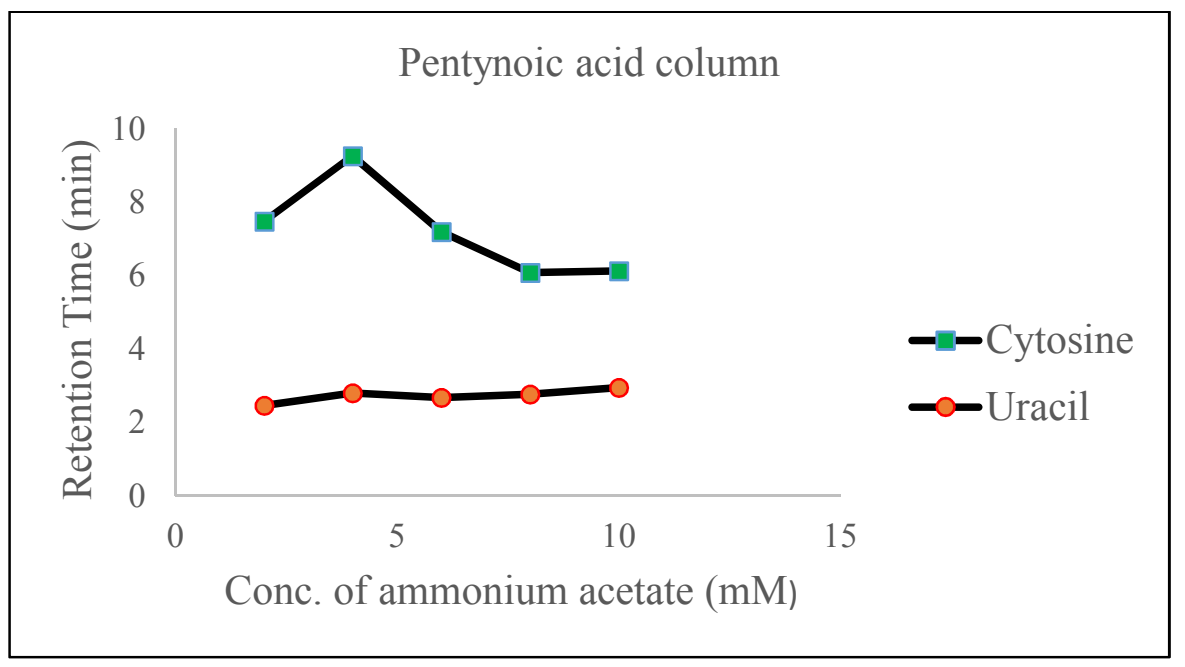

Figure 32. Retention time as a function of concentration of ammonium acetate (pentynoic acid column) 
Table 24. Retention times for polar solutes with ammonium acetate buffer.

\begin{tabular}{|c|c|c|}
\hline $\begin{array}{c}\text { Ammonium Acetate } \\
(\mathrm{mM})\end{array}$ & Cytosine & Uracil \\
\hline 1 & 3.9563 & 1.853 \\
\hline 2 & 2.7863 & 1.7853 \\
\hline 5 & 2.9306 & 1.9563 \\
\hline 10 & 2.733 & 1.8683 \\
\hline 15 & 2.6103 & 1.894 \\
\hline
\end{tabular}

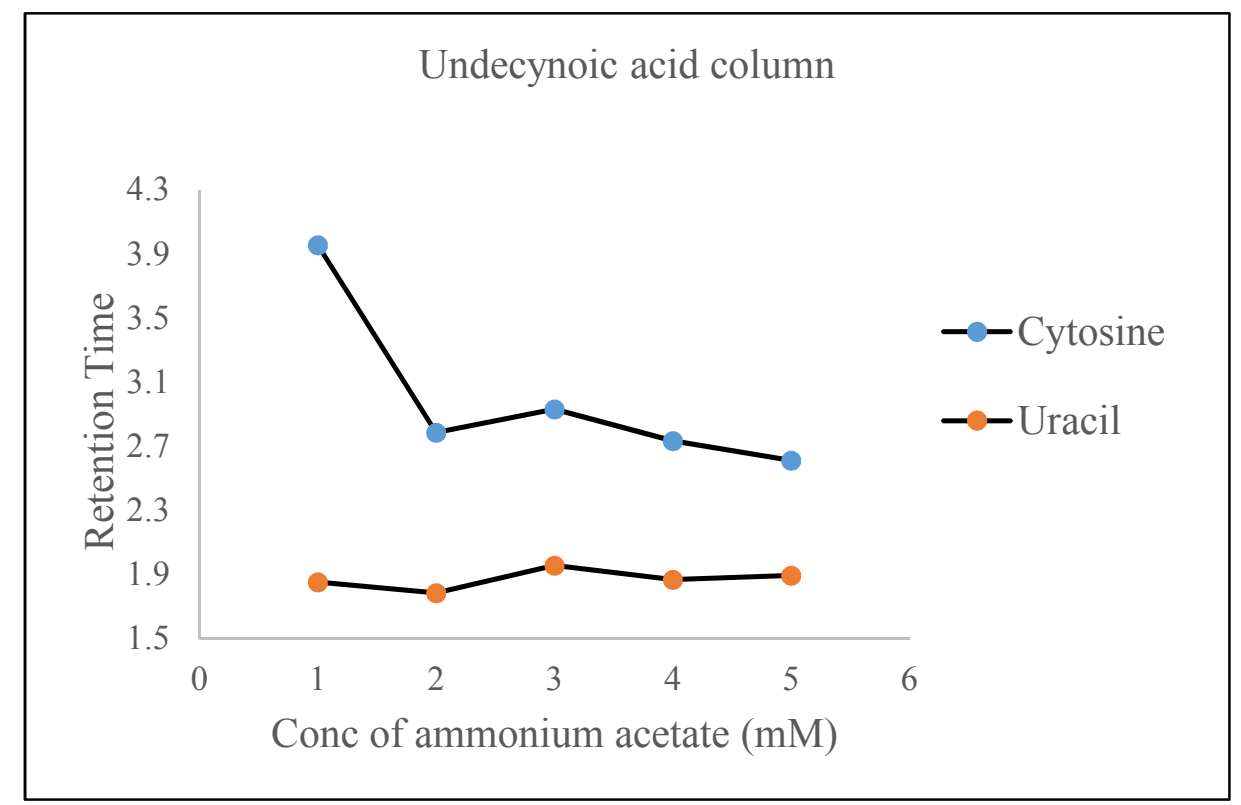

Figure 33. Retention time as a function of concentration of ammonium acetate (undecynoic acid column). 


\section{G. Column Efficiency}

The efficiency of a column can be determined from the Equation 1. Column efficiency can be expressed by the number of theoretical plates(N)

$$
N=16(t / w) 2 \ldots \ldots \ldots \ldots \ldots(1)
$$

where $t$ is the analyte retention time, $w$ is the peak width measured at the base. The narrower the peak width, the smaller the value of $w$, the higher the value of $N$, and the better the separation between the two peaks.

\section{H. Peak Symmetry Factor}

An ideal peak is symmetric in shape. Unwanted interactions of basic compounds with residual silanols on the stationary phase or a contaminated mobile phase or sample can sometimes cause peak tailing effects and the analytes can retain for a long time in the column [3]. Peak tailing is often measured by the peak asymmetry factor (As). The peak asymmetry factor is defined as the distance from the center line of the peak to the back slope divided by the distance from the center line of the peak to the front slope, with all measurements made at $10 \%$ of the maximum peak height. The peak asymmetry factor can be defined by Equation 2 .

$$
\mathrm{As}=\mathrm{B} / \mathrm{A} \ldots \ldots .[2]
$$

Where As is the asymmetry factor, B and A are determined at 10\% peak height as shown in Figure 34 [3]. 


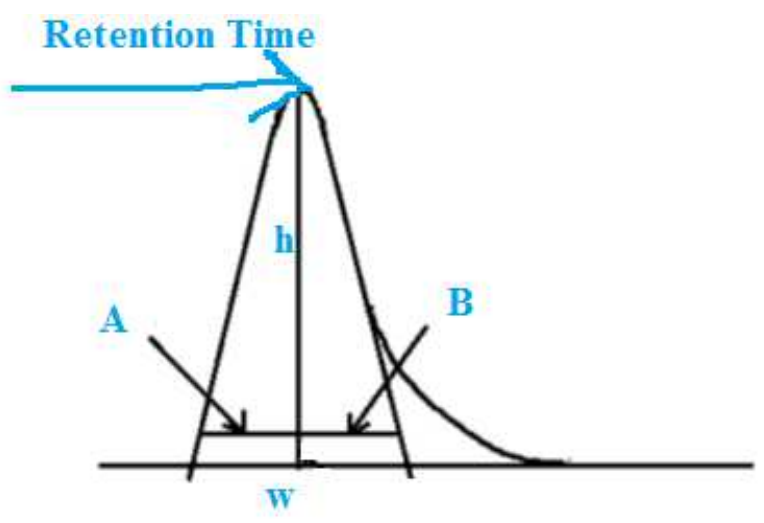

Figure 34. Determination of peak asymmetry factor. Adapted from reference [28].

Details of the column and method information are shown in Table 25. Figure 35 shows the separation of acetophenone and biphenyl on the silica hydride based pentynoic acid column. Both compounds are well separated. The symmetry factor and column efficiency were calculated for both compounds and the data is reported in Table 23. Column efficiency and symmetry factor are relative numbers and depend on several parameters like column length, particle size, flow rate and the packing process. Some external factors like sample -injection technique, tubing and the detector can also effect these two column parameters. It can be seen from Table 26 that the efficiency and symmetry for pentynoic acid column are moderately good. Better symmetry can be achieved by adding some modifiers like formic acid or ammonium acetate or by using a gradient elution mode. 
Table 25. Method information

\begin{tabular}{|c|c|c|}
\hline Pentynoic Acid Hydride & Particle size: $4 \mu \mathrm{m}$ & $\begin{array}{l}\text { Pore: } 100 \\
\text { Angstrom } \\
\end{array}$ \\
\hline \begin{tabular}{|c|} 
Column size: $4.6 \mathrm{~mm}$ i.d. $\mathrm{x}$ \\
$75 \mathrm{~mm}$
\end{tabular} & Lot\#: test lot & $\begin{array}{c}\text { SN. \#: } \\
141014 \mathrm{~A}\end{array}$ \\
\hline Detection: $254 \mathrm{~nm}$ & Flow Rate: $1.0 \mathrm{ml} / \mathrm{min}$ & $\begin{array}{l}\text { Pressure: } \\
2465 \text { psi }\end{array}$ \\
\hline
\end{tabular}

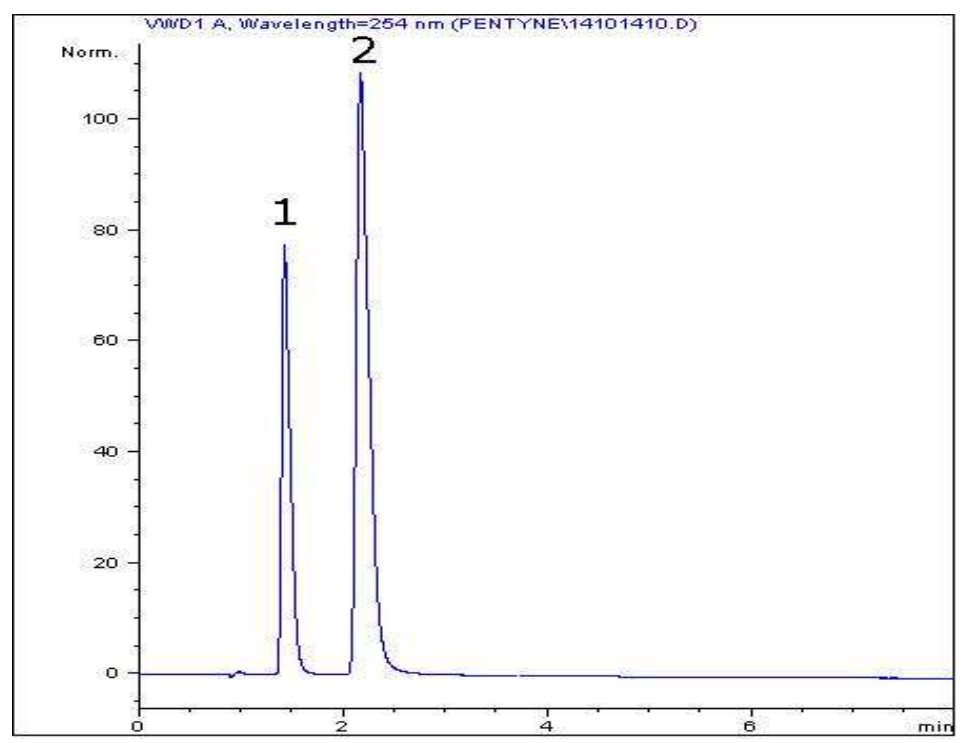

Figure 35. Separation of acetophenone and biphenyl compounds. 
Table 26. Retention times, asymmetry and column plates data.

\begin{tabular}{|c|c|c|c|c|c|}
\hline Index & Time & Name & $\begin{array}{c}\text { Asymmetry } \\
\text { (USP) }\end{array}$ & $\begin{array}{c}\text { \# Column } \\
\text { Plates (HH) }\end{array}$ & \# Plates/meter \\
\hline \hline & $\begin{array}{c}{[\text { Min }} \\
]\end{array}$ & & & & 19067 \\
\hline 1 & 1.42 & Acetophenone & 1.74 & 1430 & 19840 \\
\hline 2 & 2.17 & Biphenyl & 1.76 & 1488 & \\
\hline
\end{tabular}

\section{Reproducibility Study}

The reproducibility study was conducted for this column using uracil, pyridine and phenol, in 90:10 ACN: DI water as mobile phase. Five consecutive injections of the analytes resulted in retention times with close proximity, as shown in Table 27 and the chromatograms are shown in Figure 36.

Table 27. Reproducibility of 5 injections using UV.

\begin{tabular}{|l|l|l|l|}
\hline \multicolumn{2}{|l|}{ Retention Time (min) } \\
\hline $\begin{array}{l}\text { Number of } \\
\text { injections }\end{array}$ & Uracil & Pyridine & Phenol \\
\hline 1 & 1.319 & 2.438 & 2.438 \\
\hline 2 & 1.320 & 2.439 & 2.439 \\
\hline 3 & 1.318 & 2.439 & 2.439 \\
\hline 4 & 1.319 & 2.440 & 2.440 \\
\hline 5 & 1.320 & 2.443 & 2.443 \\
\hline$\%$ RSD & 0.06 & 0.07 & 0.07 \\
\hline
\end{tabular}




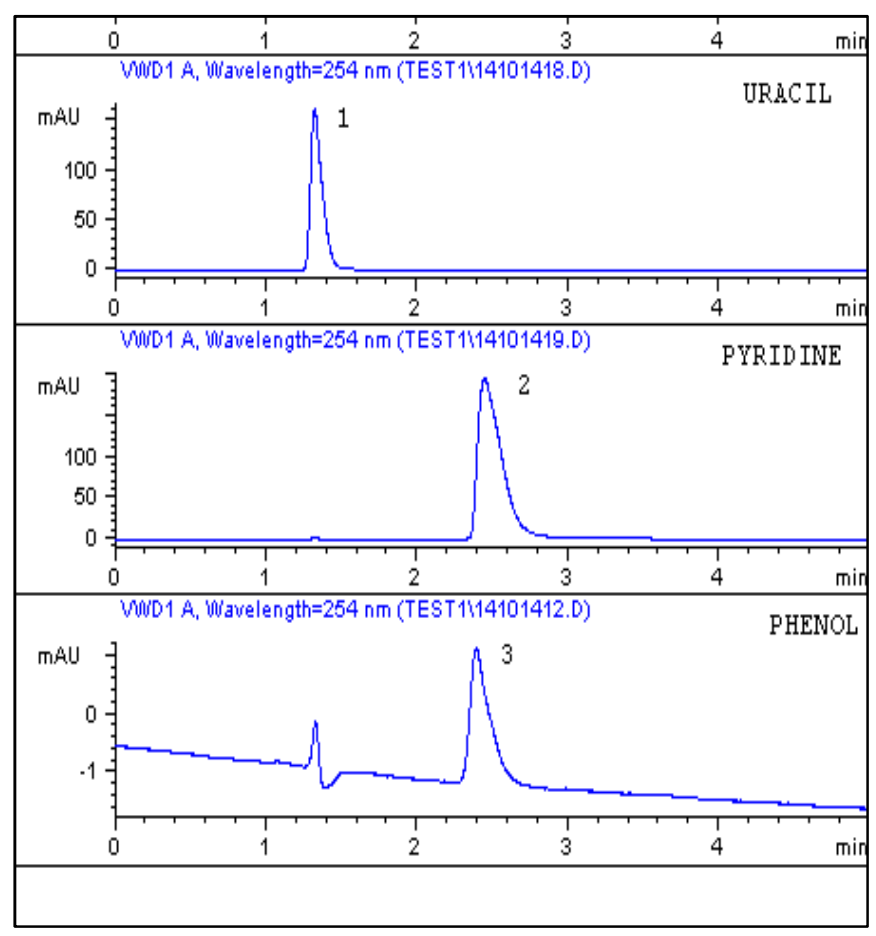

Figure 36. Retention maps of uracil, pyridine and phenol.

The range of $\%$ RSD values obtained is $0.06-0.07$ which is remarkable, since values less than 1 are difficult to obtain. The significance of this range verifies the high degree of precision in the silica hydride based pentynoic acid stationary phase for ANP retention data. 


\section{CONCLUSIONS}

The main goal of this study was to a synthesize novel stationary phase that could perform in both reversed-phase and aqueous normal phase modes and to characterize the column in terms of the RP/ANP properties. The synthetic procedures of silanization/ hydrosilation have successfully produced a silica hydride based pentynoic acid stationary phase. DRIFT and carbon analysis were the two techniques used to evaluate the pentynoic acid stationary phase. DRIFT spectroscopic results have qualitatively confirmed that hydrosilation /silanization utilizing Spier's catalyst is a suitable method for bonding the pentynoic acid moiety onto the silica hydride material.

The carbon elemental analysis provided percent carbon values for the newly synthesized pentynoic acid stationary phase. The surface coverage value was calculated using the Berendsen and de Galan equation. A high percent of carbon means more carbon loading on the surface, and a high surface coverage value indicates that more organic moiety has been successfully bonded to the silica surface.

The pentynoic acid stationary phase exhibited both aqueous normal phase capabilities as well as reversed-phase behavior. Polar compounds were well retained in the ANP mode, at a higher $\%$ of ACN in the mobile phase. The nonpolar compounds were retained in RP mode at lower organic content. The interactions between the stationary phase and the analyte include both hydrophobic and ionic/electrostatic interactions. The versatility of the silica hydride based pentynoic acid stationary phase to operate in the reverse phase and normal phase conditions was documented by a U-shaped retention profile. 
The effect of varying the concentration of formic acid was studied resulting in a decrease of retention time for polar compounds as the formic acid buffer concentration increases. There was no significant change for neutral compounds like benzoic acid. The observed trend is exactly opposite of HILIC [29]; hence it can be predicted that the retention mechanism involved in silica hydride-based stationary phase is not a partitioning mechanism. Instead, the separation mechanism of this column might be due to ionic/electrostatic interactions. The compatibility of the ammonium acetate buffer with the column was tested using polar solutes. As the concentration of ammonium acetate increased, retention times of analytes did not show any specific trend on the silica hydride based pentynoic acid column. The peak symmetry factor and column efficiency parameters for the pentynoic acid column were moderately good.

Future work includes expanding the range of the analytes to molecules such as proteins/peptides and carbohydrates that could provide additional information on the behavior of the newly synthesized pentynoic acid stationary phase. The effects of varying temperature, reaction type and type of catalyst on the surface coverage should be examined. Batch-to-batch reproducibility of the pentynoic acid stationary phase needs to be investigated. 


\section{REFERENCES}

1. Skoog, A. D.; Holler, F. J.; Nieman, T. A. Principles of Instrumental Analysis, 5thed.; Saunders College Publishing: Orlando, Florida, 1998; Chapters 26, 28.

2. Weston, A.; Brown, P. Introduction to High Performance Liquid Chromatography, Chapman \& Hall, London, NY, 1982, Chapters 1-6.

3. Cunico, R. L.; Gooding, K. M.; Wehr, T. Basic HPLC and CE of Biomolecules, Bay Bioanalytical Laboratory, CA, 1998.

4. Skoog, D.; West, D.; Holler, F. L.; Crouch, S. Fundamentals of analytical chemistry, 8th ed.; Cengage Learning: Boston, Massachusetts, 2006; Chapters 30,32 .

5. Moldoveanu, S., David, V. Essentials in modern HPLC separations; Elsevier: Waltham, Massachusetts, 2013; Chapters 1-46.

6. Scott, R. P. W. Principles and Practice of Chromatography, Chrom-Ed Book Series, Library for Science, 2003, 65.

7. Sandoval, J. E.; Pesek, J. J. Analytical Chemistry, 1991, 63(22),2634-2641.

8. Pesek, J.; Matyska, M. T. A Comparison of Two Separation Modes: HILIC and Aqueous Normal Phase Chromatography, LCGC 25, 2007, 480-490.

9. Pesek, J. J.; Matyska, M. T. LCGC North America. 2006, 24, 3, 296-303.

10. Pesek, J. J.; Matyska, M. T.; Fischer, S. M.; Sana, T. R. Journal of Chromatography A, 2008, 1204, 48-55.

11. Lindsay.S, High performance liquid chromatography, $2^{\text {nd }}$ ed; , John Wiley and sons, Chichester, England,1992; Chapters 1, 7.

12. Jacek, N. J. Chromatogr. A. 1997, Journal of Chromatography A, 779, 1, 29-71.

13. Vansant, E. F.; Van Der Voort, P.; Vrancken, K. C. Characterization and Chemical Modification of Silica; Elsevier: Amsterdam, New York, 1995, Chapter 1-6.

14. Heftmann, E. Chromatography: Fundamentals and applications of chromatography and related differential migration Methods-Part B: Applications; Elsevier: Boston, Massachusetts, 2004; Chapters 1, 2. 
15. Pesek, J. J; Matyska, M. T.; Takhar, S. Chromatographia, 1998, 48, 631-636

16. Pesek, J. J.; Matyska, M. T. Our favorite materials: Silica hydride stationary phases. Journal of Separation Science 2009, 32, 3999-4011.

17. http://microsolvtech.com/hplc/typec_about.asp

(accessed on May 20th, 2016)

18. Pesek, J. J.; Matyska, M. T.; Sandoval, J. E.; Williamsen, E. J. J.

Liq.Chromatogr. \& Rel. Technology. 1996, 19, 2843-2865

19. Salehi, Niloofar, "Synthesis and Evaluation of Four Novel Stationary Phases in High Pressure Liquid Chromatography" (2012). Master's Theses. Paper 4209.

20. Pesek, J. J.; Matyska, M. T. Journal of Chromatography A, 2005, 1079, 366-371.

21. Gee, M. L.; Healy, T. W.; White, L. R. J. Colloid Interface Sci. 1990, 140, 450465.

22. Pesek, J. J.; Matyska, M. T. Interface Sci. 1997, 5, 103-117.

23. Chu, C. H.; Jonsson, E.; Auvinen, M.; Pesek, J. J.; Sandoval, J. E. Analytical Chemistry, 1993, 65(6), 808-816.

24. Soukup, J.; Janás, P.; Jandera, P. Journal of Chromatography A, 2013, 1286, 111-118.

25. Kulsing, C.; Yang, Y.; Munera, C.; Tse, C.; Matyska, M. T.; Pesek, J. J.;

Hearn,M. T. Analytica Chimica Acta, 2014, 817, 48-60.

26. Kulsing, C.; Yang Nolvachai, Philip J. Marriott, Reinhard I. Boysen, Maria T. Matyska, Joseph J. Pesek, and Milton T. W. Hearn,Journal of Physical Chemistry Part B, 2015,119 (7), 3063-3069.

27. Kozhikote, Veena Menon, "Evaluation of a silica-hydride based undecynoic acid for high performance liquid chromatography"(Future release) Master's Theses.

28. Parmar, Nima C., "Characterization of Hydride-Based Silica and Diamond Hydride Stationary Phases" (2013). Master's Theses. Paper 4306.

29. Boysen, R. I.; Yang, Y.; Chowdhury, J.; Matyska, M. T.; Pesek, J. J.; Hearn, M. T. Journal of Chromatography A, 2011, 1218(44), 8021-8026. 